\title{
Thiacyclophane Cages and Related Bi- and Tripodal Molecules via Transient Polysulfenic Acids
}

Maria Chiara Aversa, ${ }^{\dagger}$ Anna Barattucci, ${ }^{* \dagger}{ }^{\dagger}$ Paola Bonaccorsi, ${ }^{*}{ }^{\dagger}$ Cristina Faggi, ${ }^{\dagger}$ and Teresa Papalia ${ }^{\dagger}$

${ }^{\dagger}$ Dipartimento di Chimica organica e biologica, Università degli Studi di Messina, Salita Sperone 31 (vill. S. Agata), 98166 Messina, Italy, and ${ }^{\ddagger}$ Centro interdipartimentale di Cristallografia, Università degli Studi di Firenze, Via della Lastruccia 3, 50019 Sesto Fiorentino, Firenze, Italy

paola.bonaccorsi@unime.it

\section{Supporting Information}

\section{Table of Contents}

Experimental for X-ray crystallographic analyses 
Experimental details for X-ray crystallographic analyses of rac-1,4-bis\{[1-(4ethynylphenyl)ethenylsulfinyl]methyl\}benzene (21) and meso-1,12-dimethylene-2,11dithia[3.3]metametacyclophane 2,11-dioxide (39).

Numerical details are presented in Table S1.

Table S1. Details of X-ray structure analyses of $\mathbf{2 1}$ and 39.

\begin{tabular}{|c|c|c|}
\hline Compound & 21 & 39 \\
\hline formula & $\left(2 \times \mathrm{C}_{28} \mathrm{H}_{22} \mathrm{O}_{2} \mathrm{~S}_{2}\right) \cdot \mathrm{CHCl}_{3}$ & $\mathrm{C}_{18} \mathrm{H}_{16} \mathrm{O}_{2} \mathrm{~S}_{2} \cdot \mathrm{CHCl}_{3}$ \\
\hline$M_{\mathrm{r}}$ & 1028.52 & 447.80 \\
\hline habit & white crystals & white crystals \\
\hline crystal size $[\mathrm{mm}]$ & $0.16 \times 0.17 \times 0.23$ & $0.22 \times 0.19 \times 0.25$ \\
\hline crystal system & monoclinic & monoclinic \\
\hline space group & $\mathrm{P} 2{ }_{1} / \mathrm{n}$ & $\mathrm{P} 2{ }_{1} / \mathrm{n}$ \\
\hline \multicolumn{3}{|l|}{ cell constants } \\
\hline$a[\AA]$ & $24.474(1)$ & $10.787(1)$ \\
\hline$b[\AA]$ & $7.660(1)$ & $13.238(1)$ \\
\hline$c[\AA]$ & $26.684(1)$ & $14.494(1)$ \\
\hline$\alpha\left[^{\circ}\right]$ & 90 & 90 \\
\hline$\beta\left[^{\circ}\right]$ & $90.496(1)$ & $92.810(6)$ \\
\hline$\gamma\left[{ }^{\circ}\right]$ & 90 & 90 \\
\hline$V\left[\AA^{3}\right]$ & $5002.3(7)$ & $2067.2(3)$ \\
\hline$Z$ & 4 & 4 \\
\hline$\rho\left[\mathrm{Mg} \mathrm{m}^{-3}\right]$ & 1.366 & 1.439 \\
\hline$\mu\left[\mathrm{mm}^{-1}\right]$ & 3.596 & 0.656 \\
\hline$F(000)$ & 2136 & 920 \\
\hline$T\left[{ }^{\circ} \mathrm{K}\right]$ & $150(2)$ & 293(2) \\
\hline$\theta$ range for data collection $\left[{ }^{\circ}\right]$ & 4.93 to 66.03 & 4.08 to 22.72 \\
\hline completeness to $\theta[\%]$ & 96.3 & 99.0 \\
\hline \multicolumn{3}{|l|}{ no. reflections } \\
\hline measured & 30714 & 15017 \\
\hline independent & 8393 & 2749 \\
\hline$R_{\text {int }}$ & 0.0449 & 0.0569 \\
\hline
\end{tabular}




\begin{tabular}{lll}
\hline parameters & 793 & 304 \\
wavelength $[\AA]$ & 1.54178 & 0.71069 \\
limiting indices & $-28 \leq \mathrm{h} \leq 28 ;-9 \leq \mathrm{k} \leq 7 ;-31 \leq \mathrm{l} \leq 31$ & $-11 \leq \mathrm{h} \leq 11 ;-14 \leq \mathrm{k} \leq 14 ;-15 \leq 1 \leq 15$ \\
restraints & 0 & 0 \\
goodness-of-fit on $F^{2}$ & 0.935 & 1.163 \\
final R indices $[\mathrm{I}>2 \sigma(\mathrm{I})]$ & $R_{1}=0.0442, w R_{2}=0.1116$ & $R_{1}=0.0637, w R_{2}=0.1439$ \\
\hline
\end{tabular}

Data collection: Both crystals were mounted on glass fibres and analyzed using a Goniometer Oxford Diffraction KM4 Xcalibur2 with a graphite-monochromated $\mathrm{Cu} / \mathrm{K} \alpha$ radiation $(40 \mathrm{~mA} /-40 \mathrm{KV})$ in a cold $\mathrm{N}_{2}$ stream for compound 21 and at room temperature for compound 39.

Structures refinement: The integrated intensities, measured using the $\omega$ scan mode, were corrected for Lorentz and polarization effects. ${ }^{1}$ The substantial redundancy in data allowed empirical absorption corrections to be applied using multiple measurements of symmetry-equivalent reflections. Both structures were solved by direct methods of SIR $2002^{2}$ and refined using the full-matrix least squares on $\mathrm{F}^{2}$ provided by SHELXL97. ${ }^{3}$ The non-hydrogen atoms were refined anisotropically, all hydrogen atoms were found in the Fourier synthesis and refined as isotropic.

CCDC-636520 (21) and -636521 (39) contain the supplementary crystallographic data for this paper. Copies of the data can be obtained free of charge from the Cambridge Crystallographic Data Centre via www.ccdc.cam.ac.uk/data_request/cif.

\section{References:}

(1) Walker, N.; Stuart, D. Acta Crystallogr., Sect. A: Found. Crystallogr. 1983, A39, 158-166.

(2) Burla, M. C.; Camalli, M.; Carrozzini, B.; Cascarano, G. L.; Giacovazzo, C.; Polidori, G.; Spagna, R. J. Appl. Crystallogr. 2003, 36, 1103.

(3) Sheldrick, G. M. program SHELXL97, University of Göttingen, Germany. 

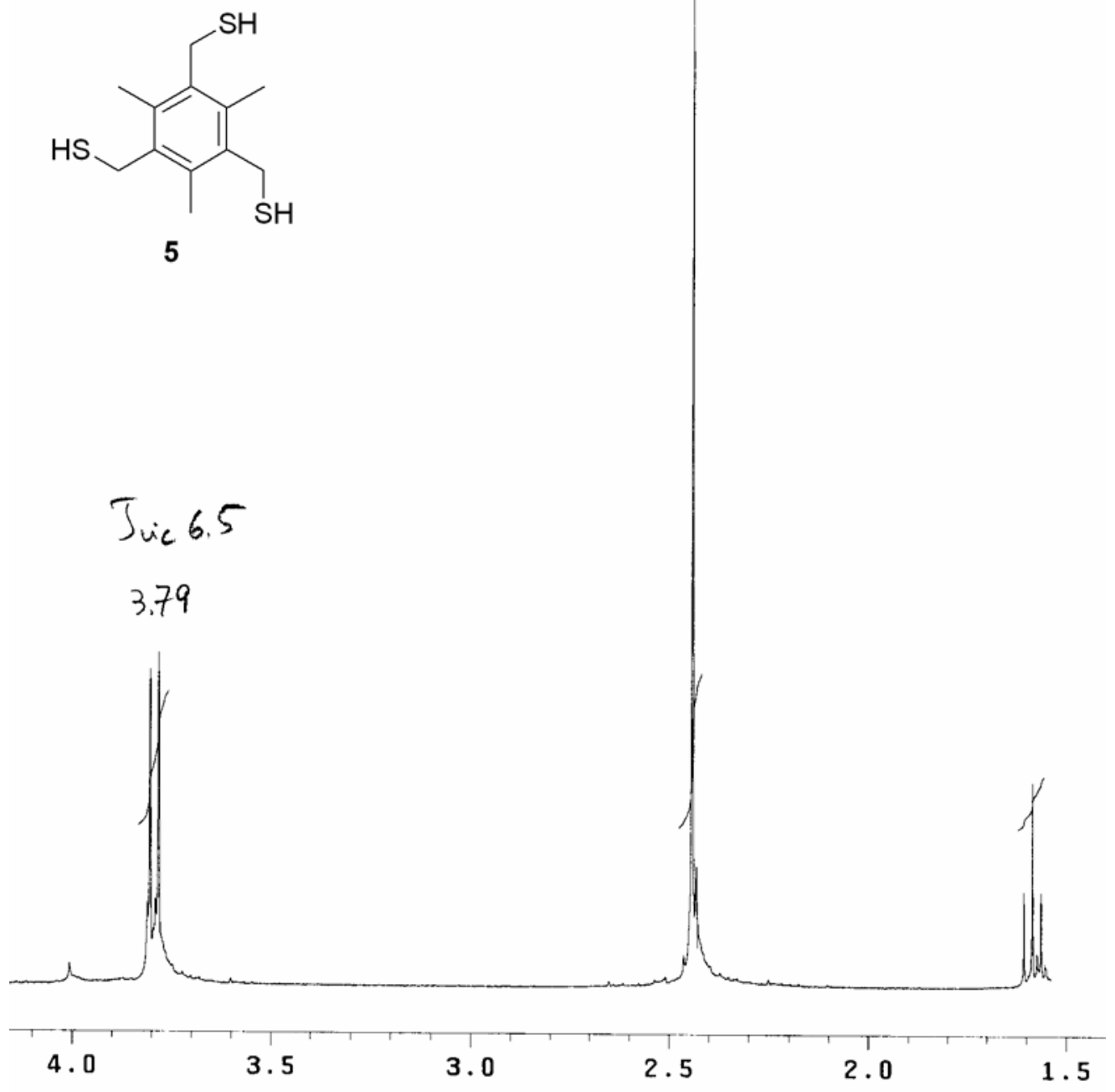

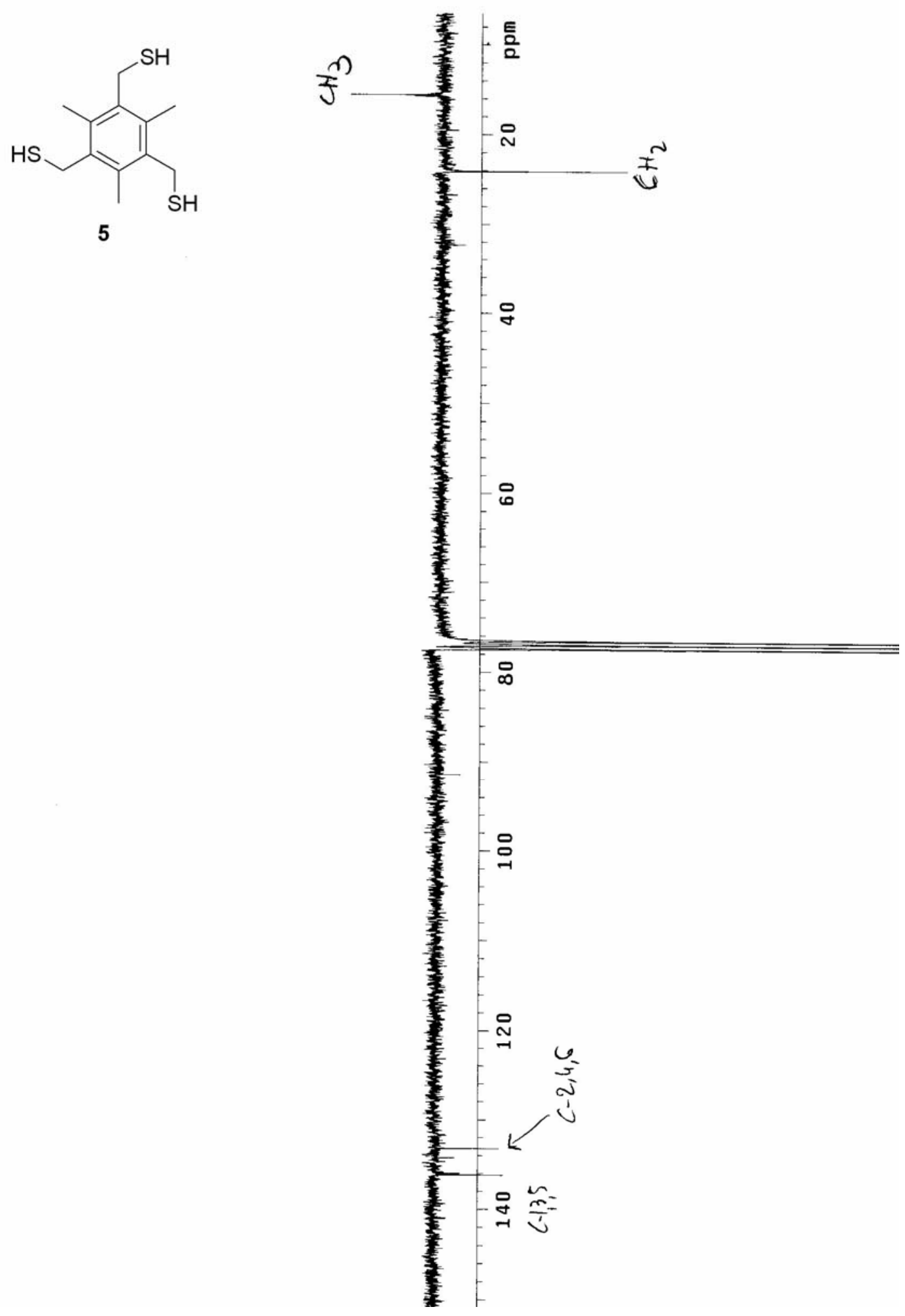


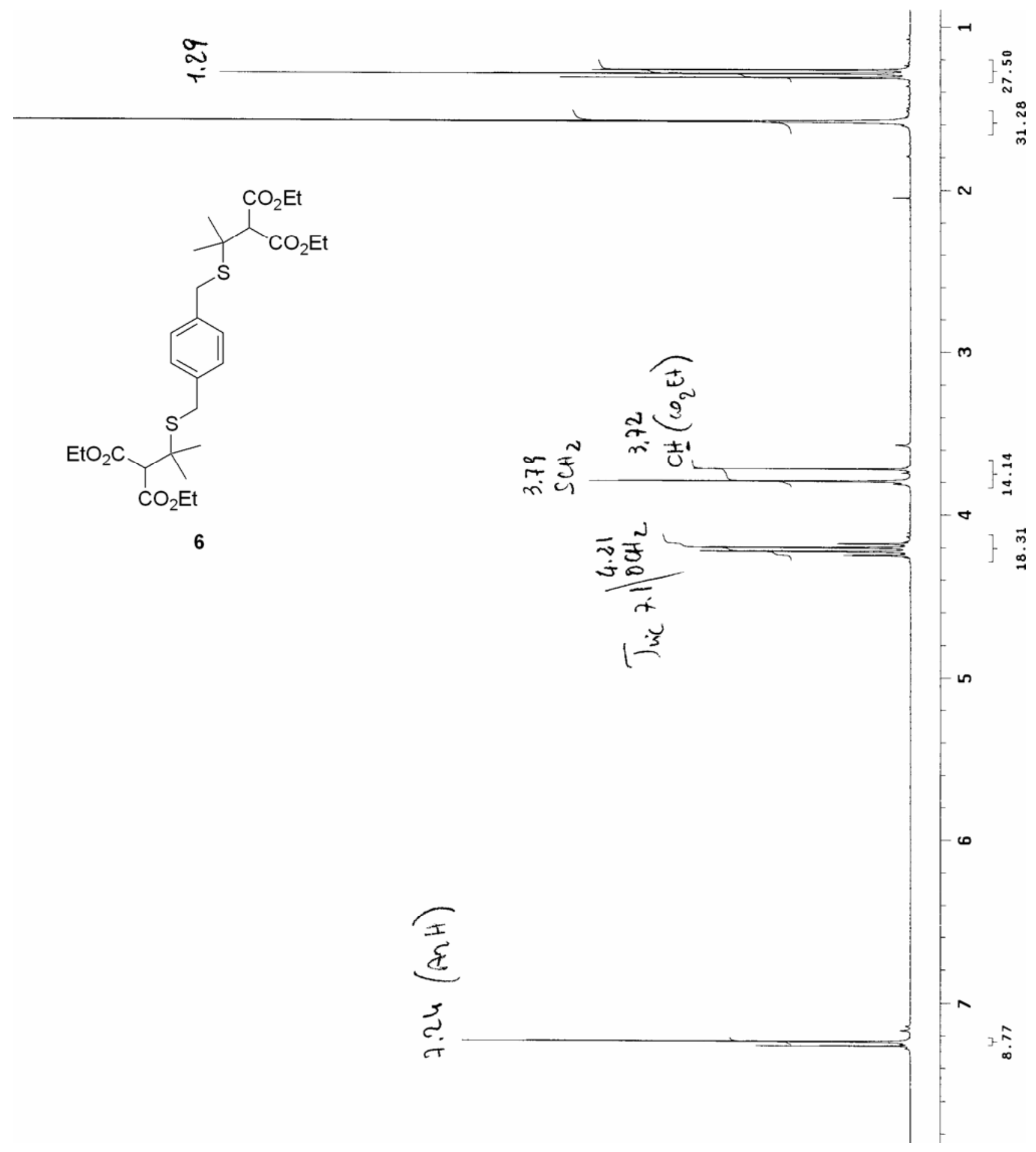




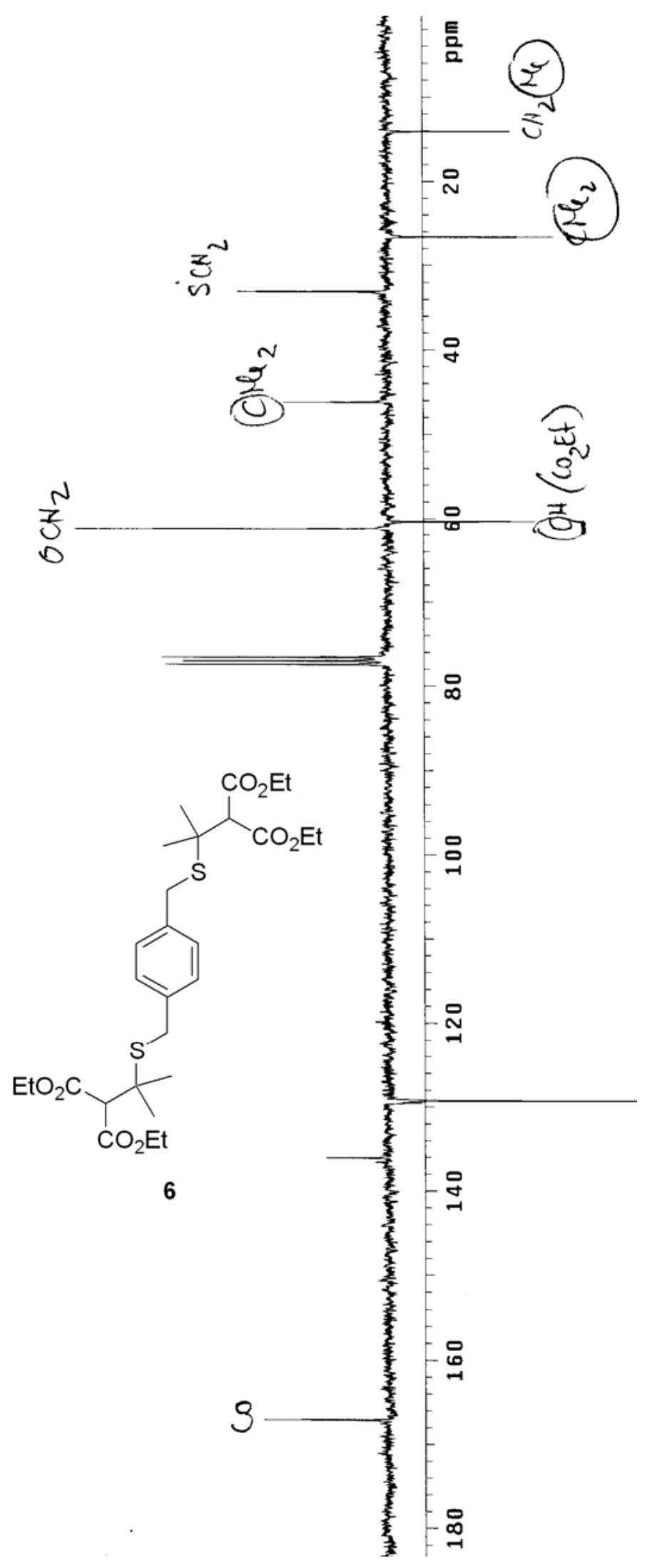




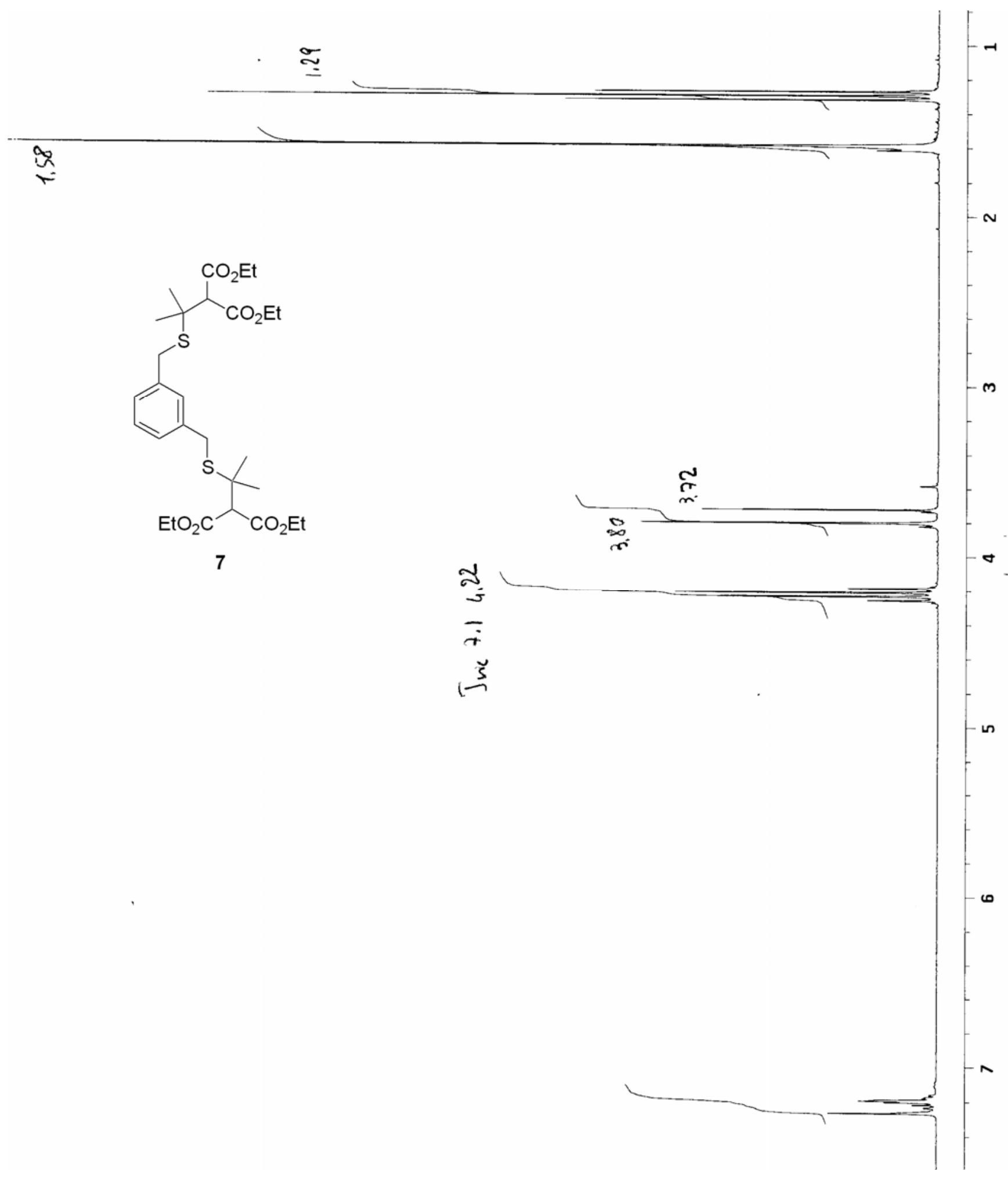




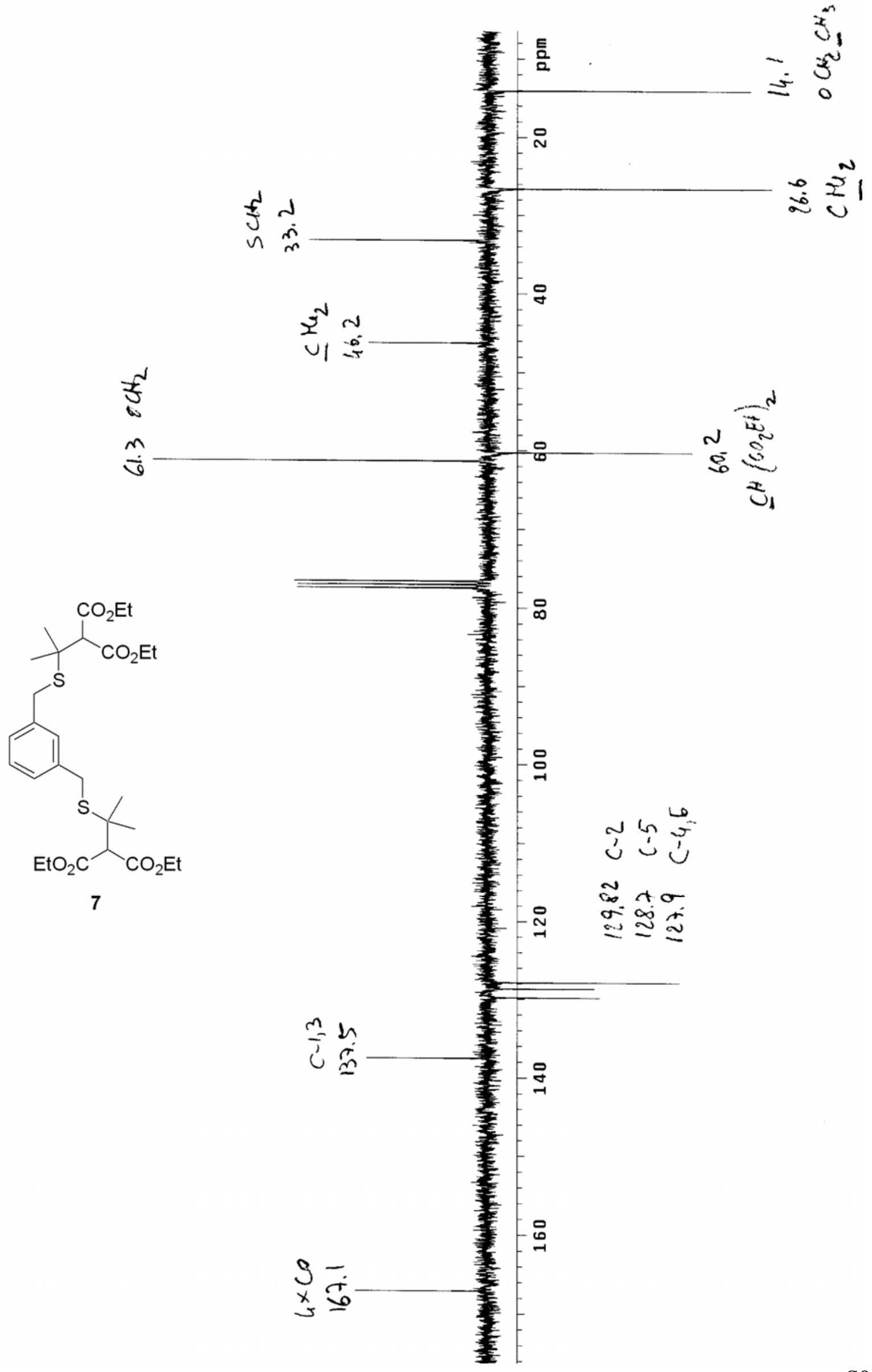




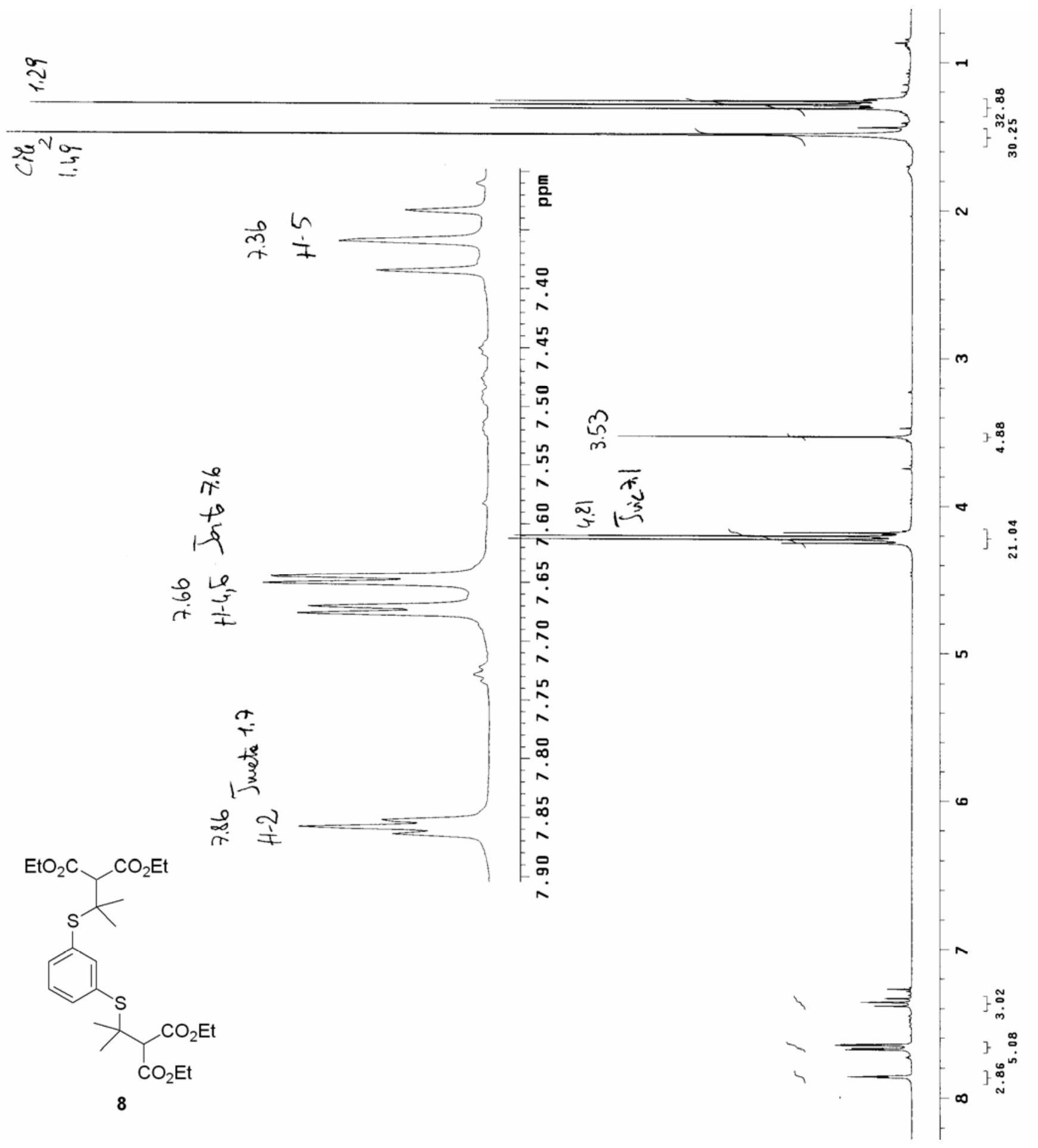



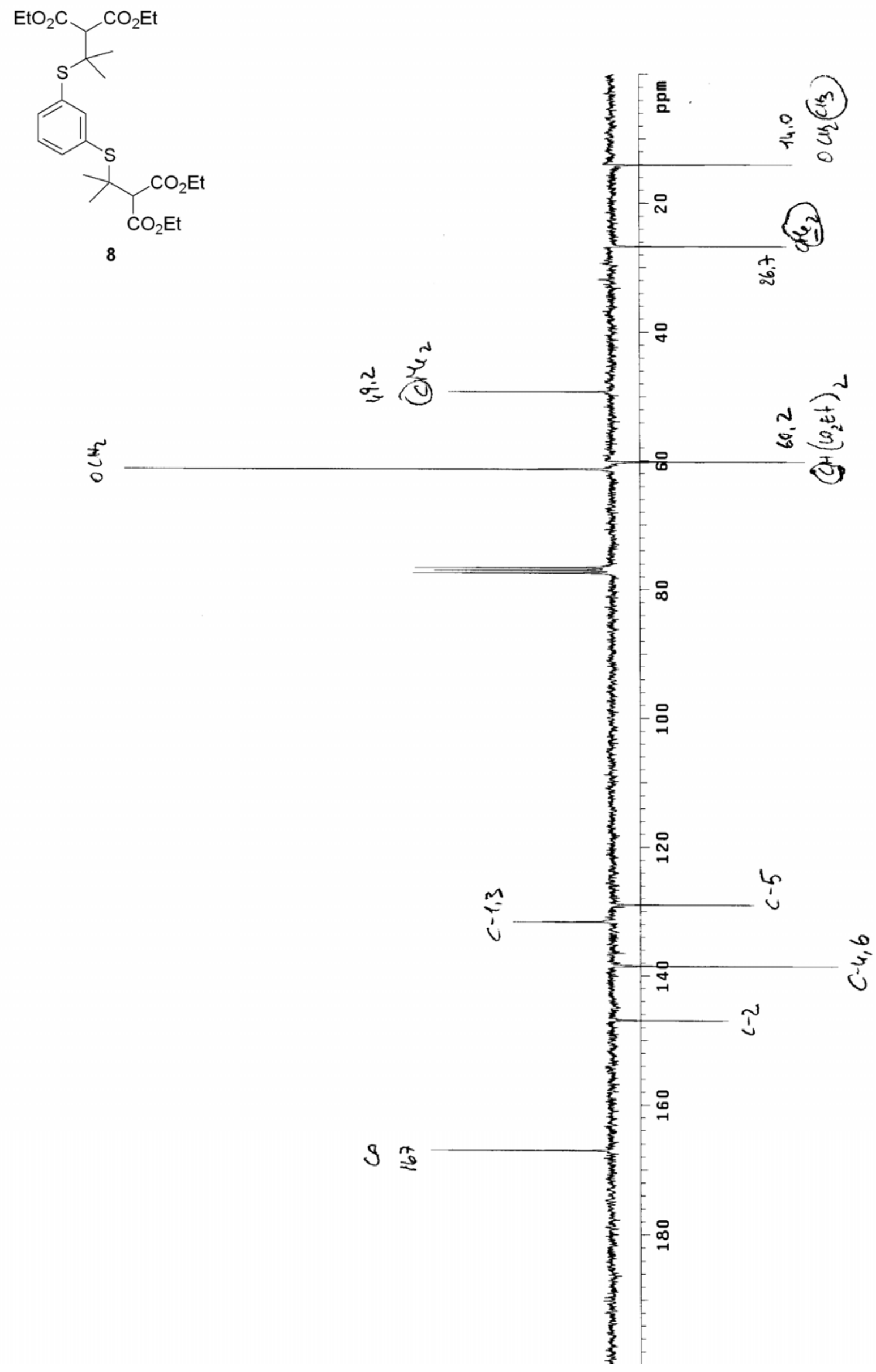


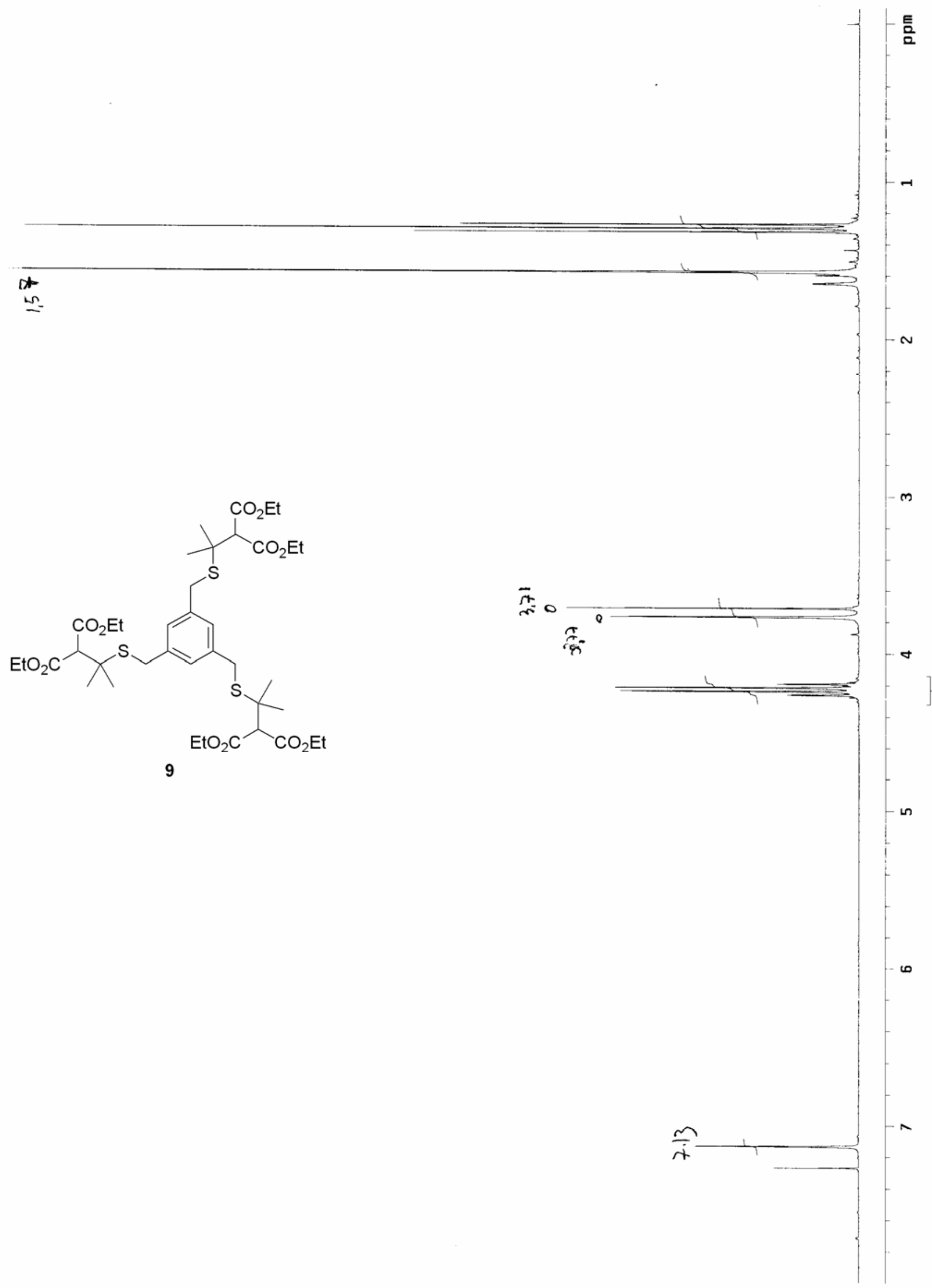



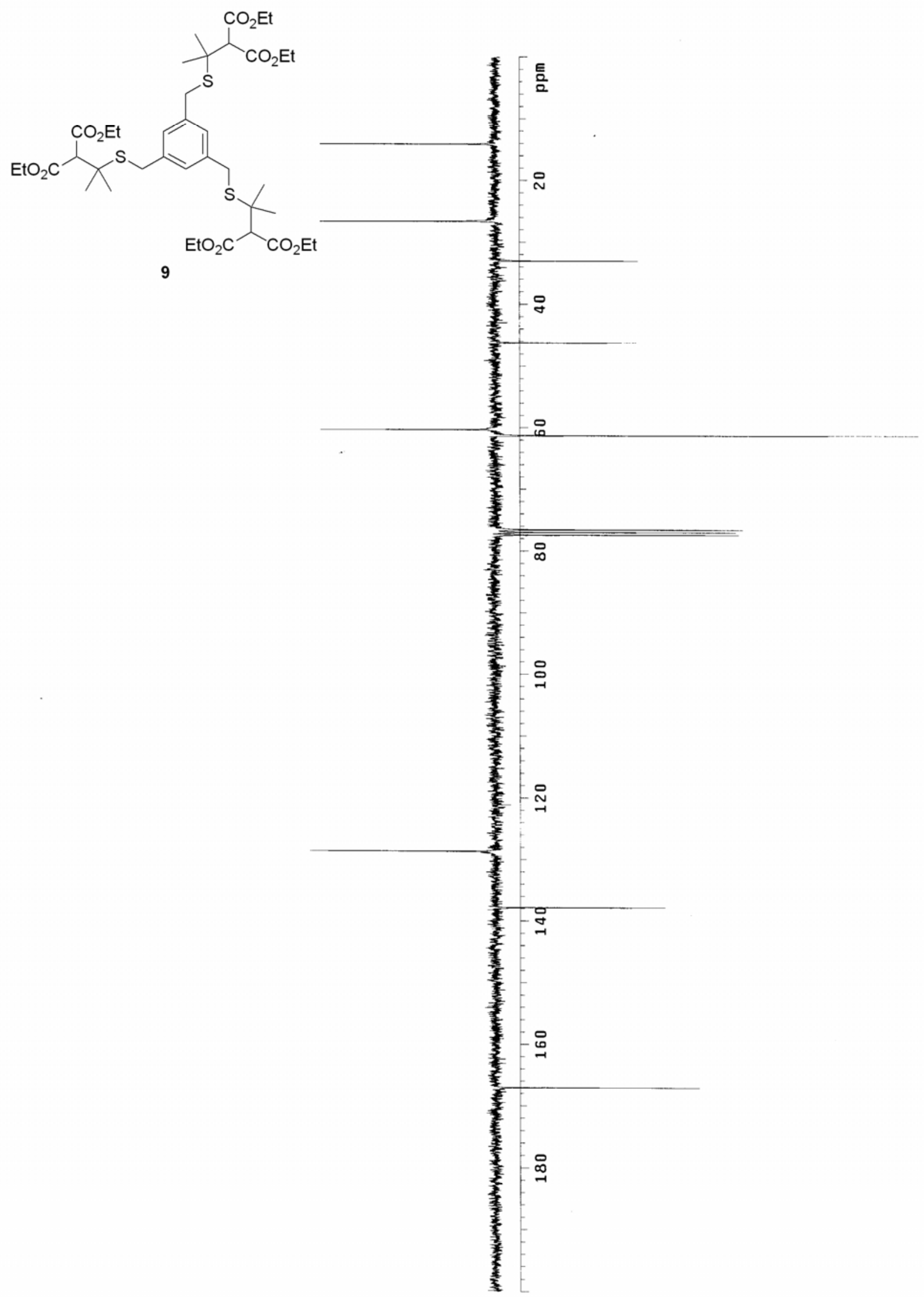


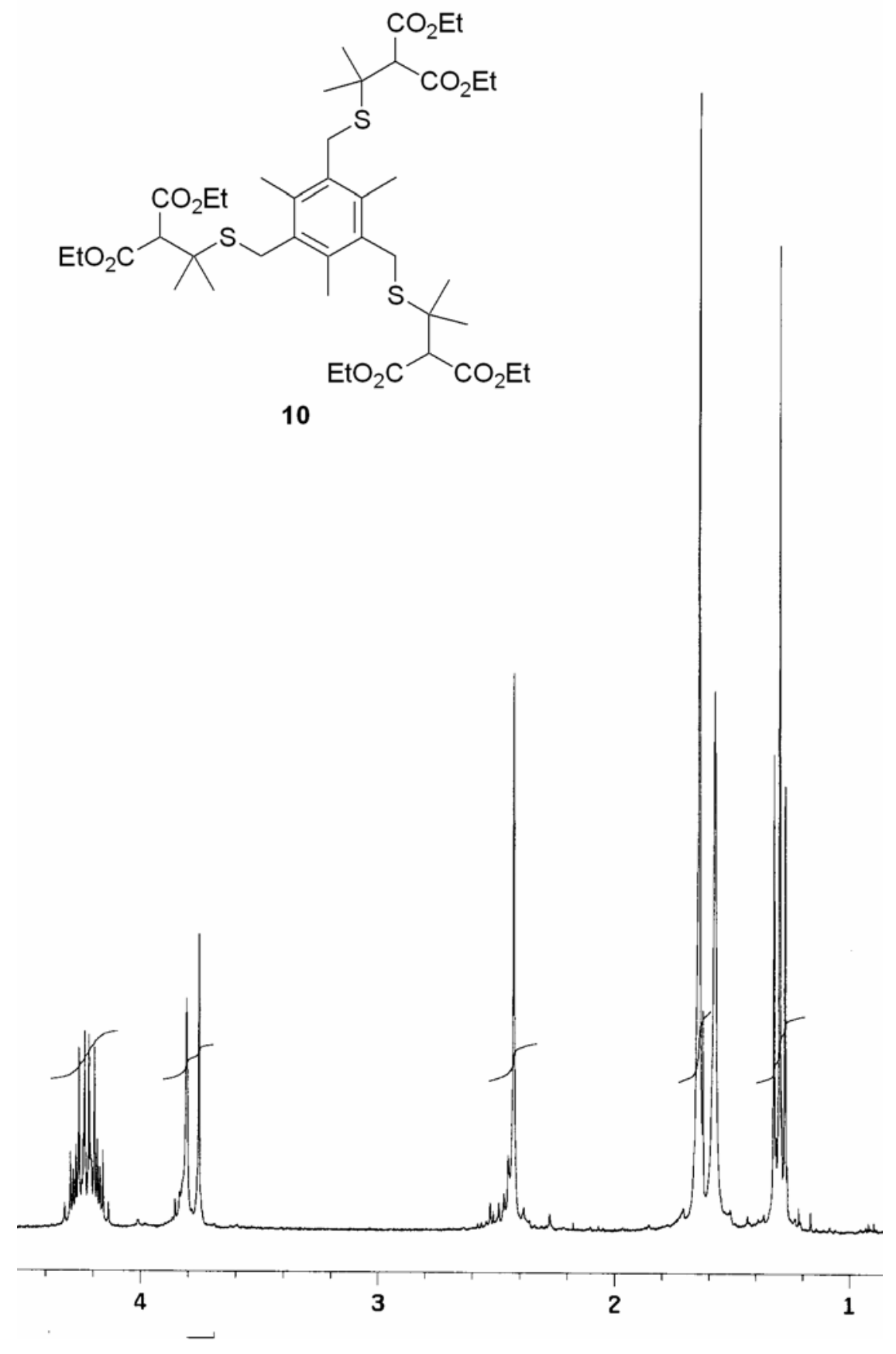




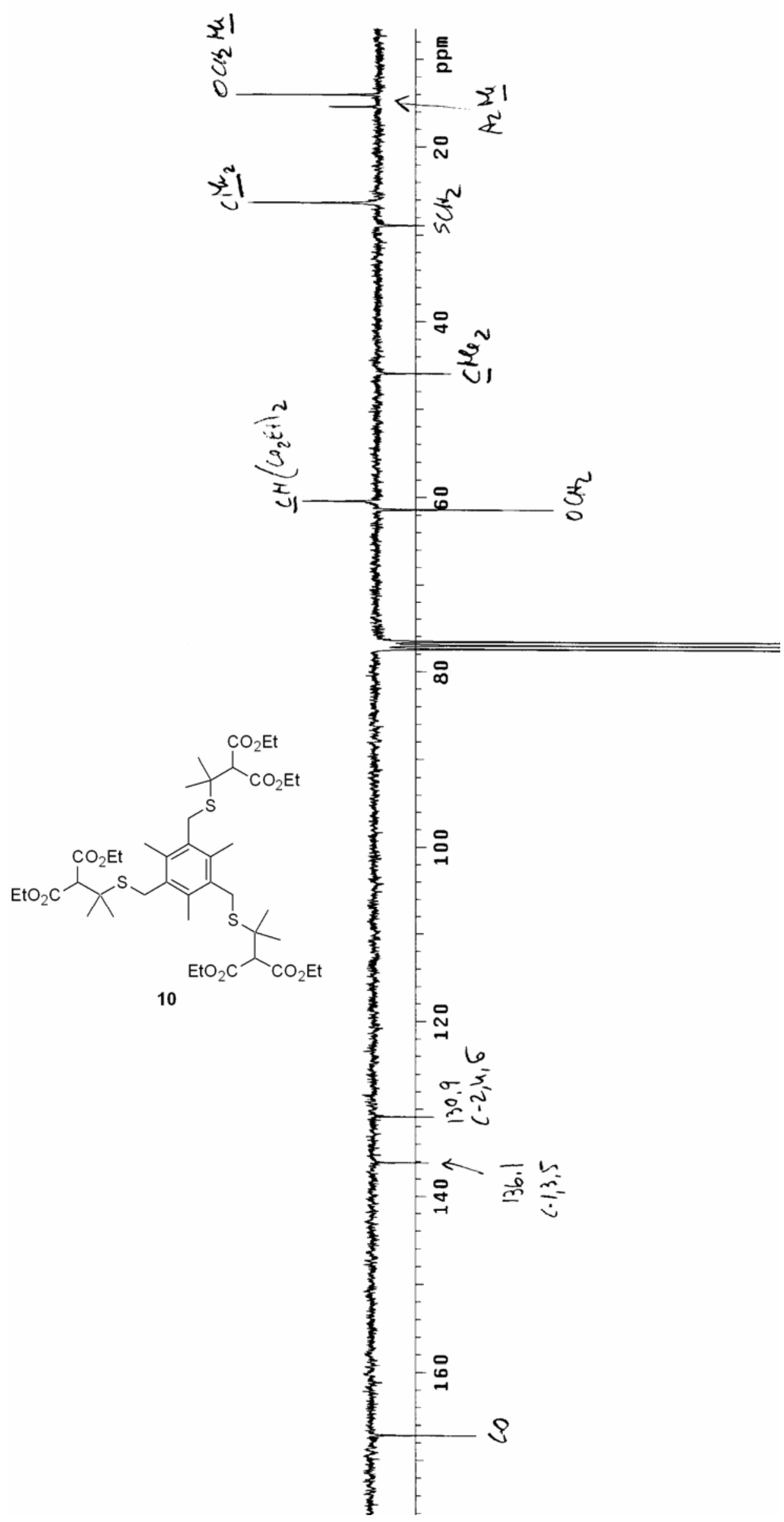




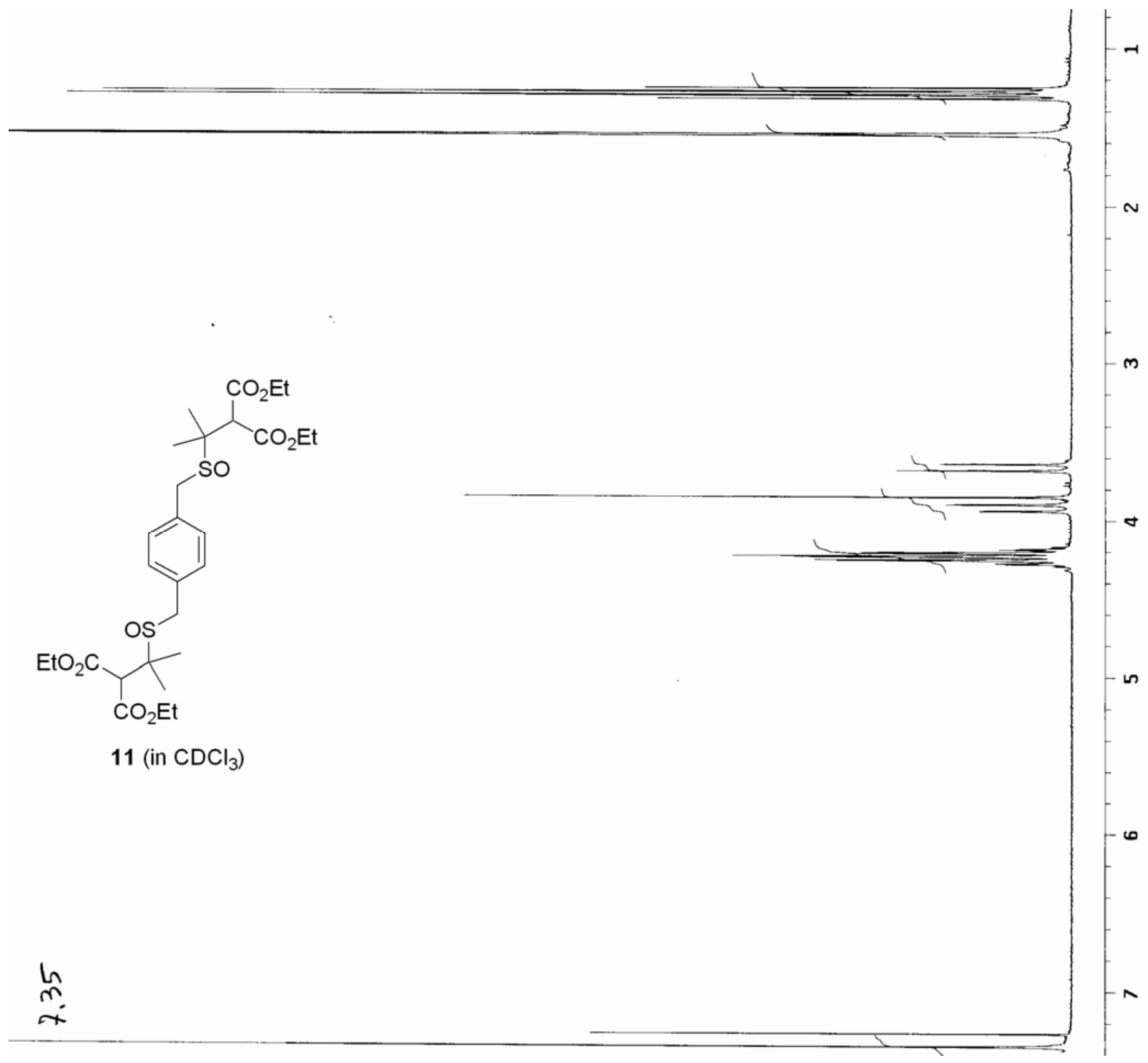




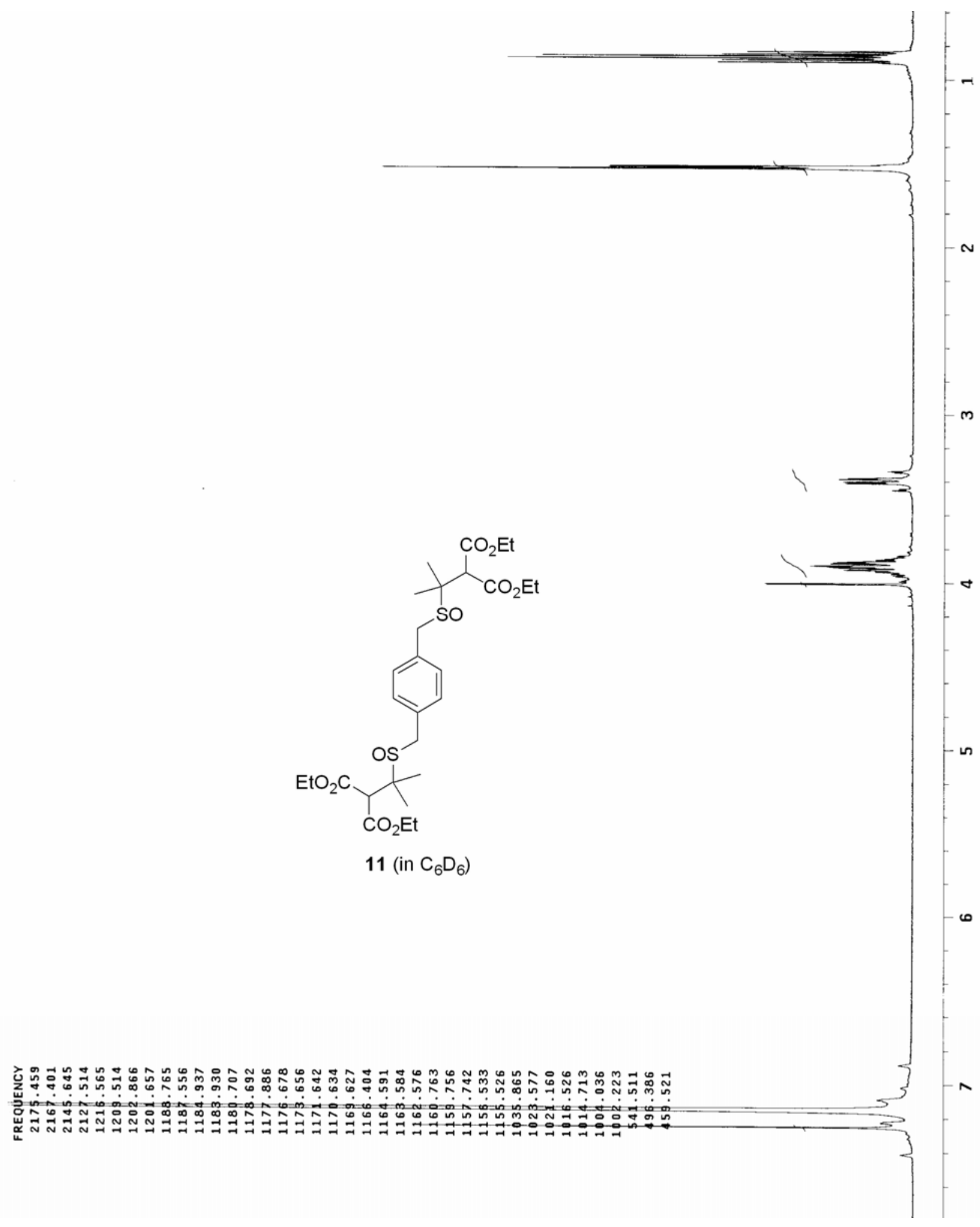




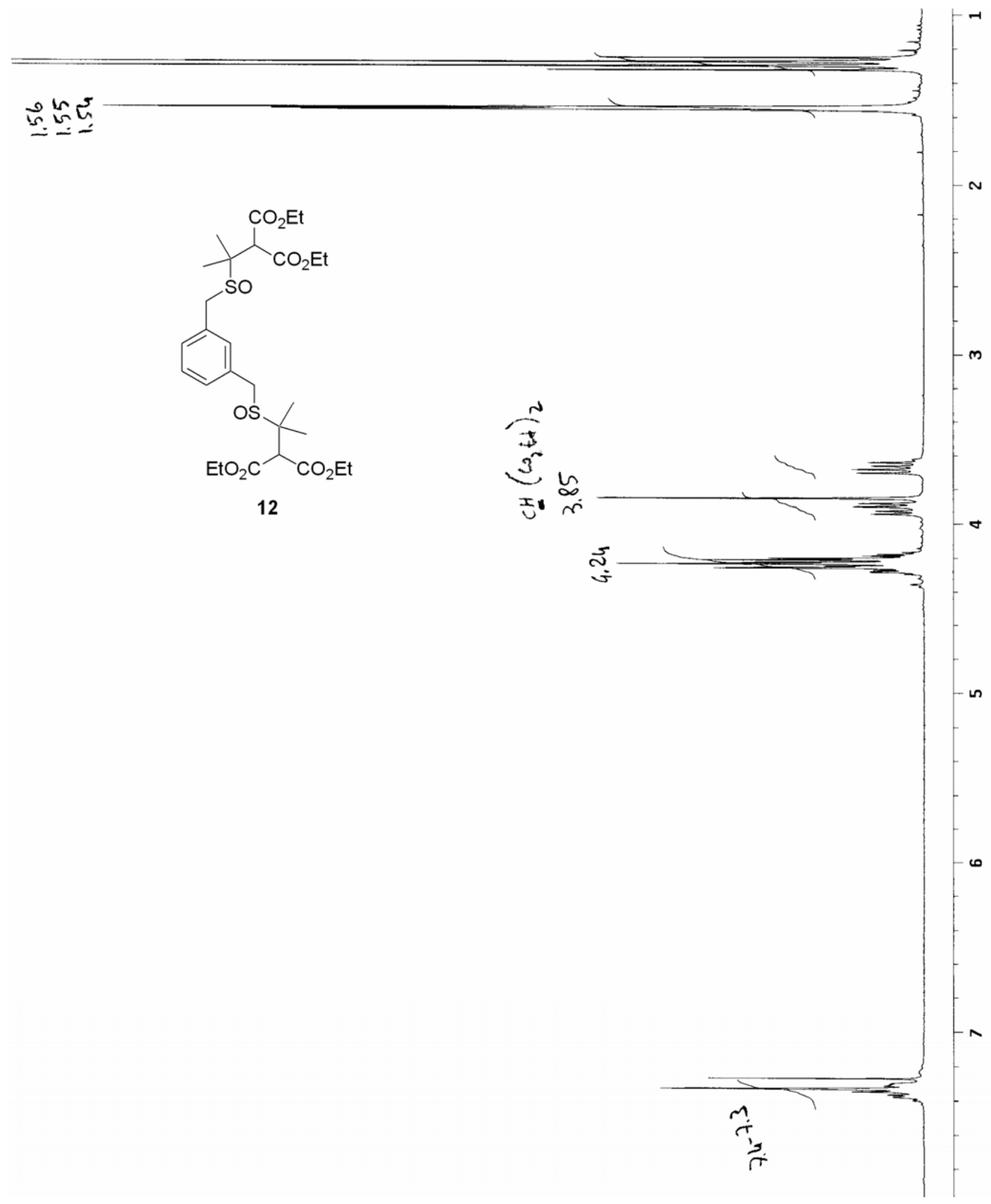


(n)

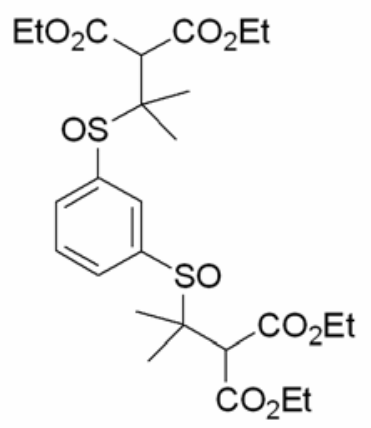

13

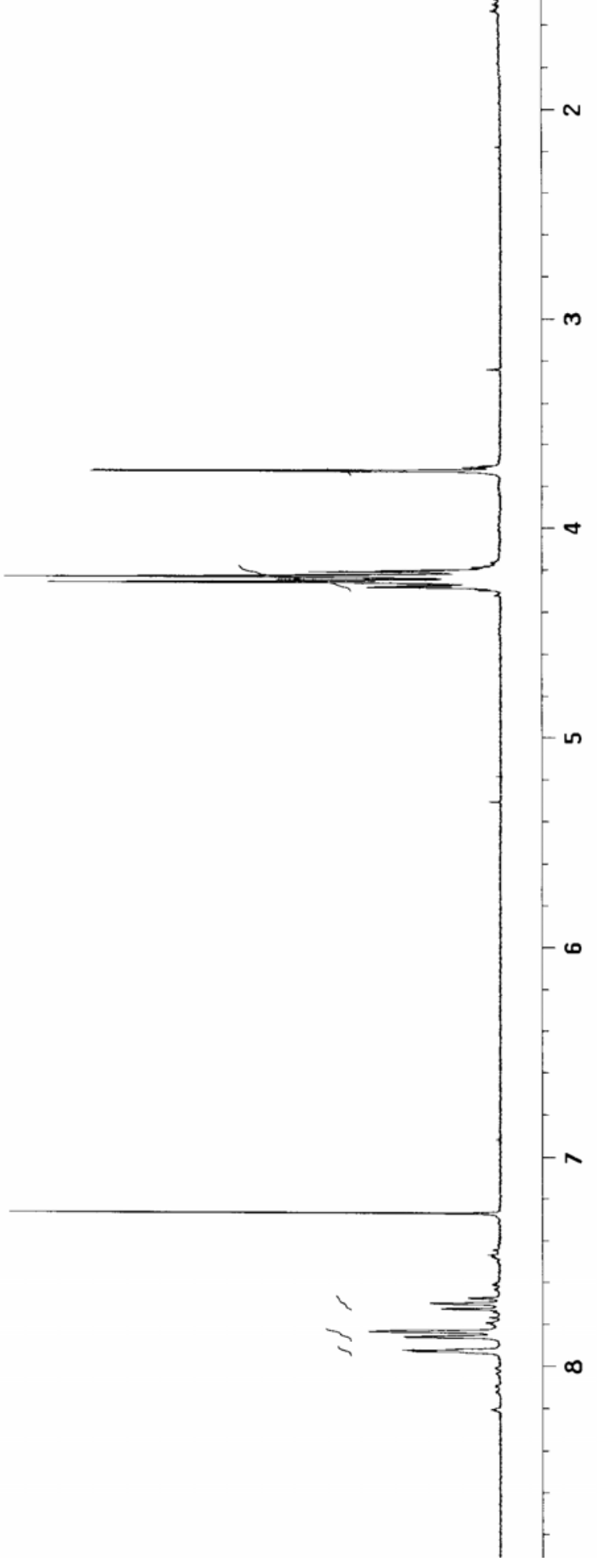




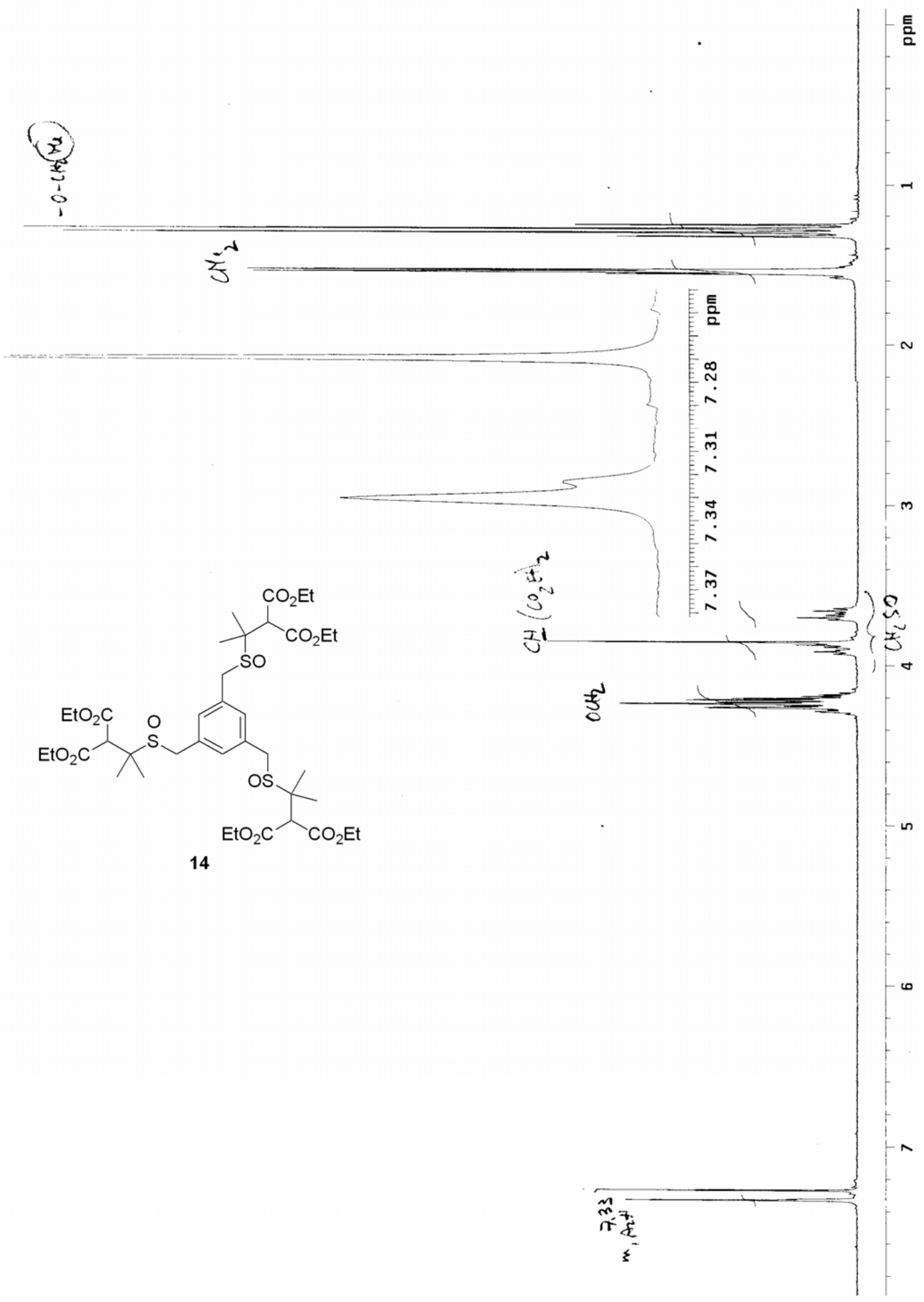




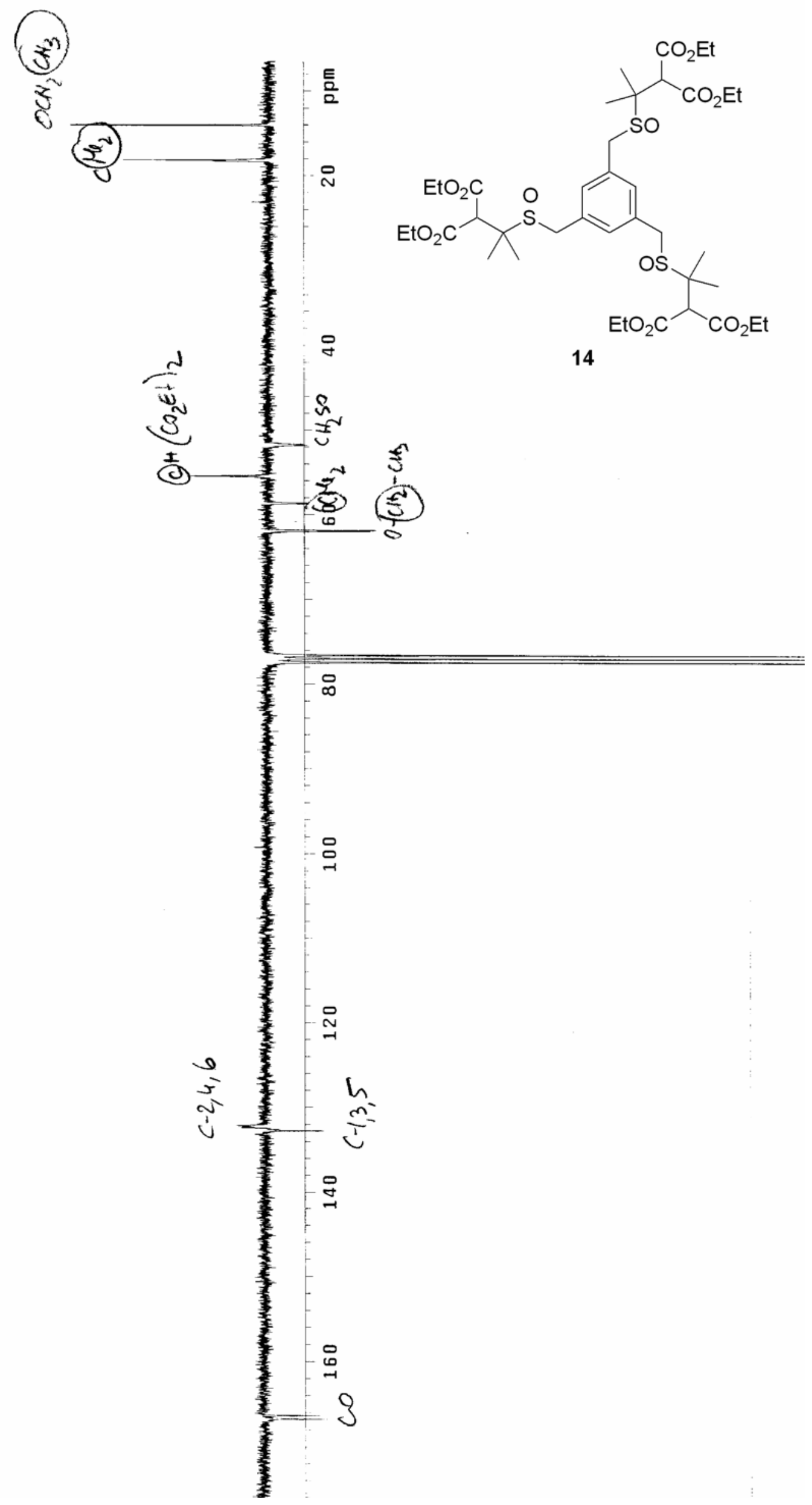




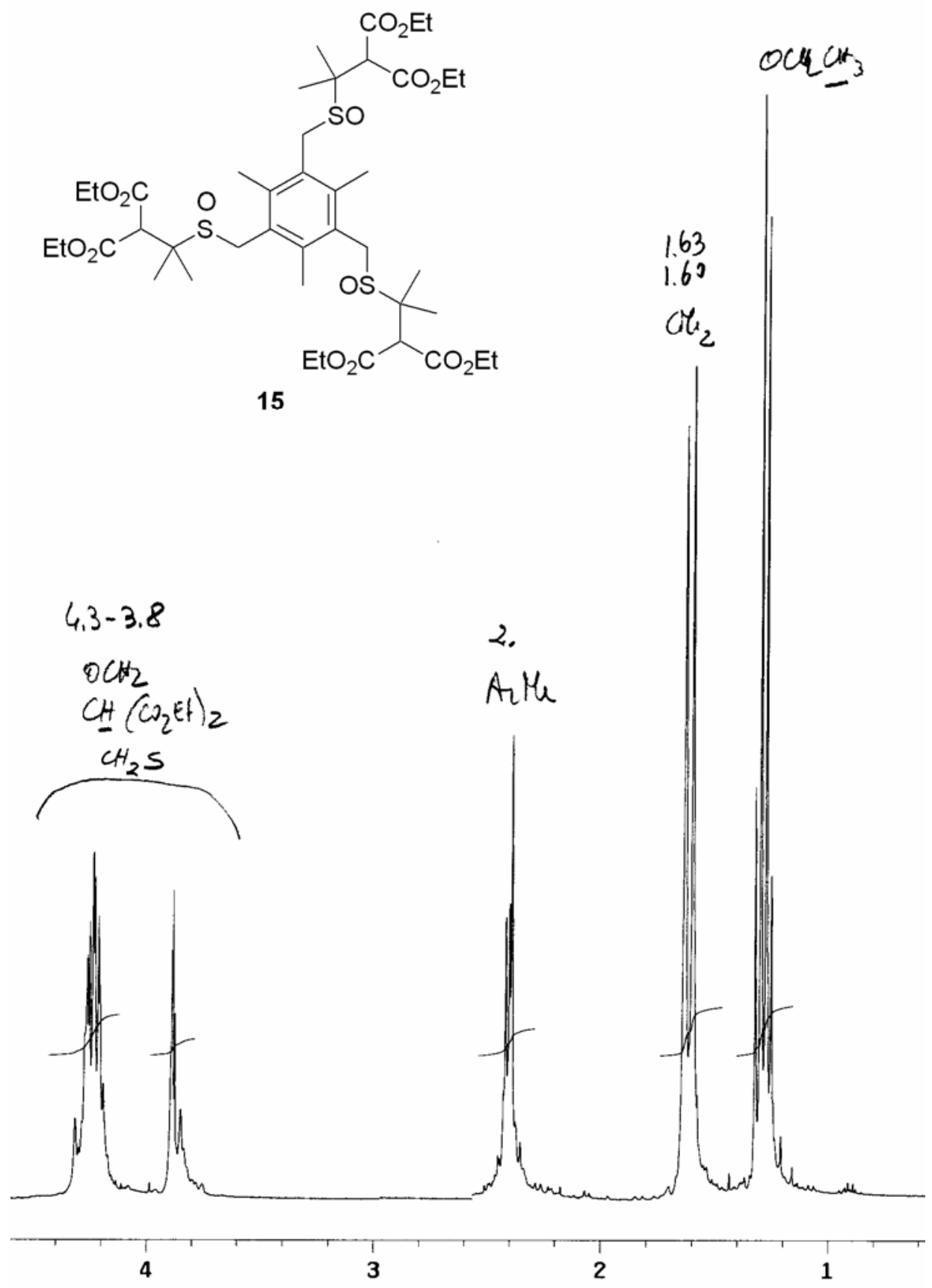




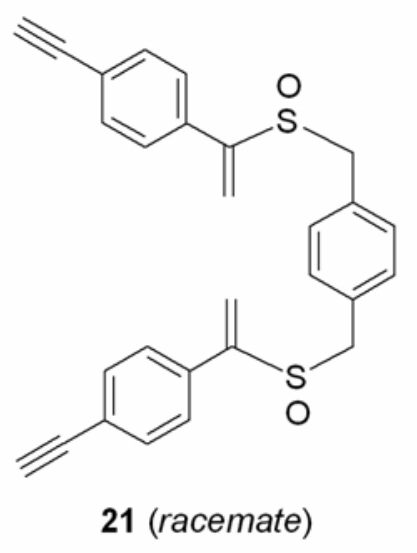

a

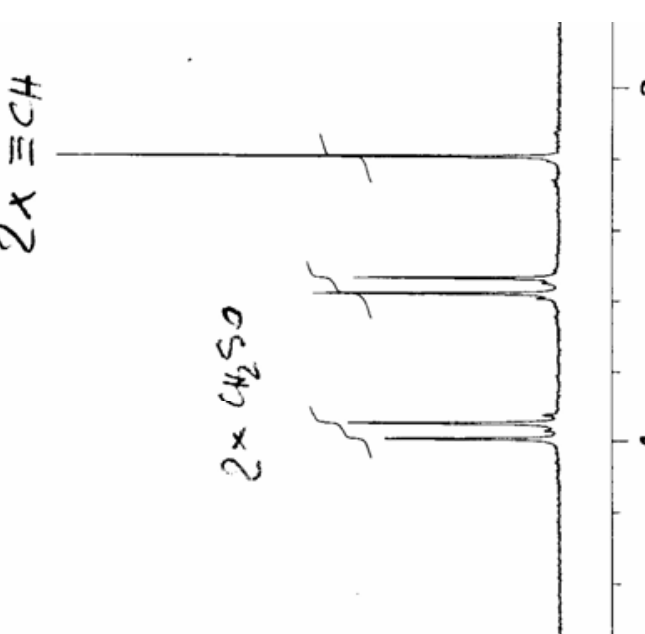

$m$

$\frac{2}{\pi} \mathbb{t}^{2}$

N

$\infty_{0}^{x} v^{x}$

i 


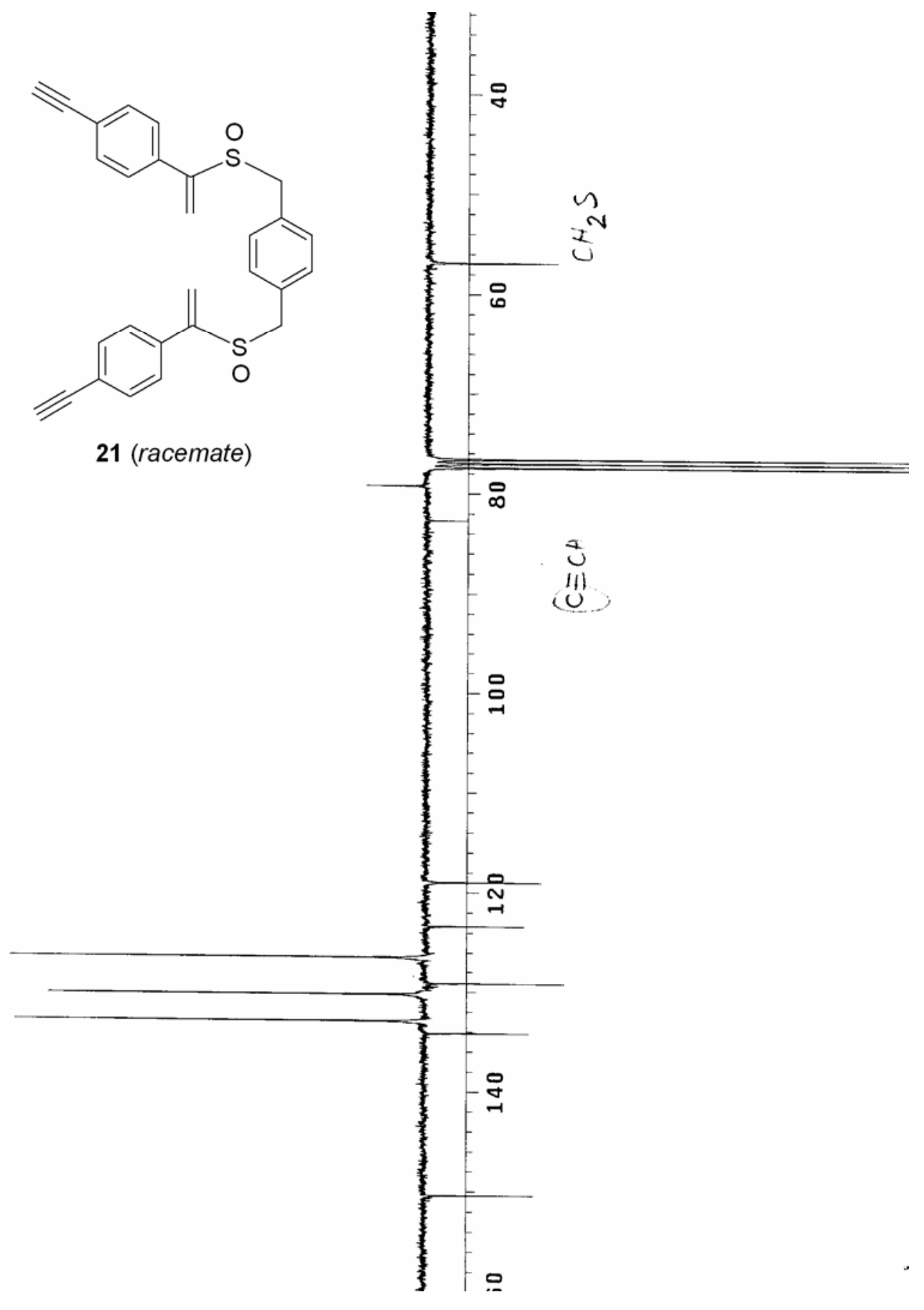




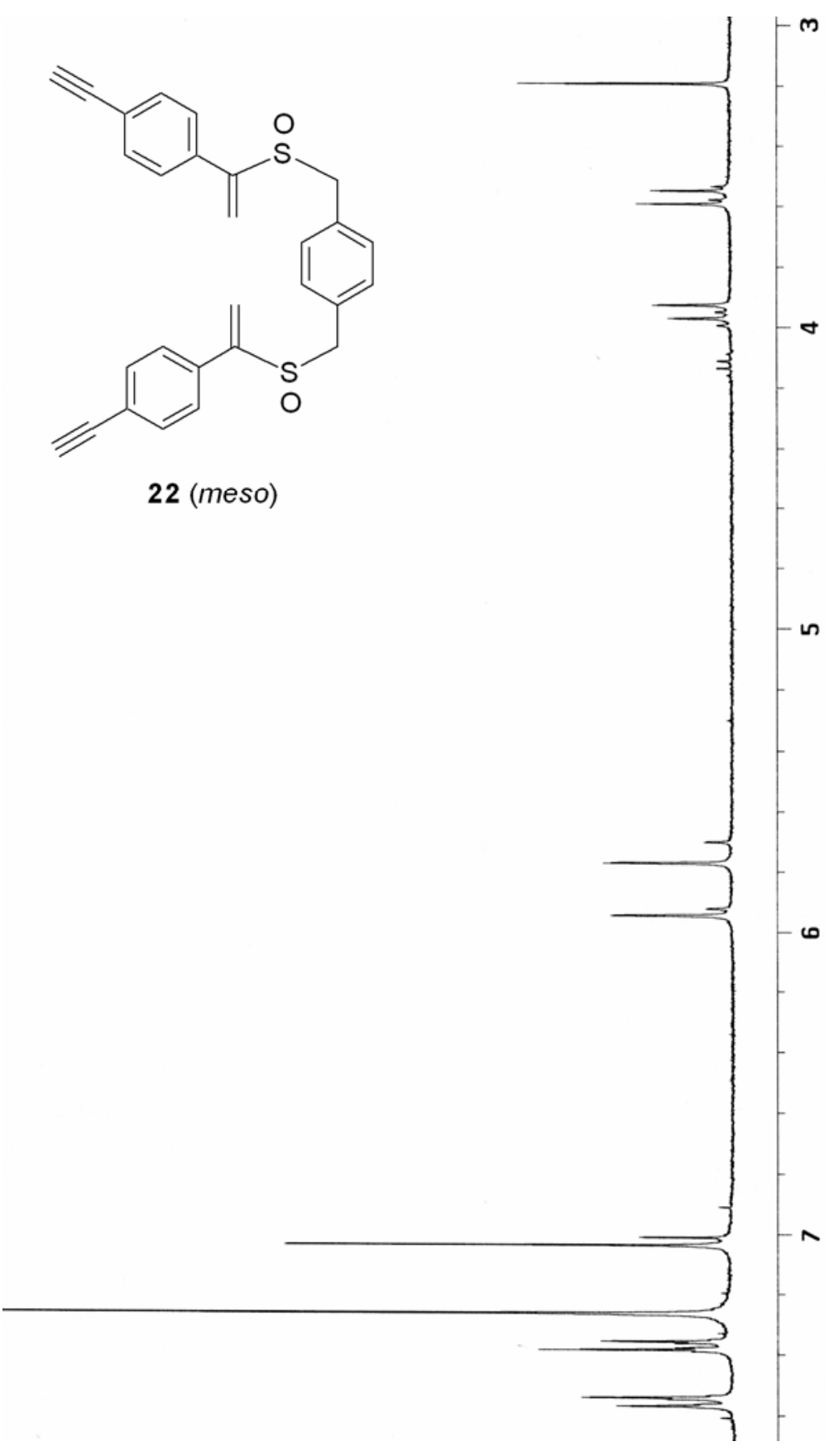




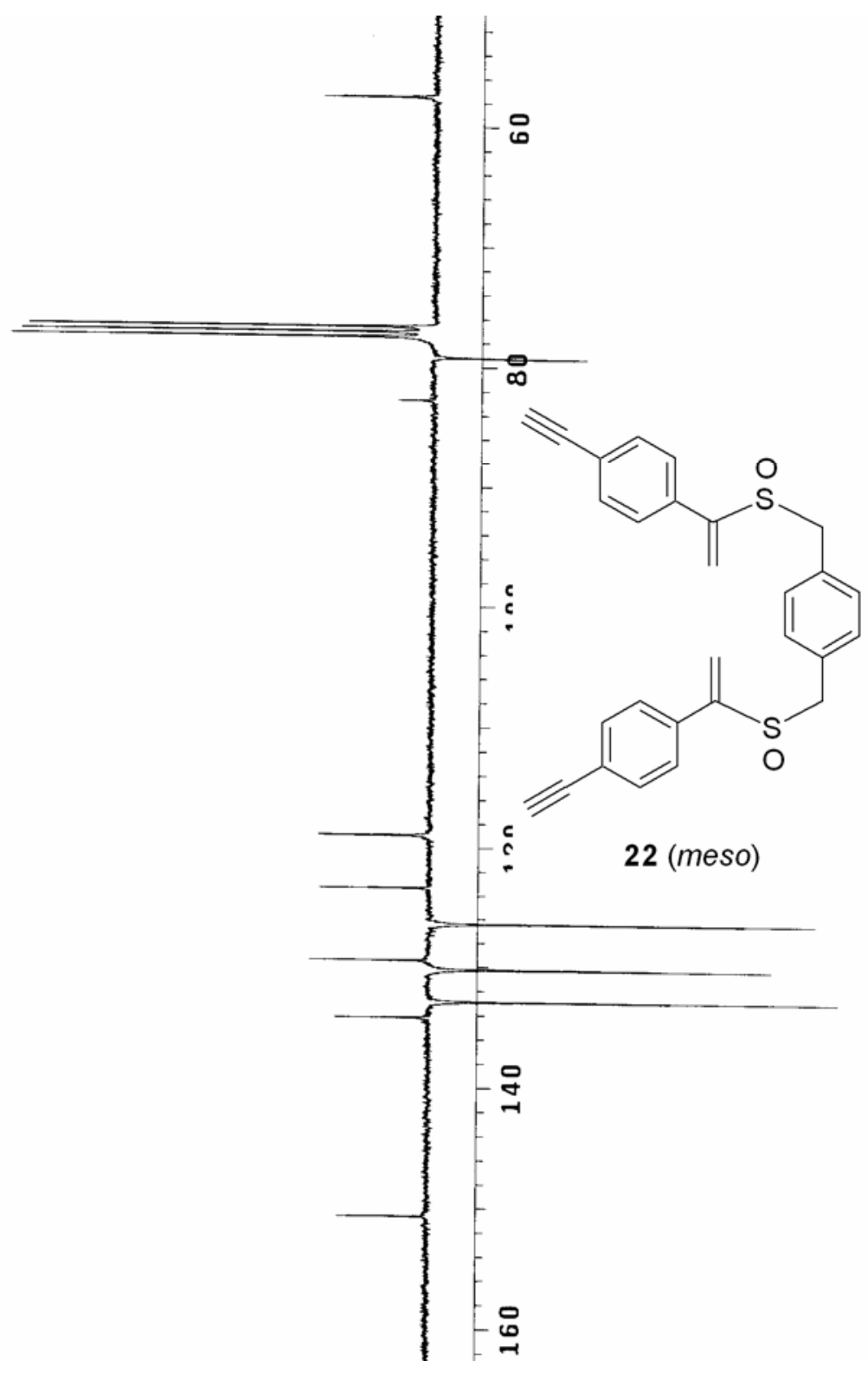




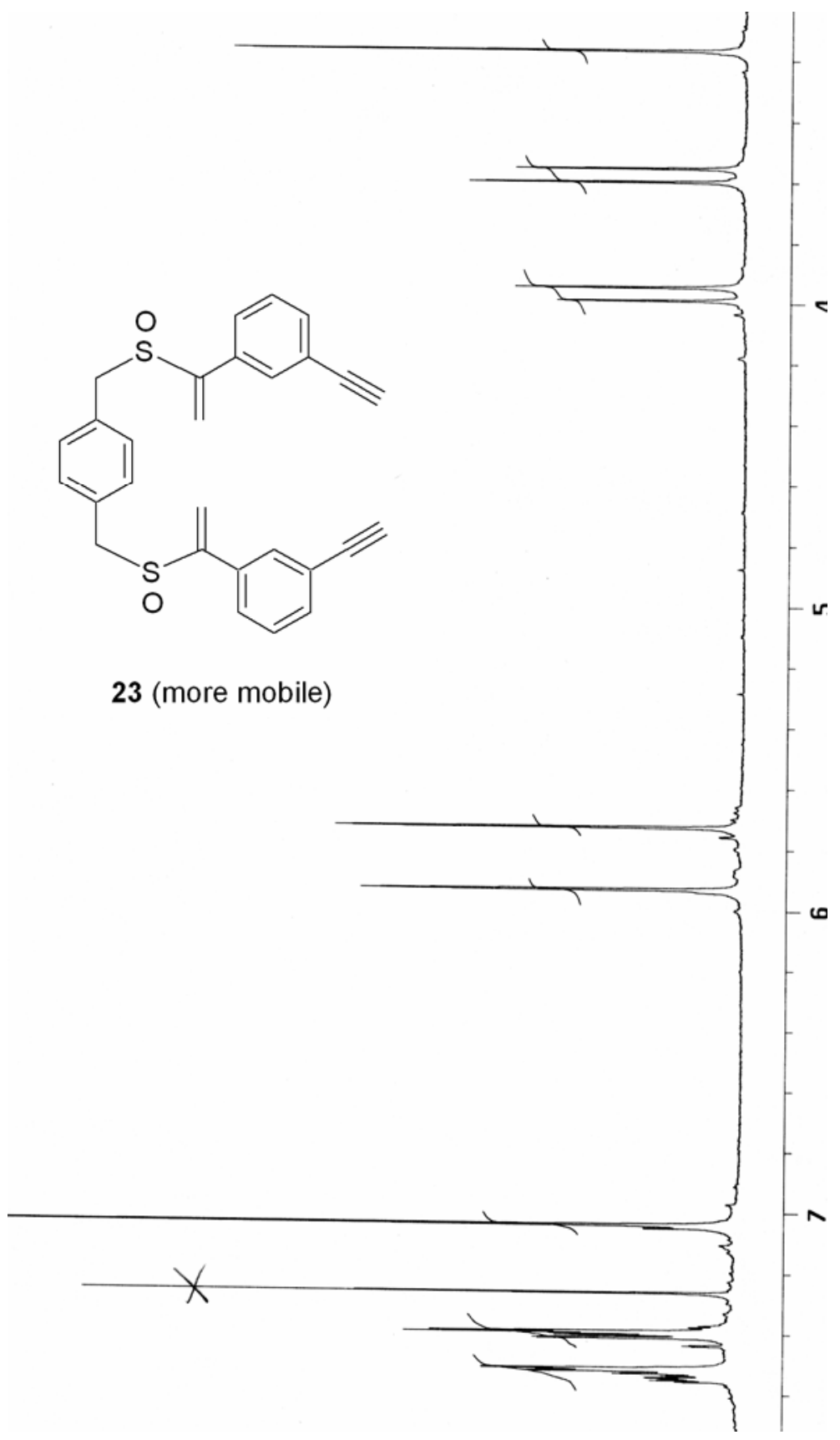




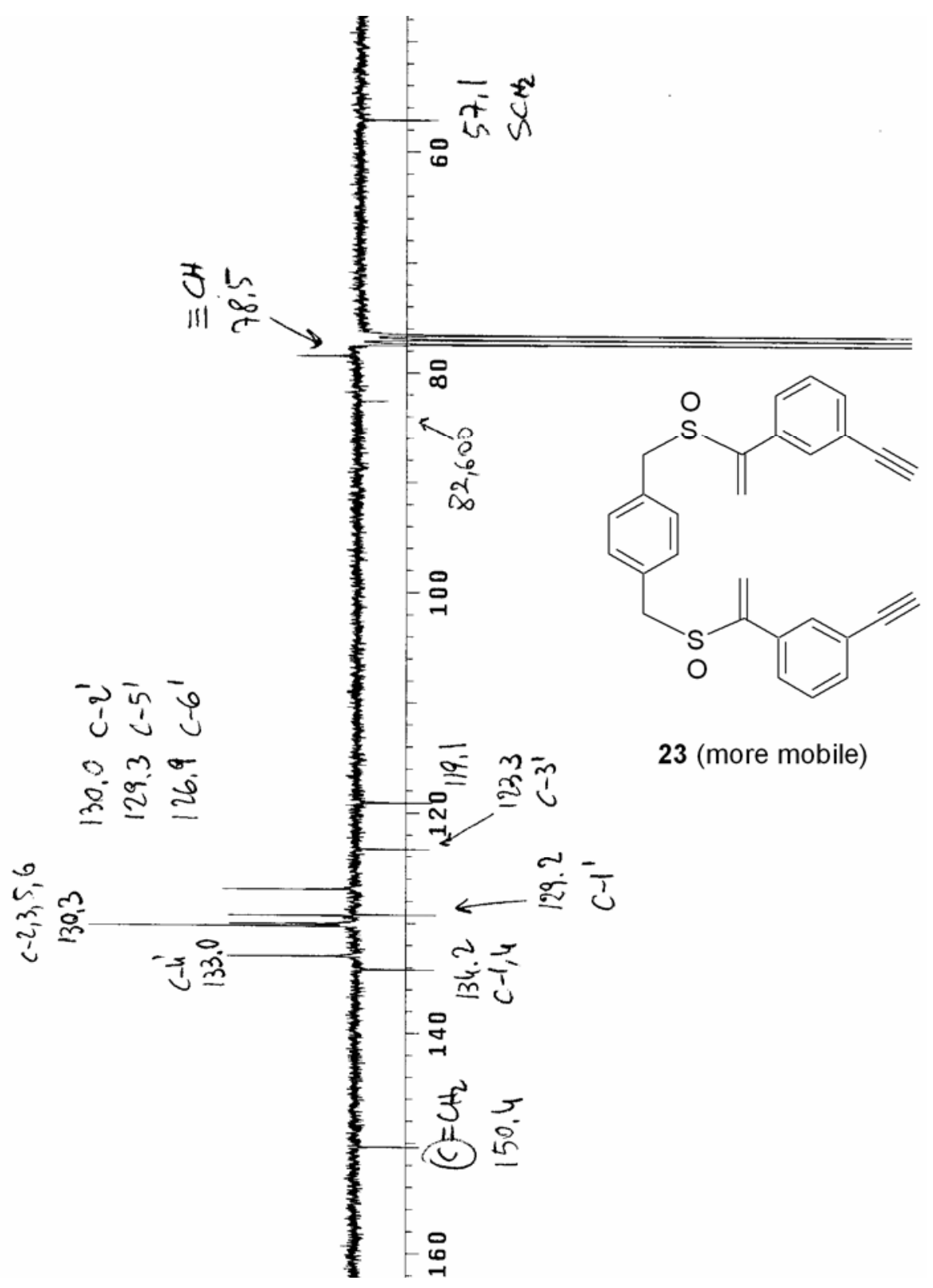



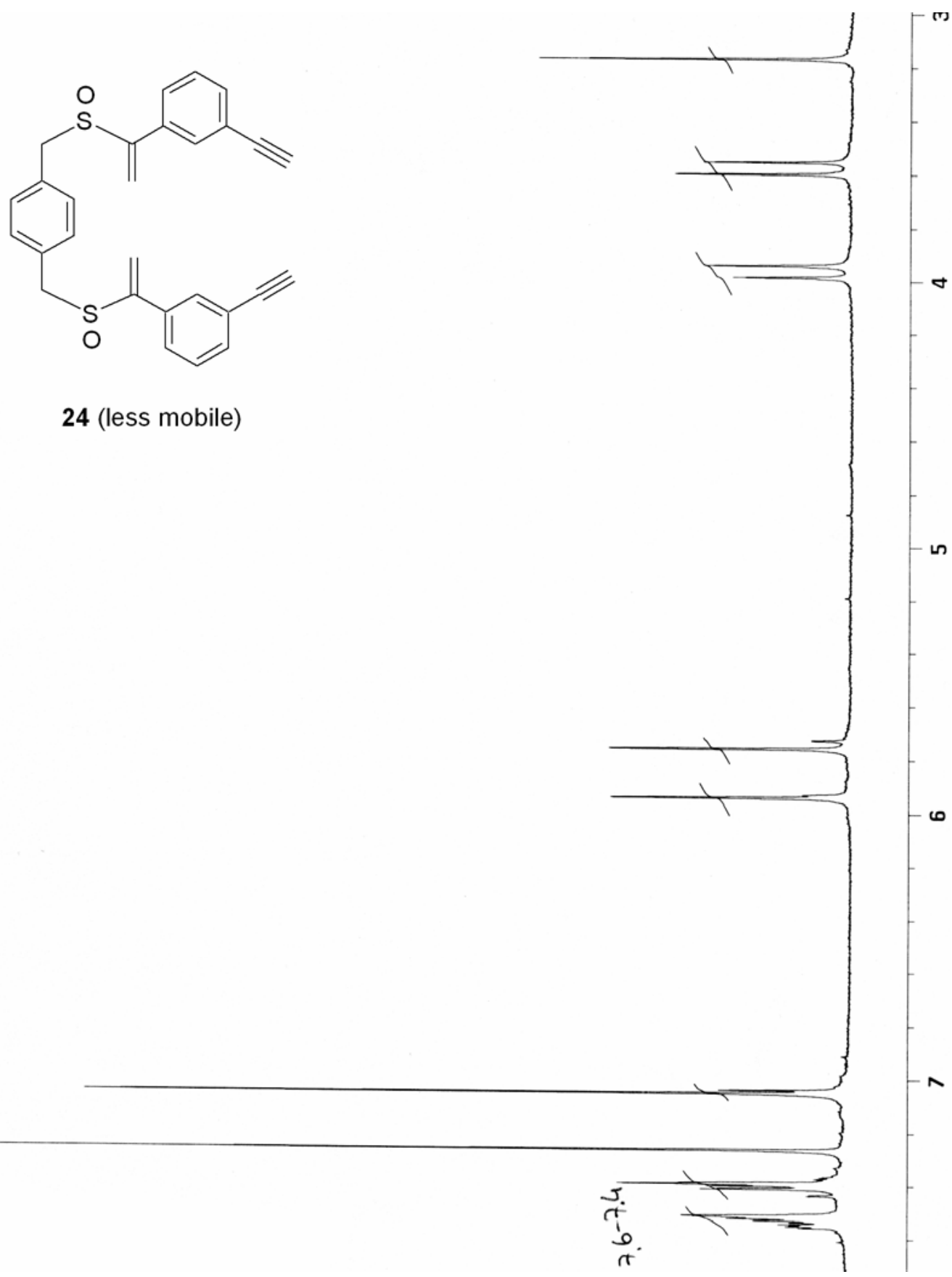


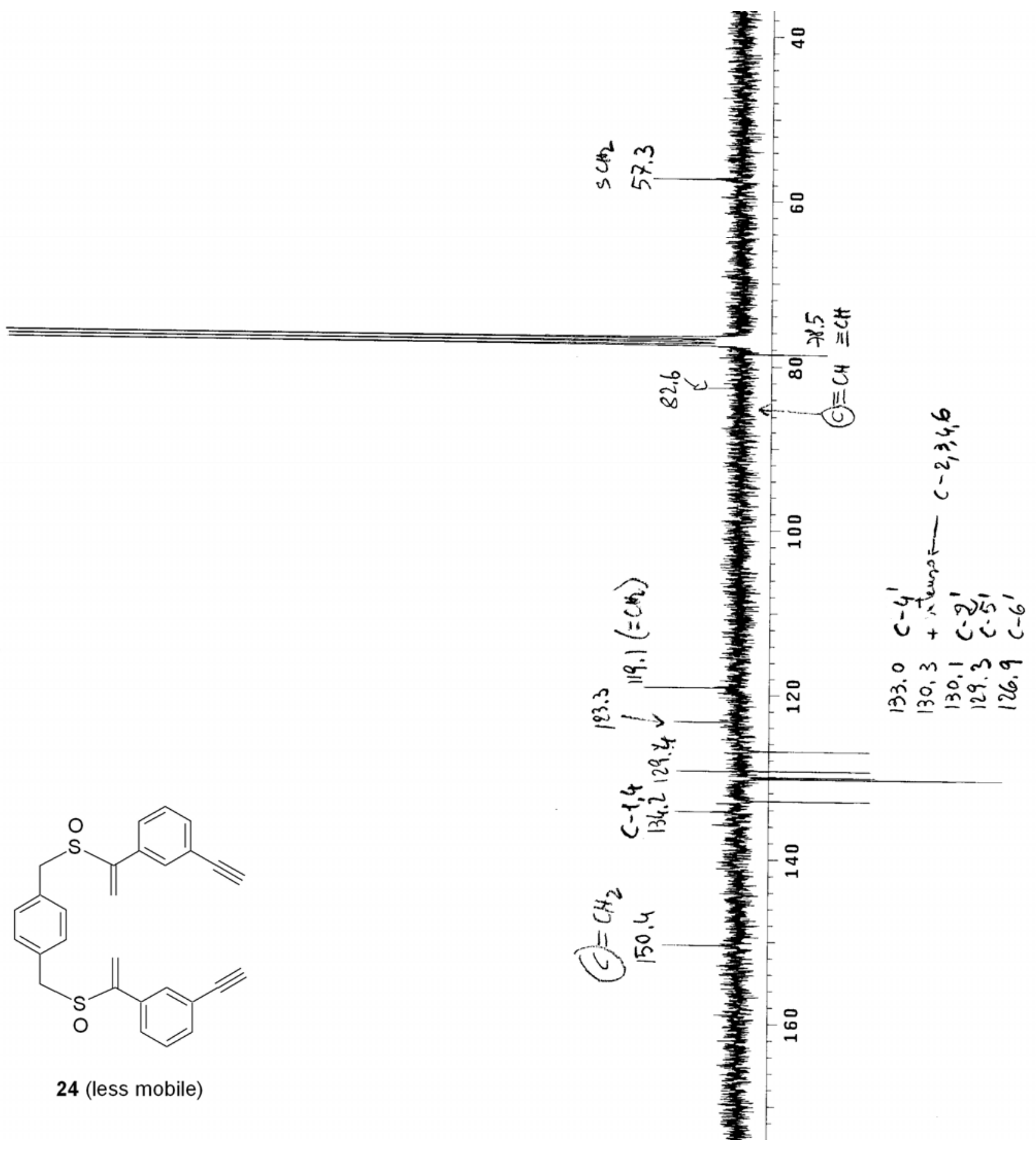




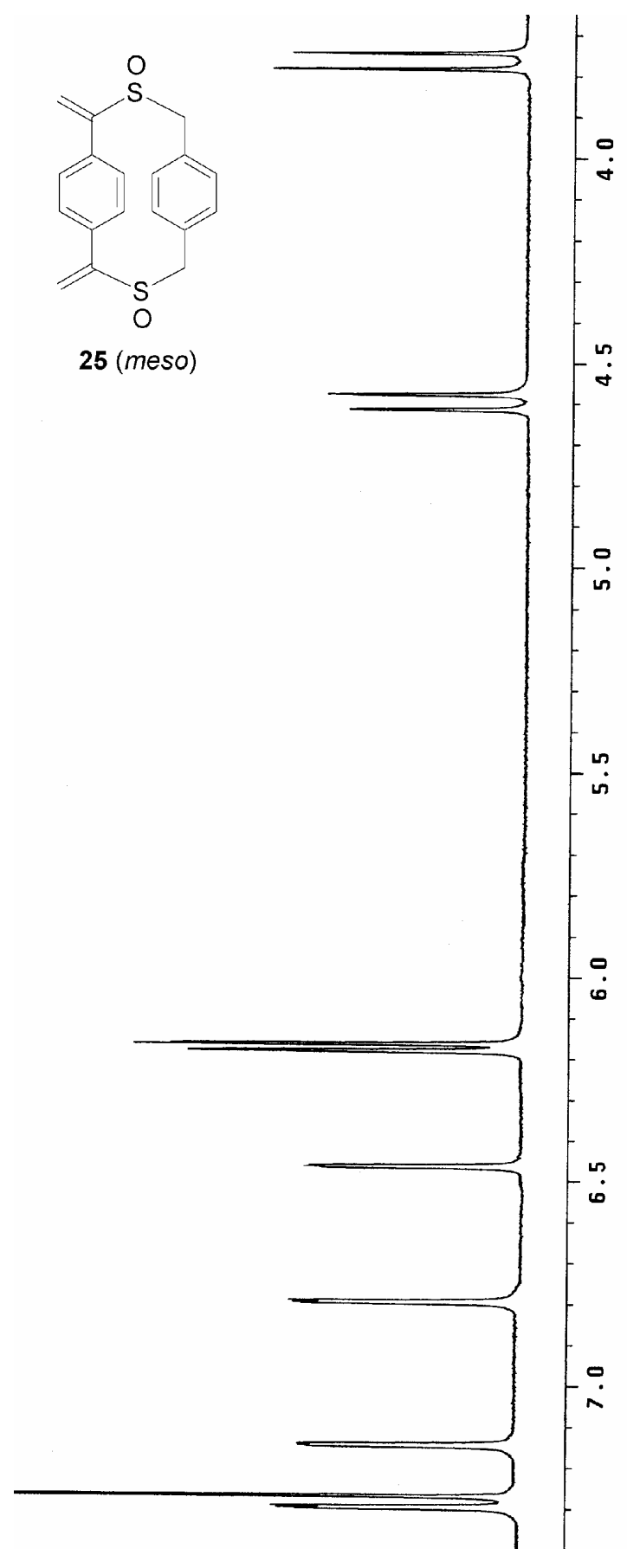




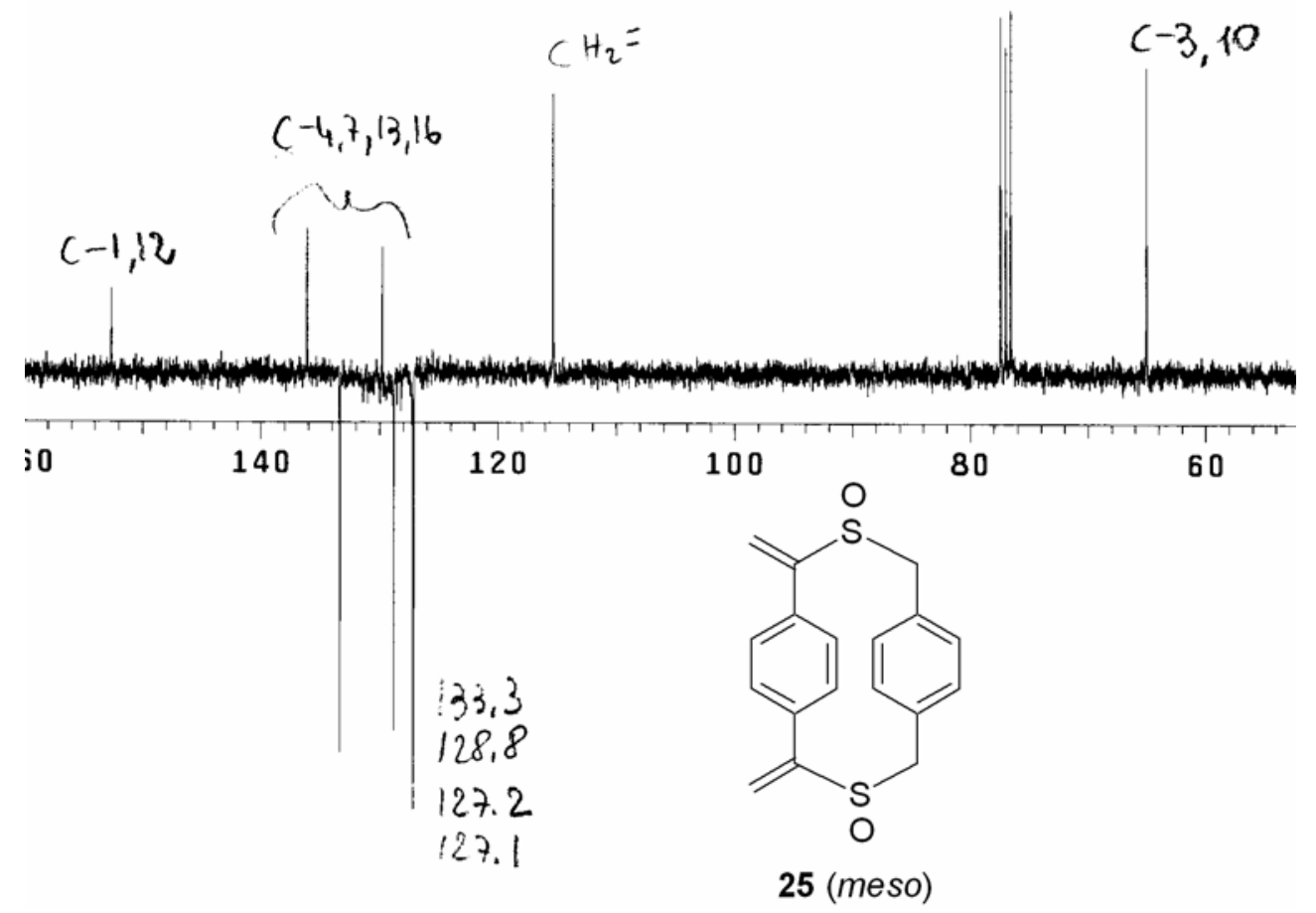




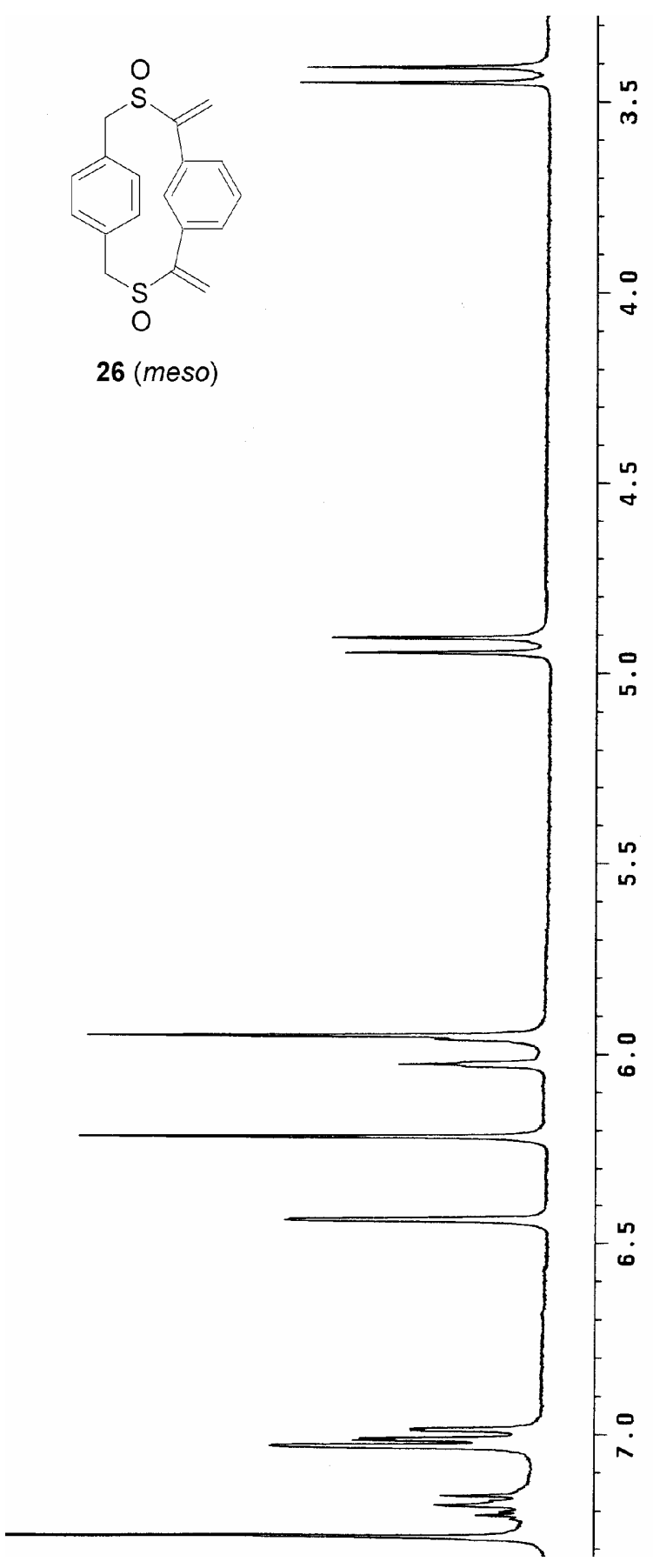




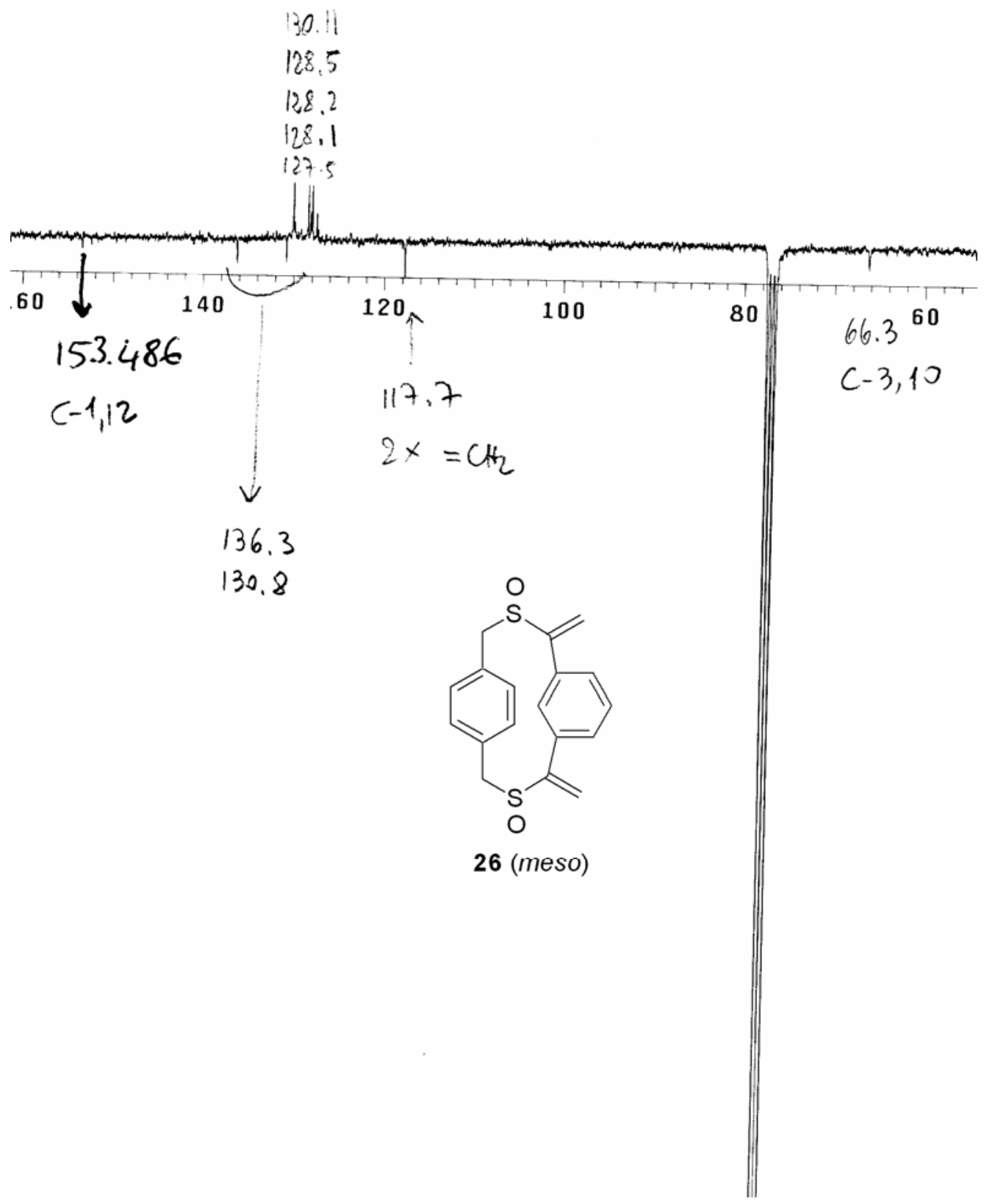



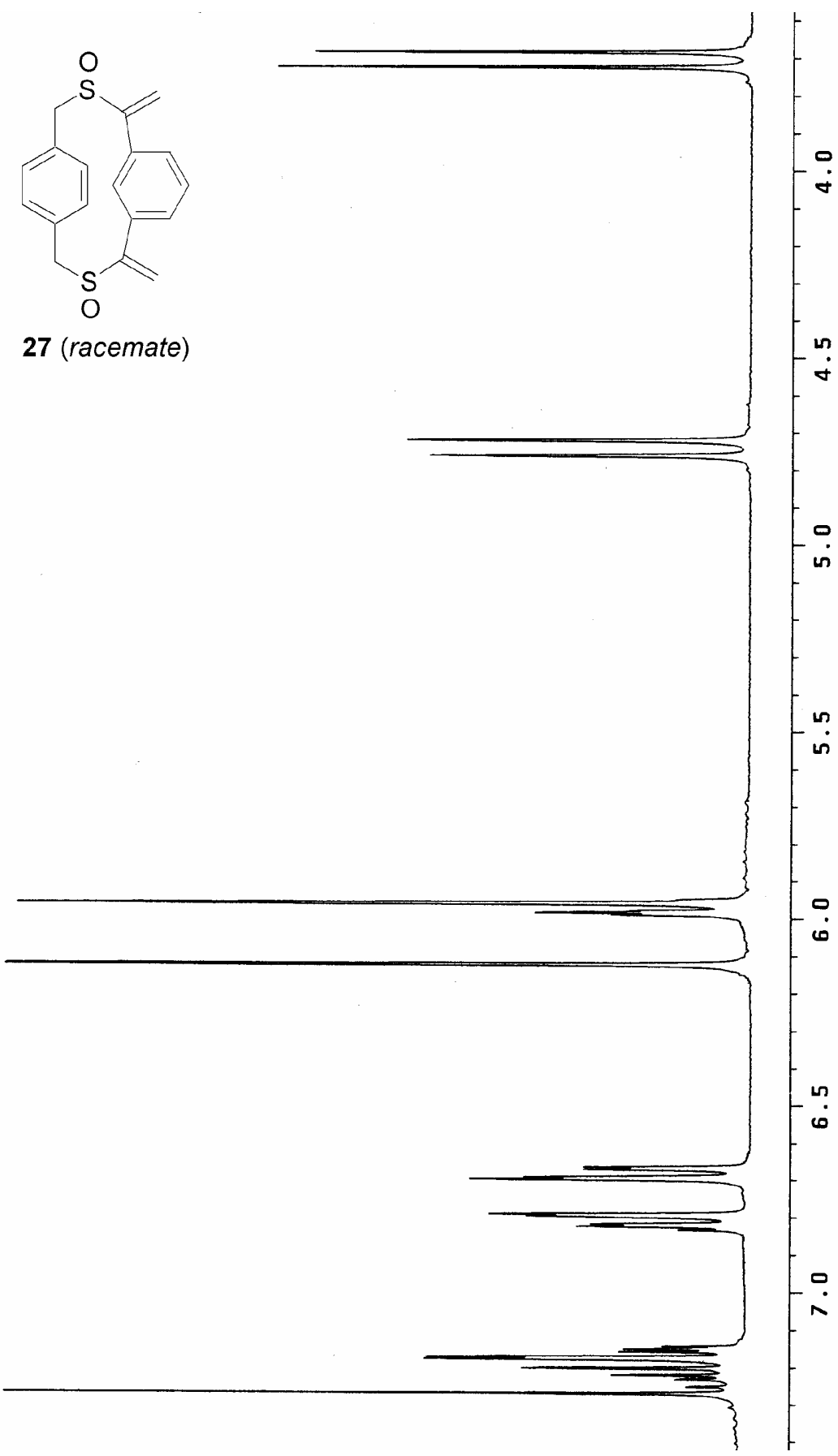


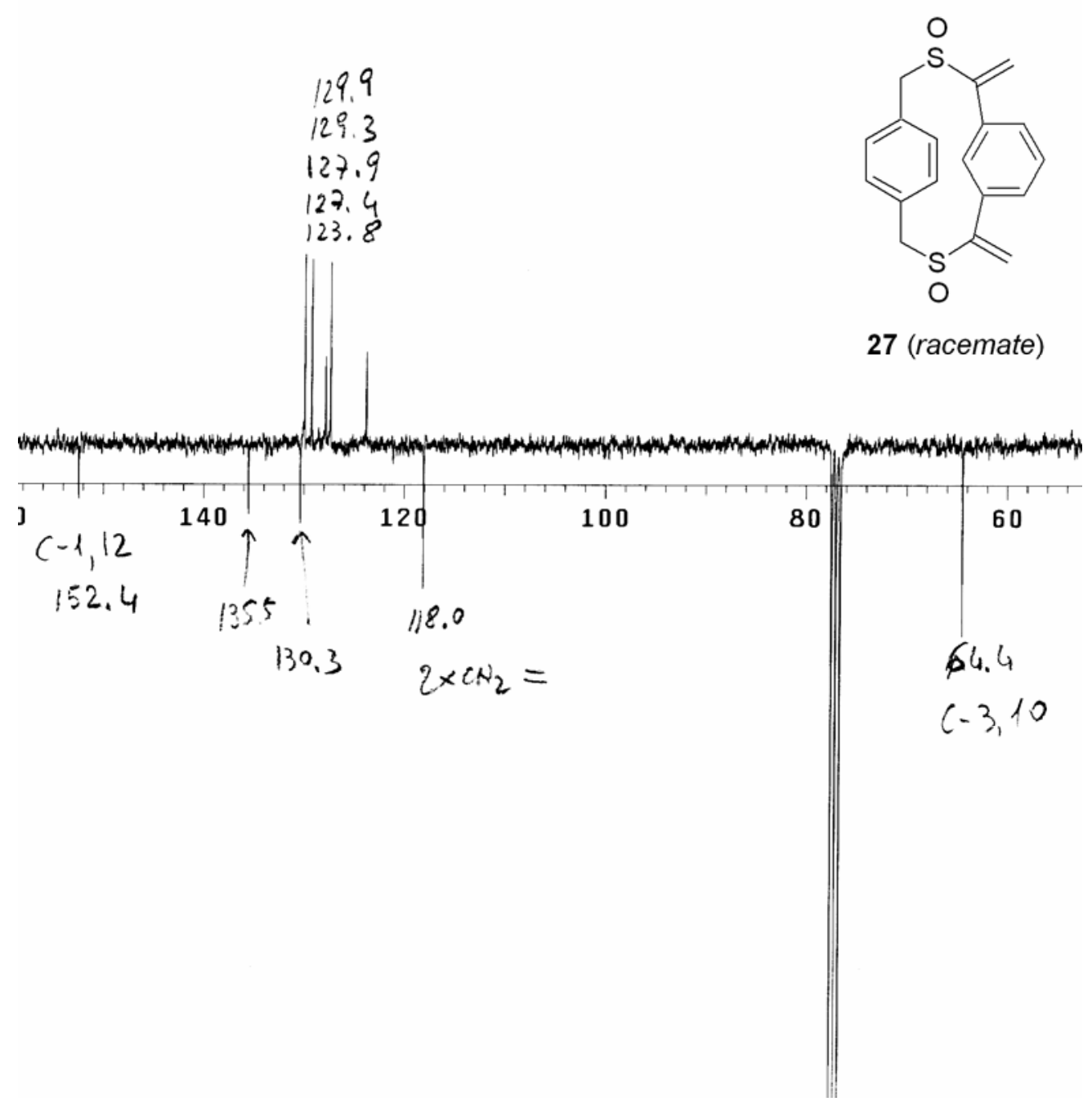




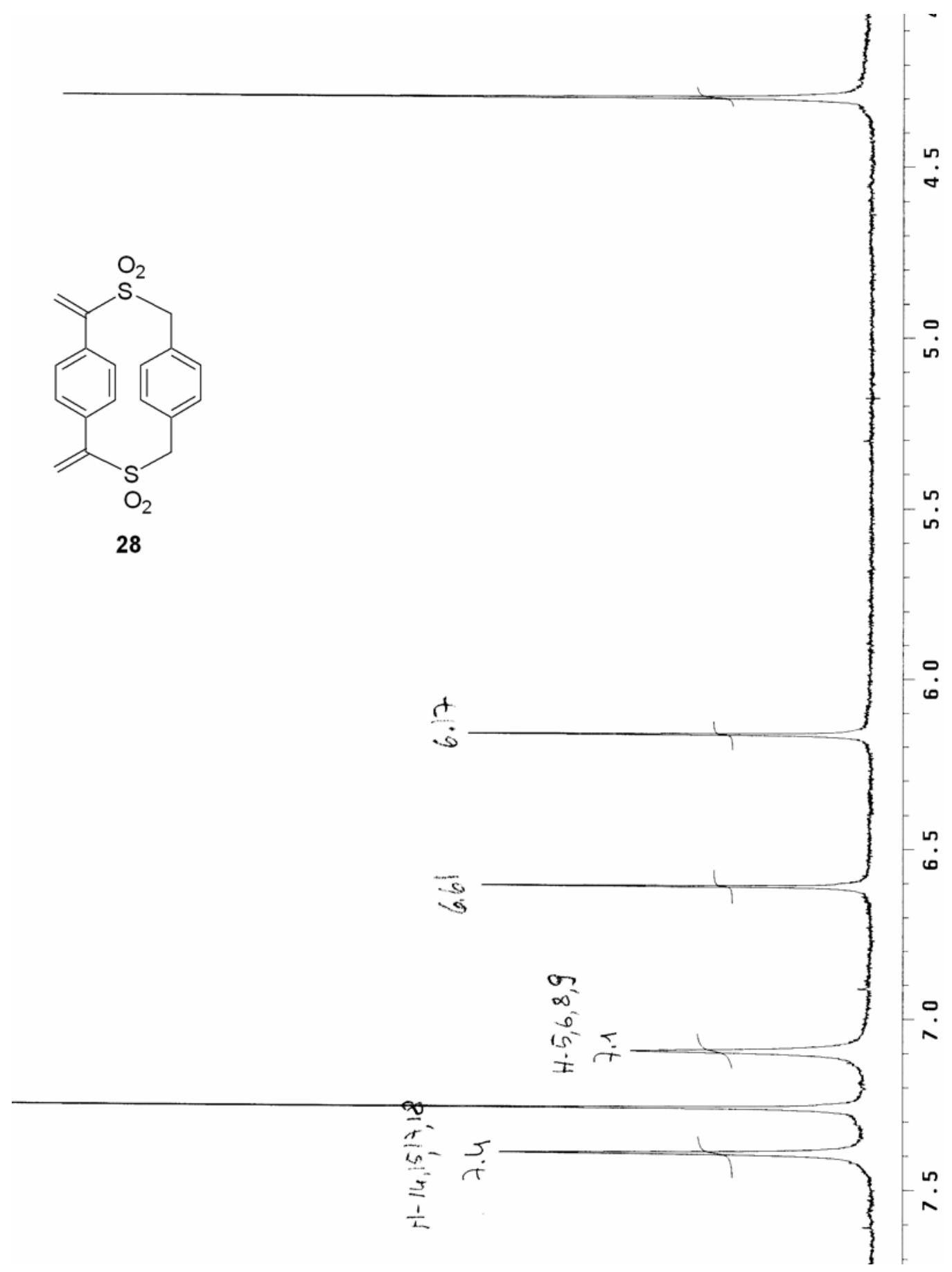




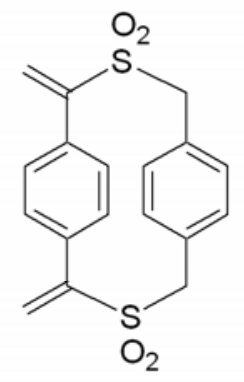

28

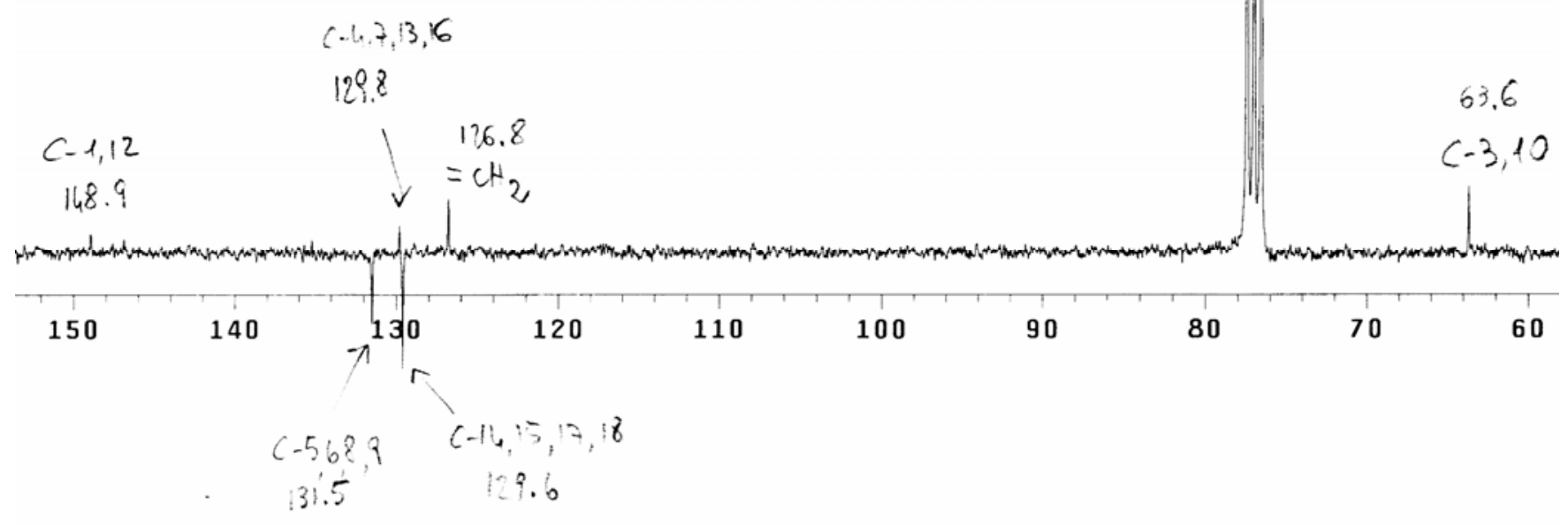




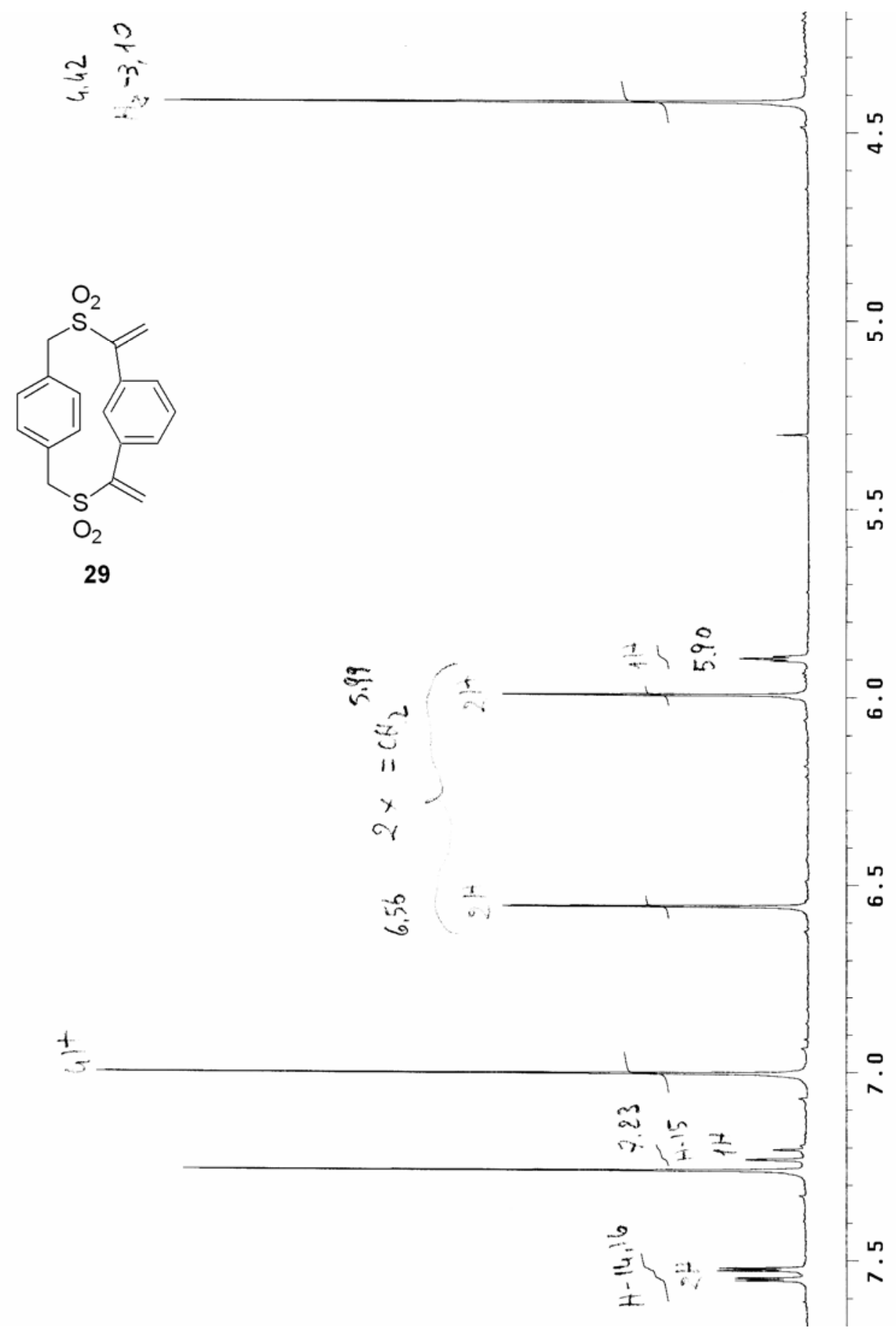




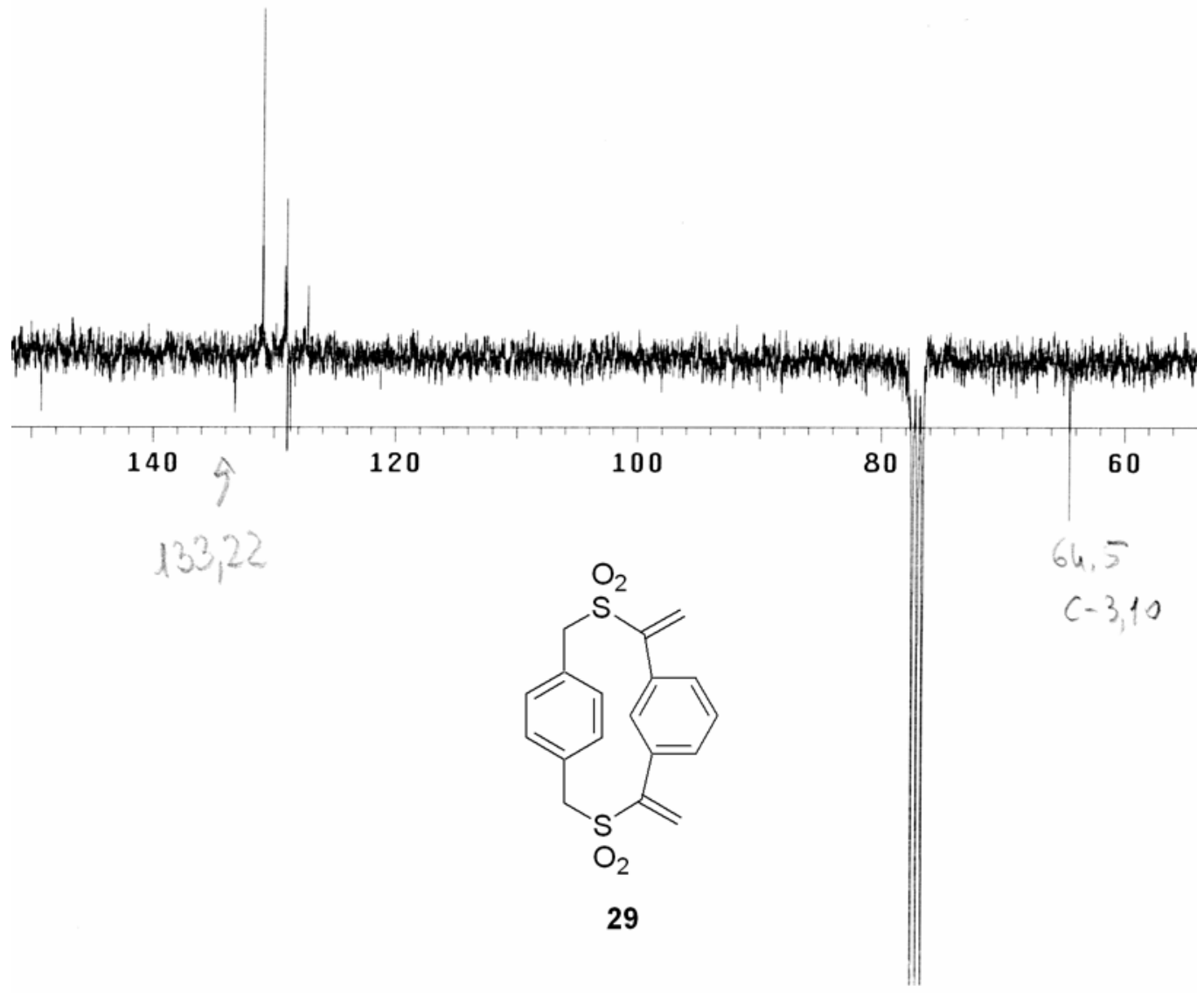




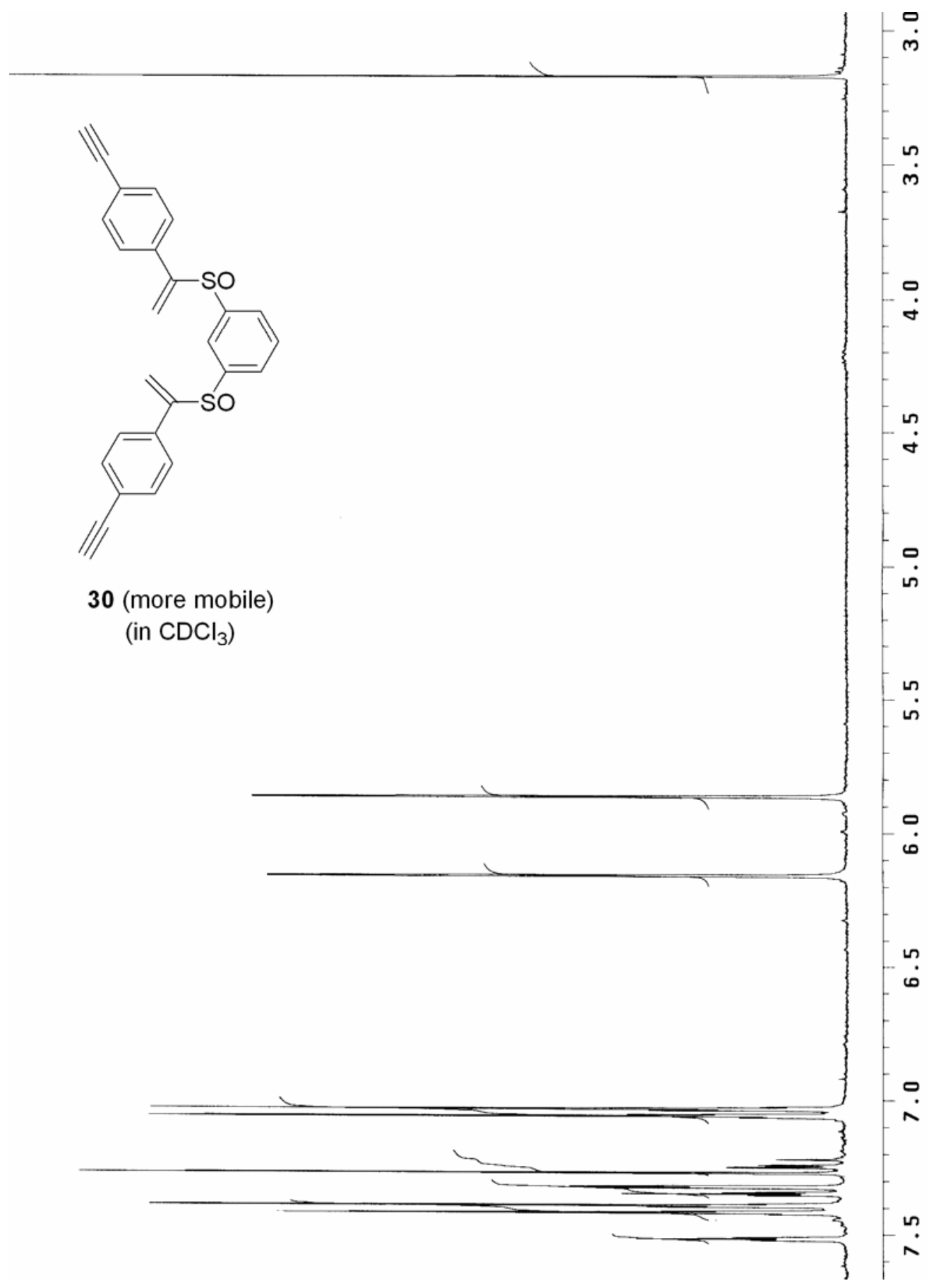




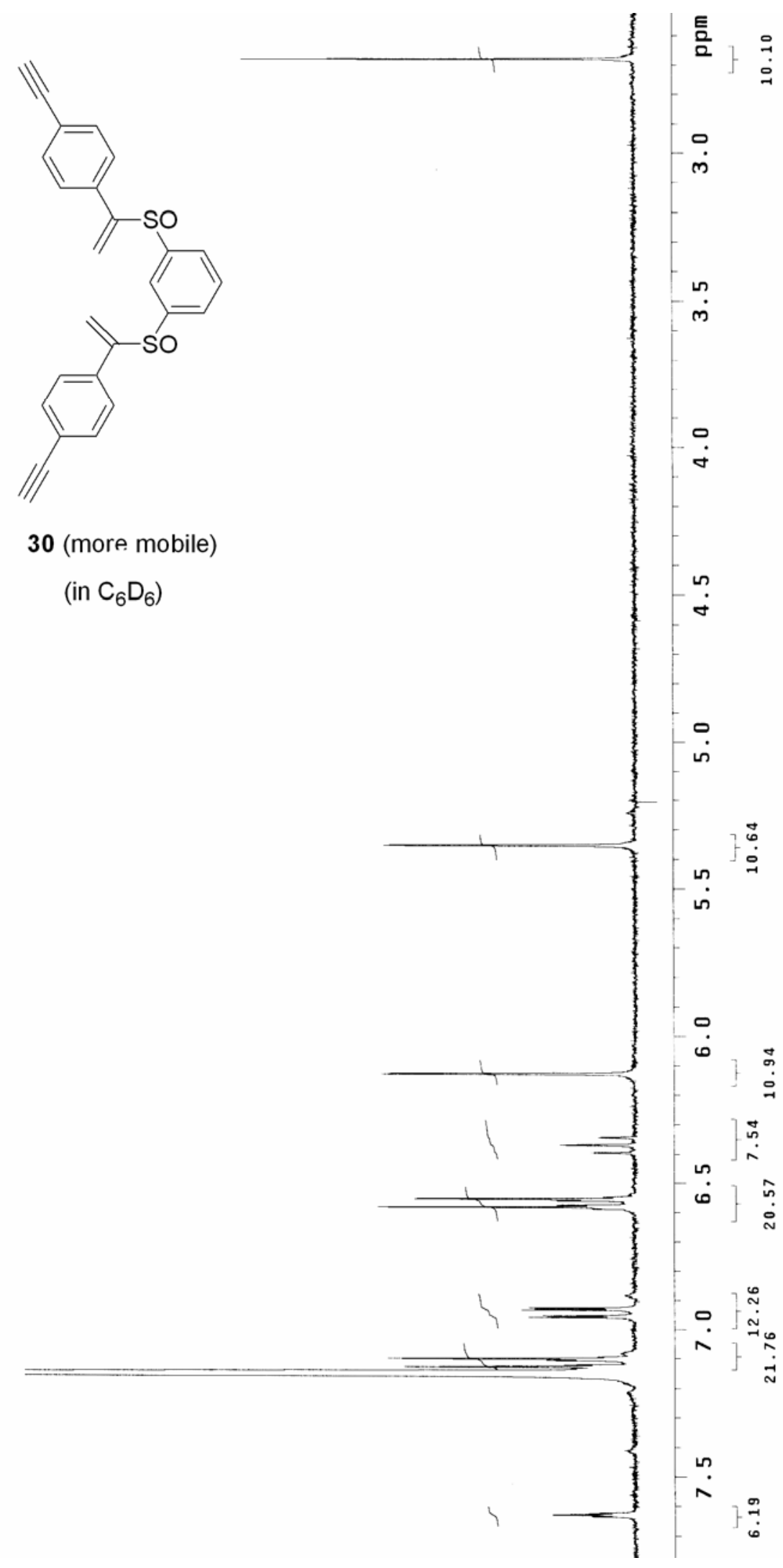




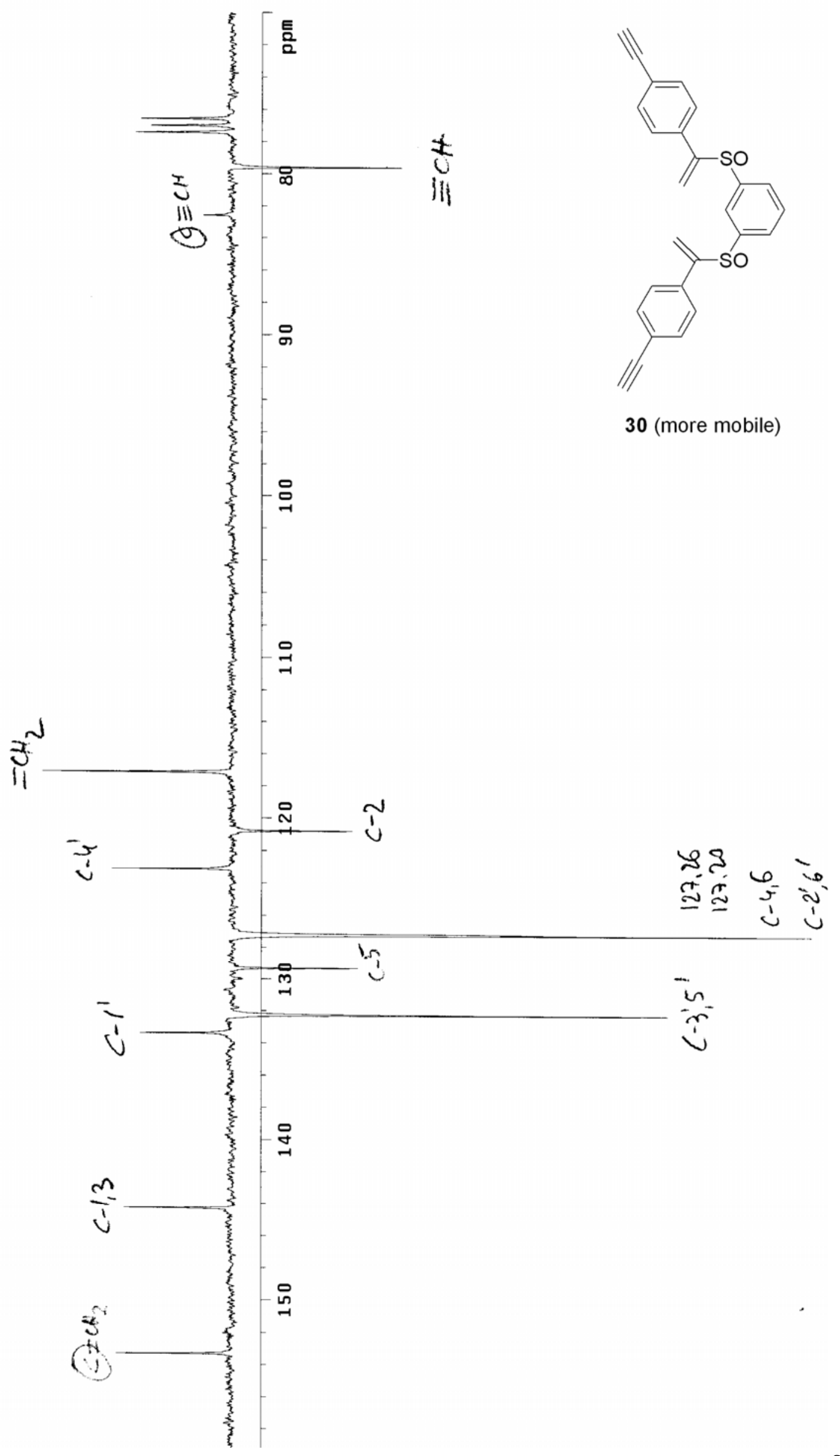




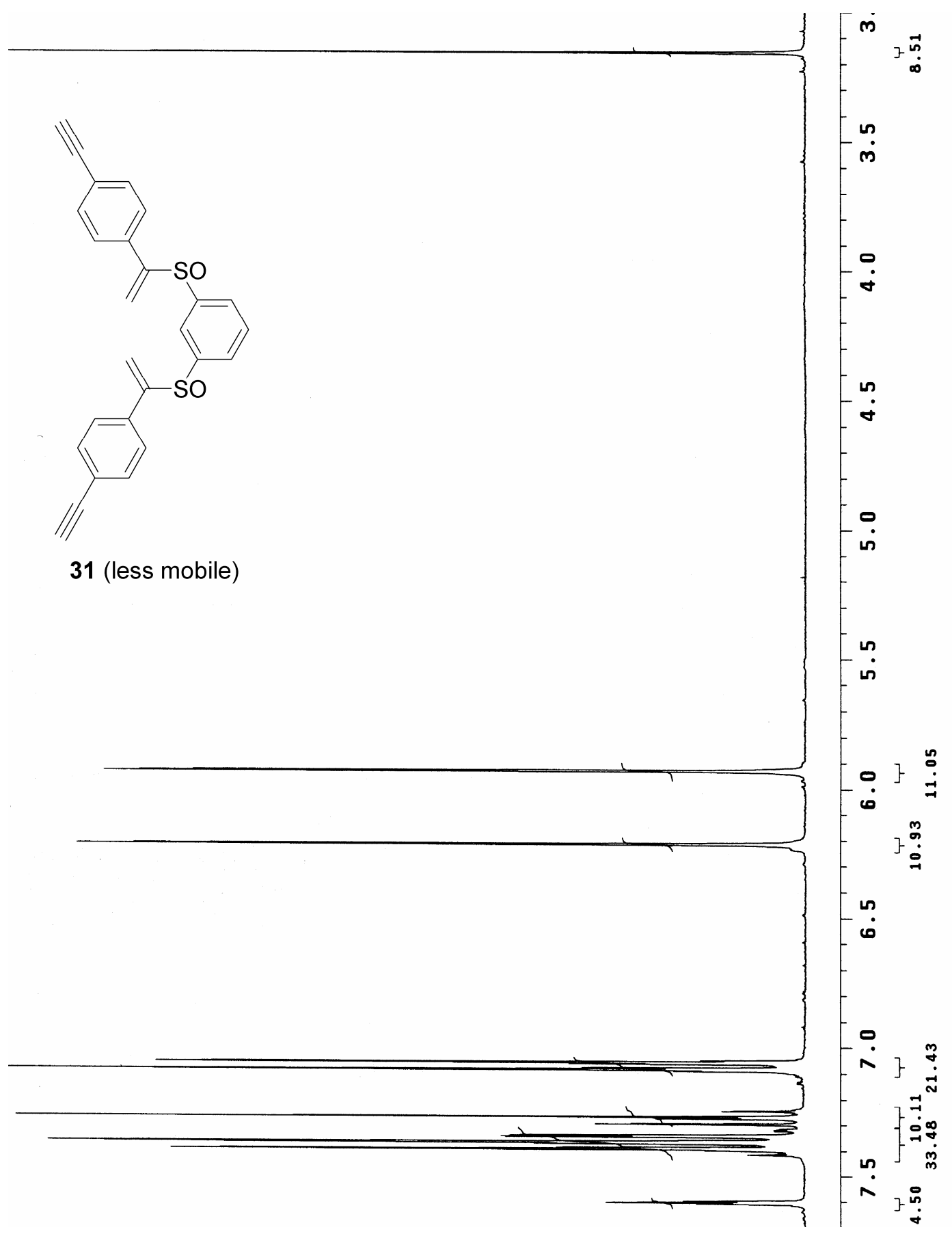



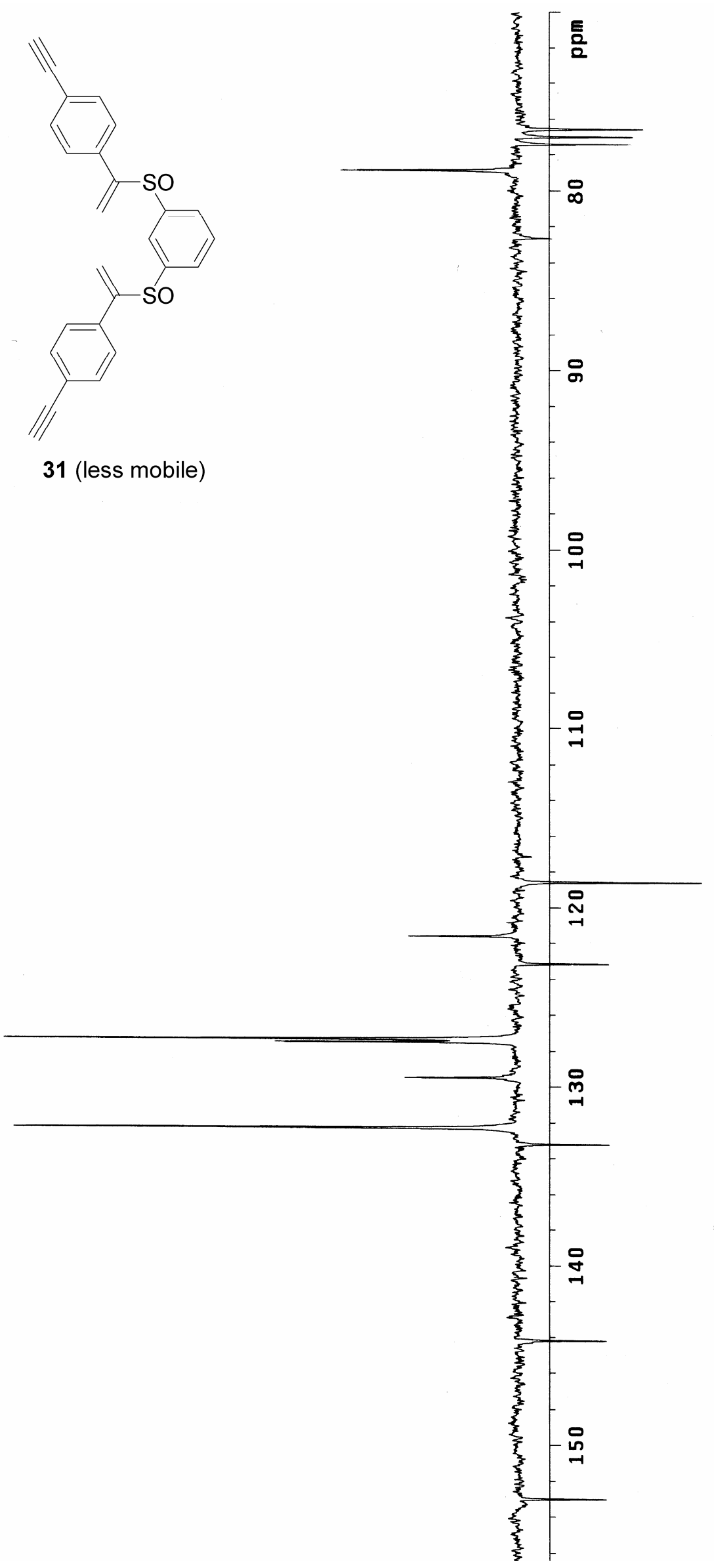


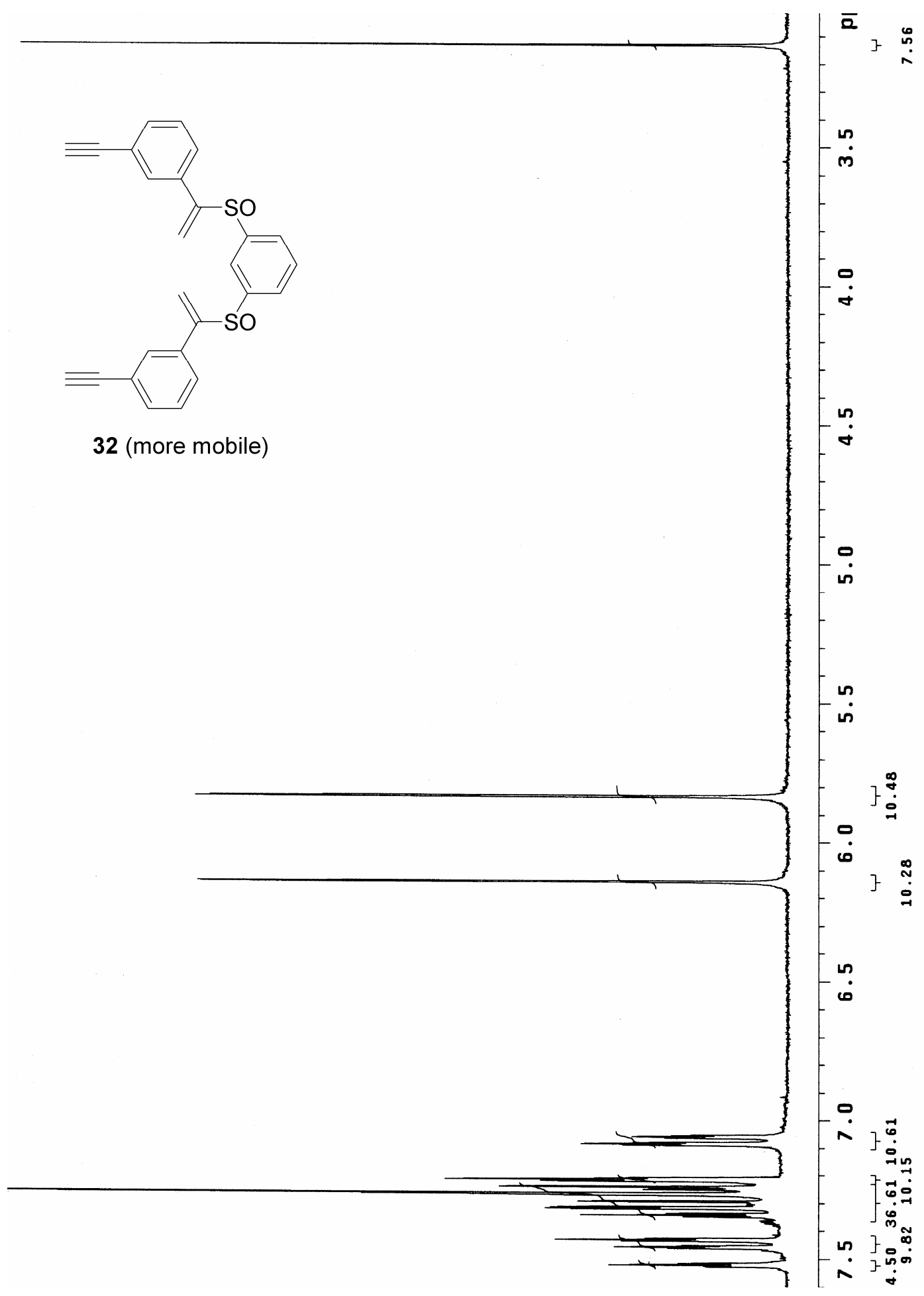




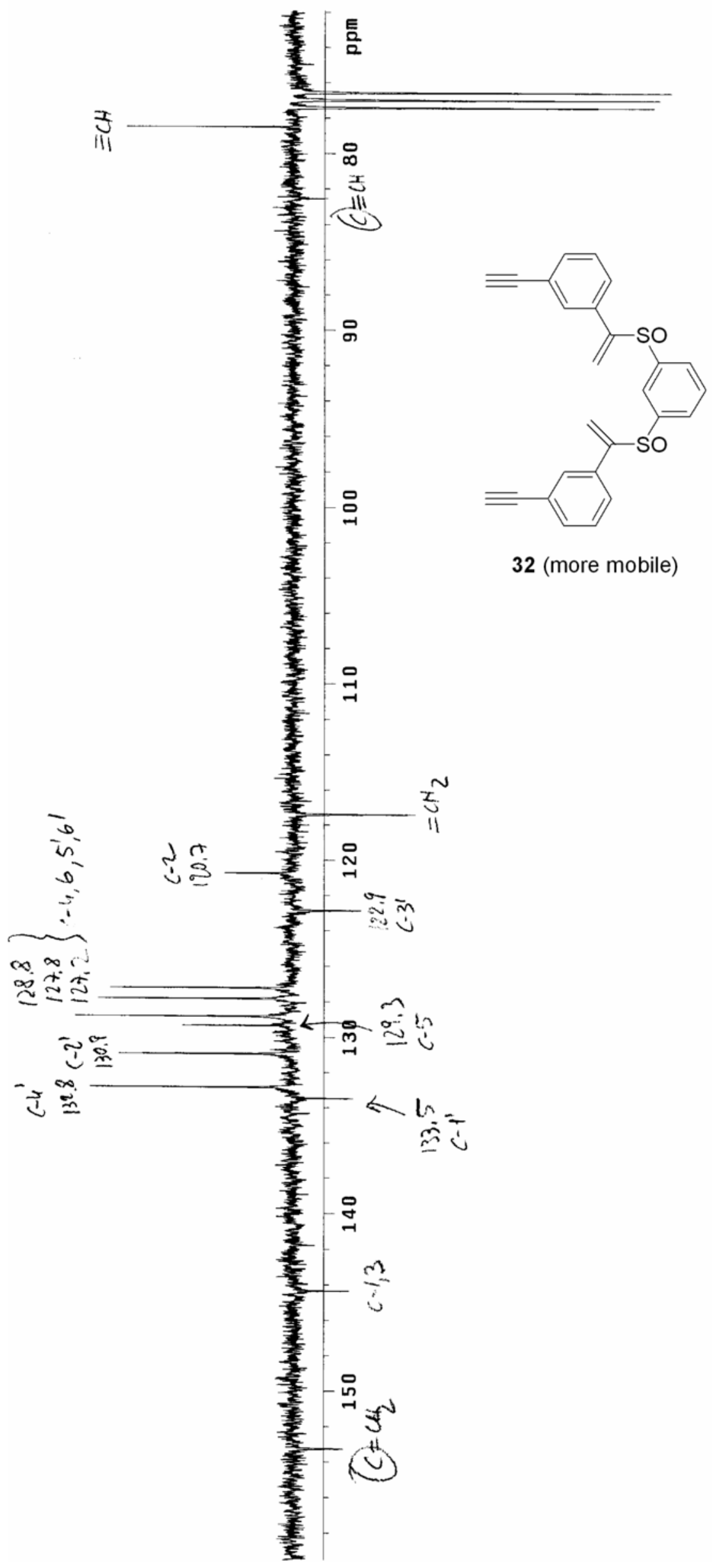




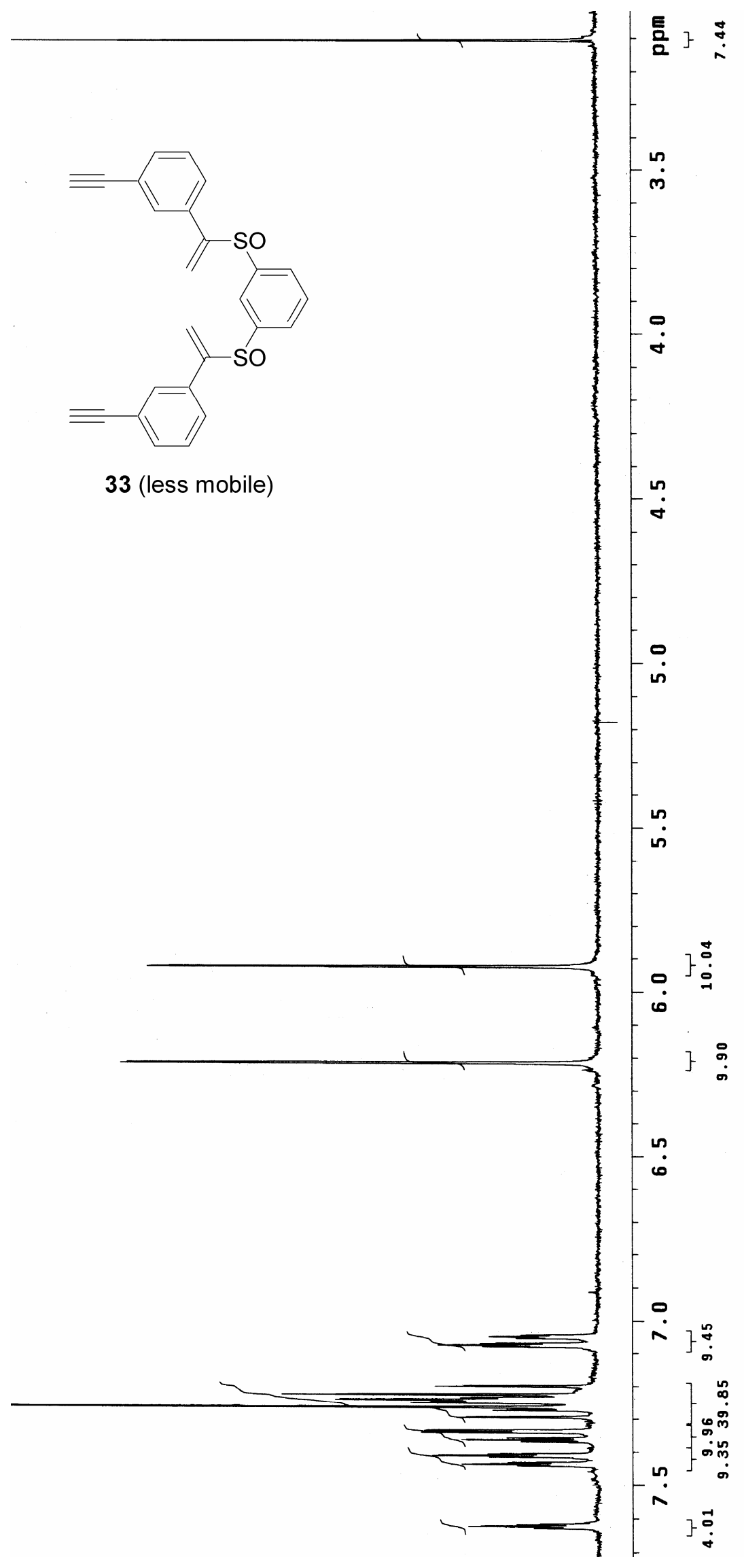




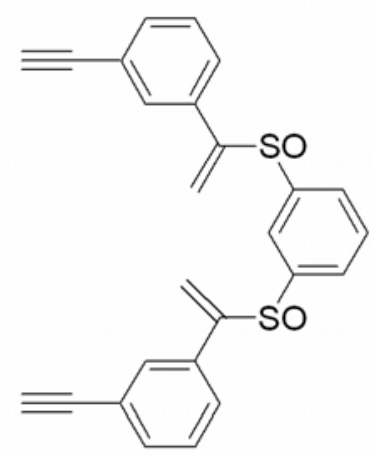

33 (less mobile)

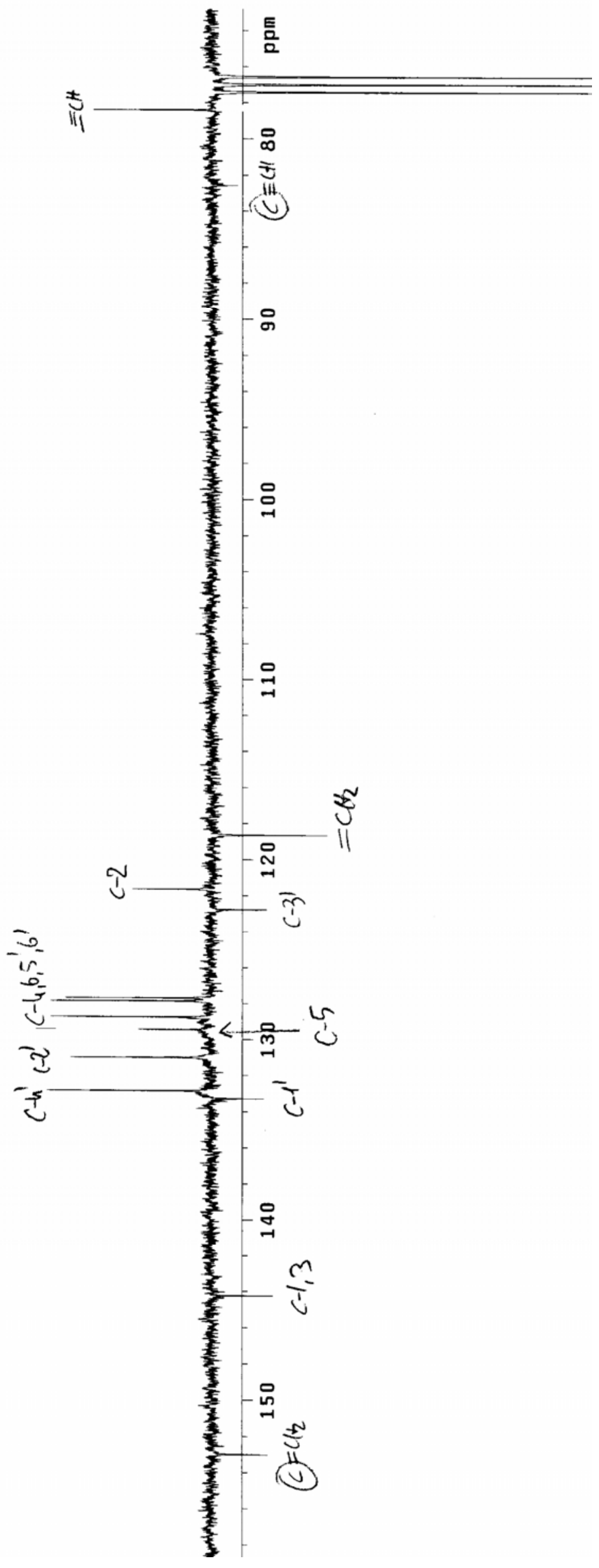




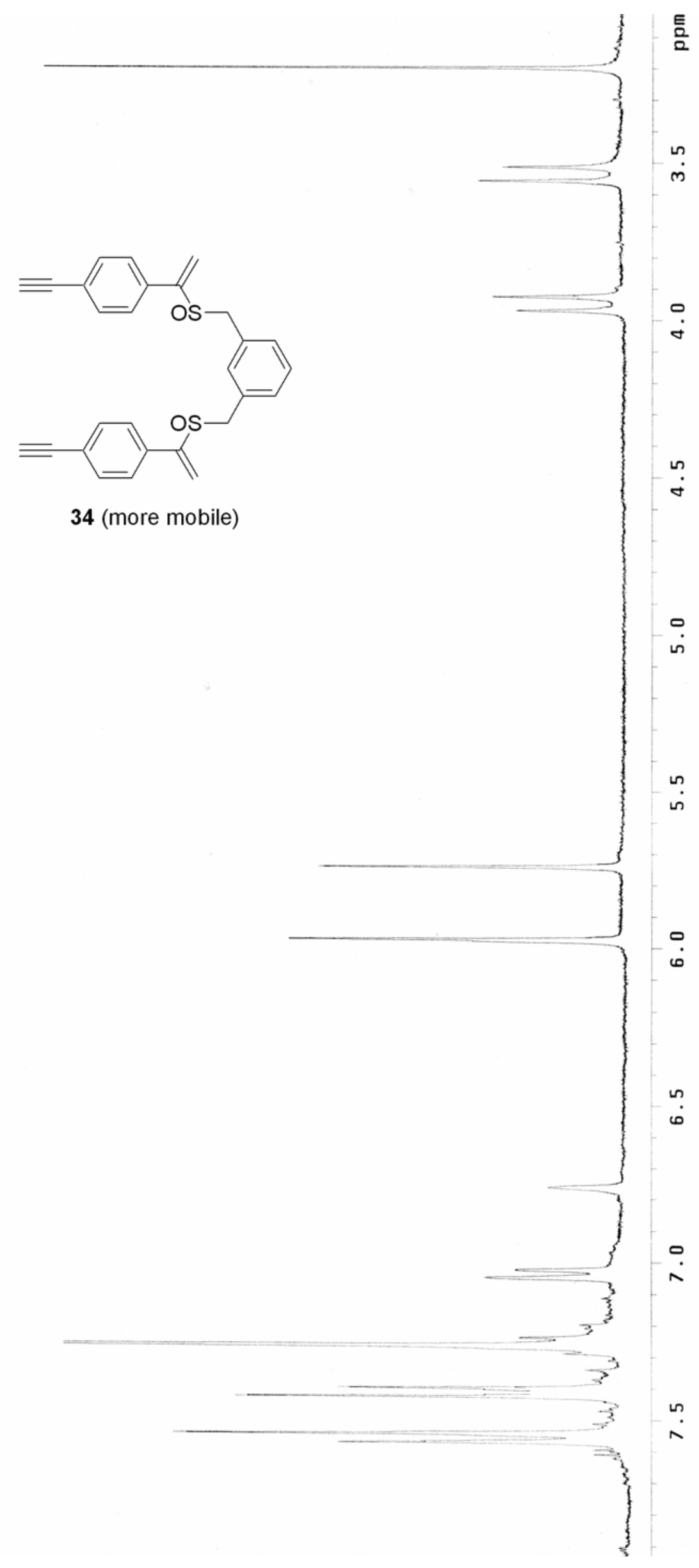




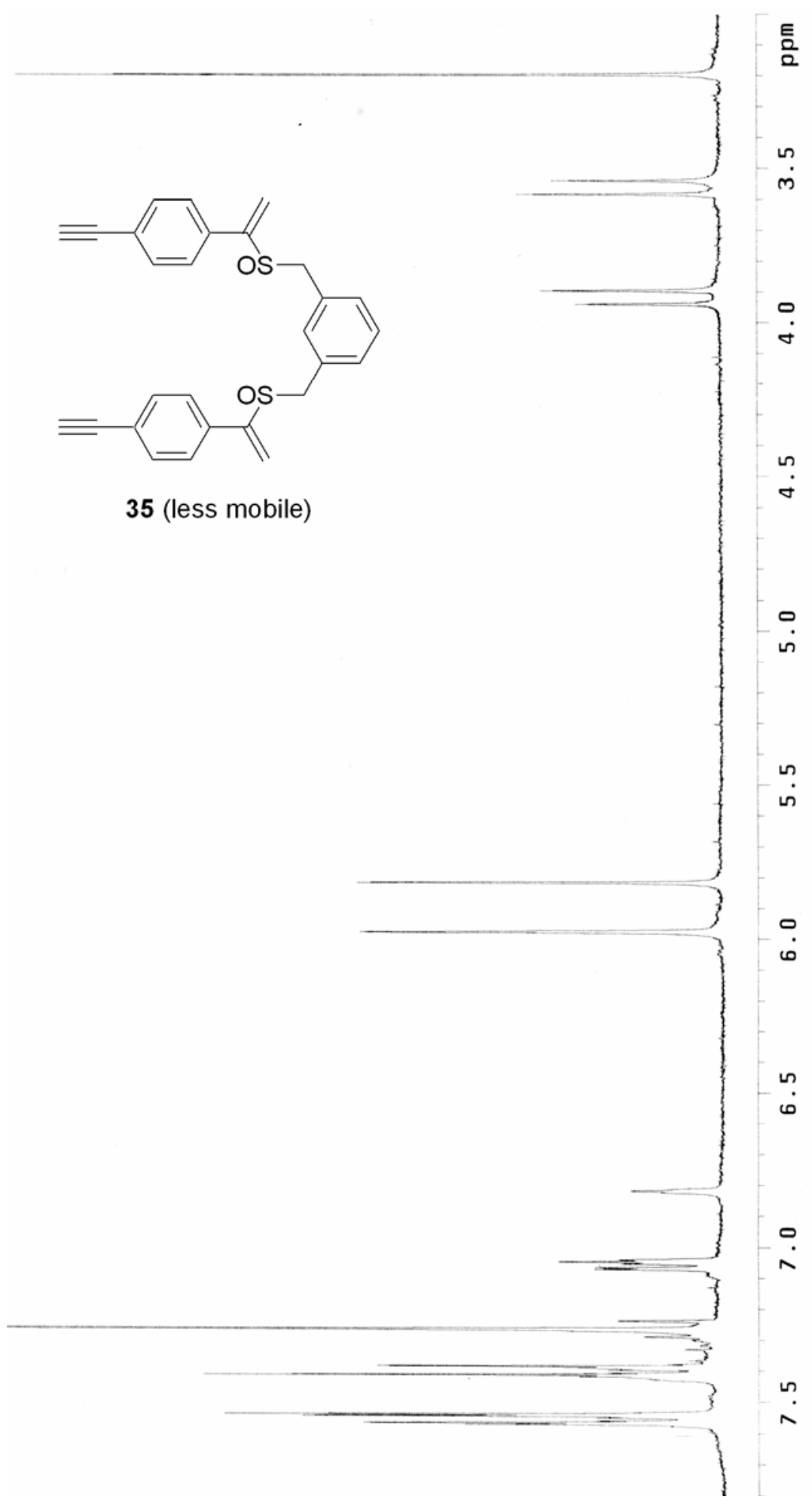




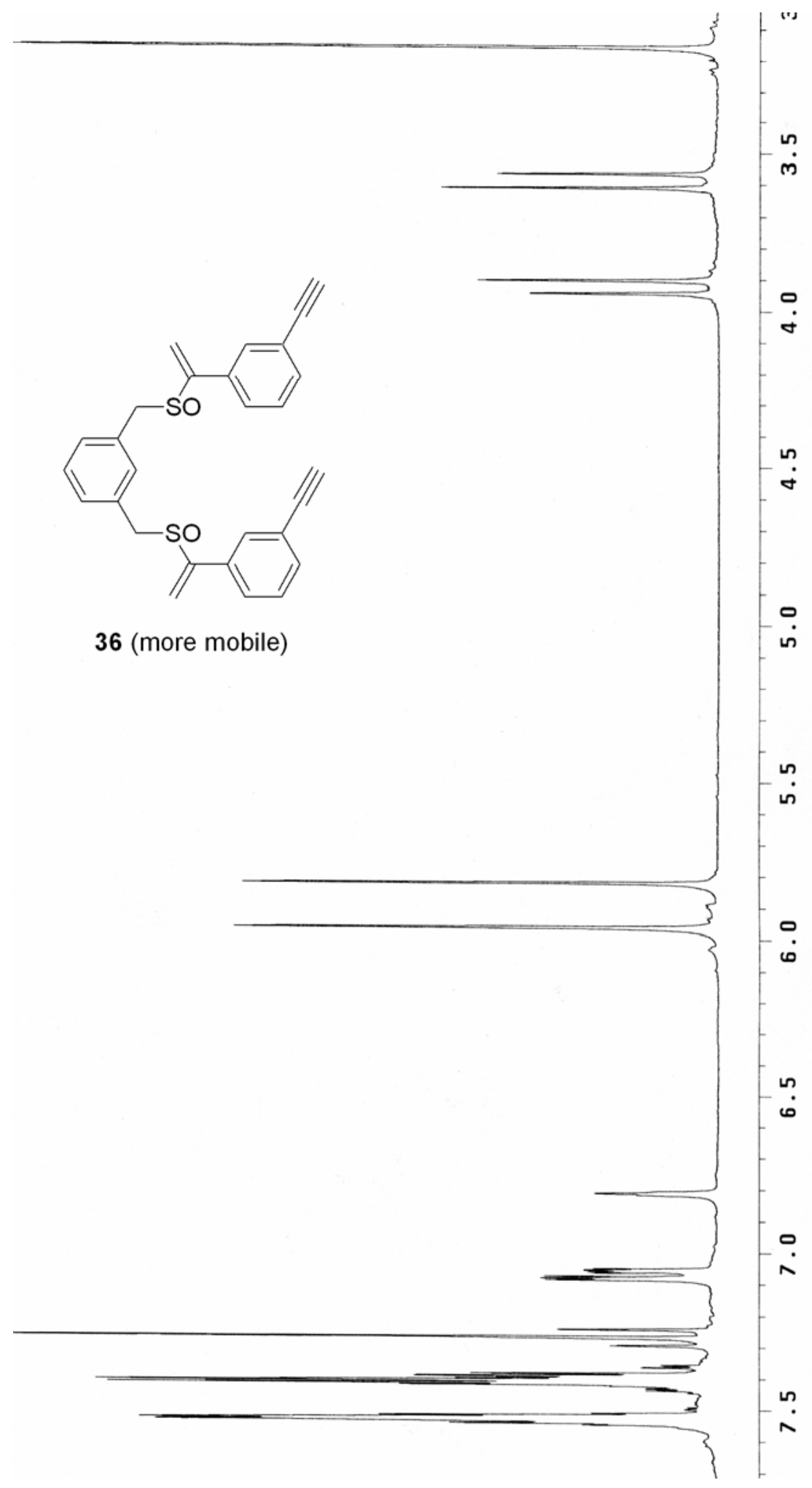




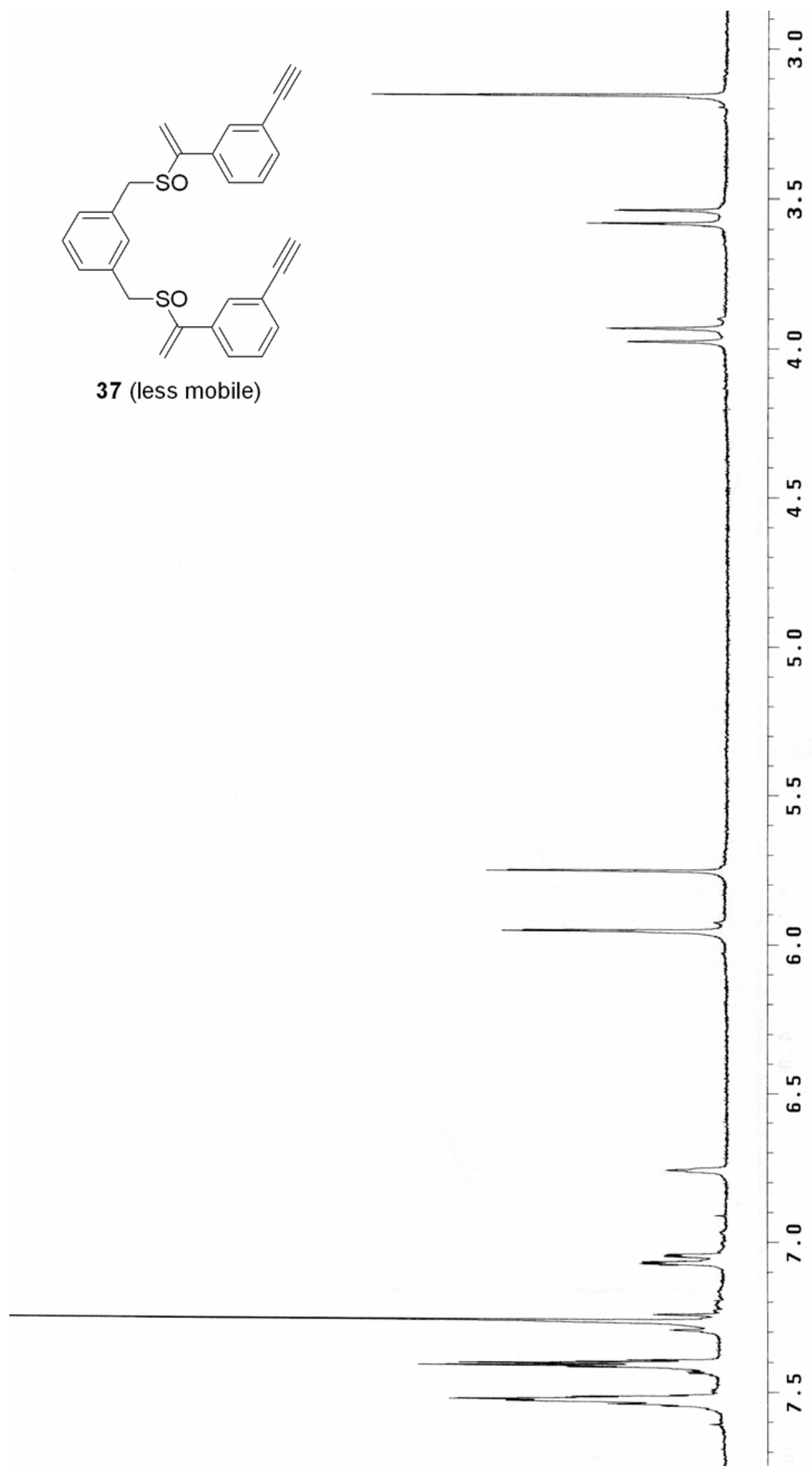




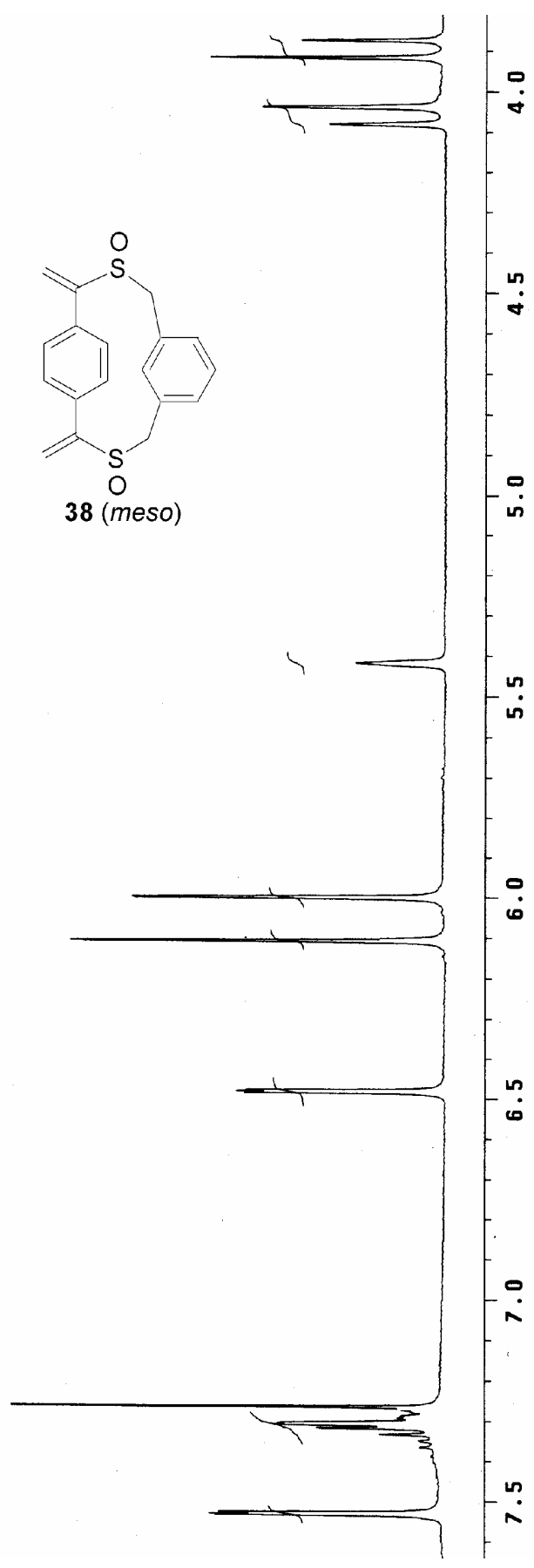



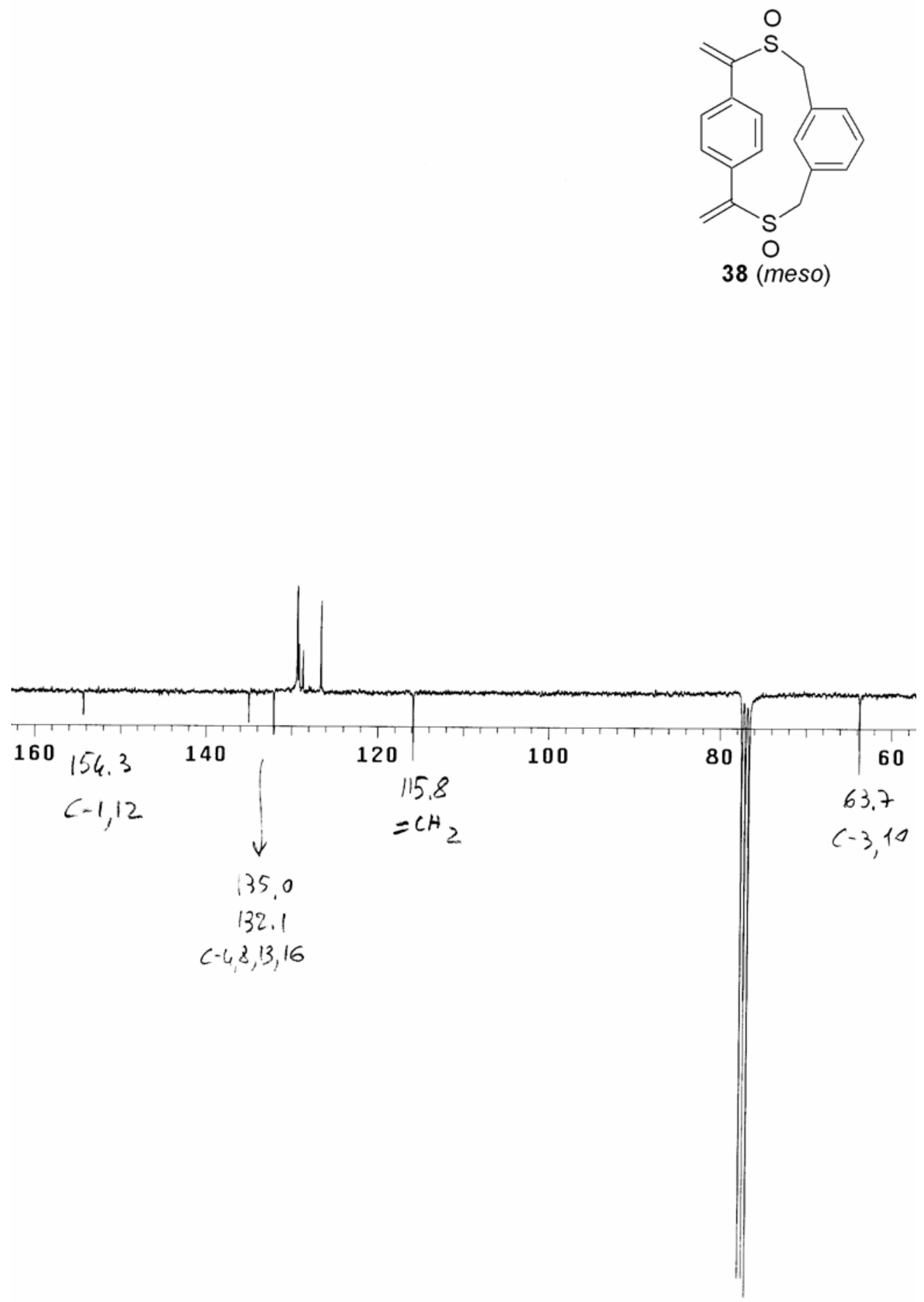

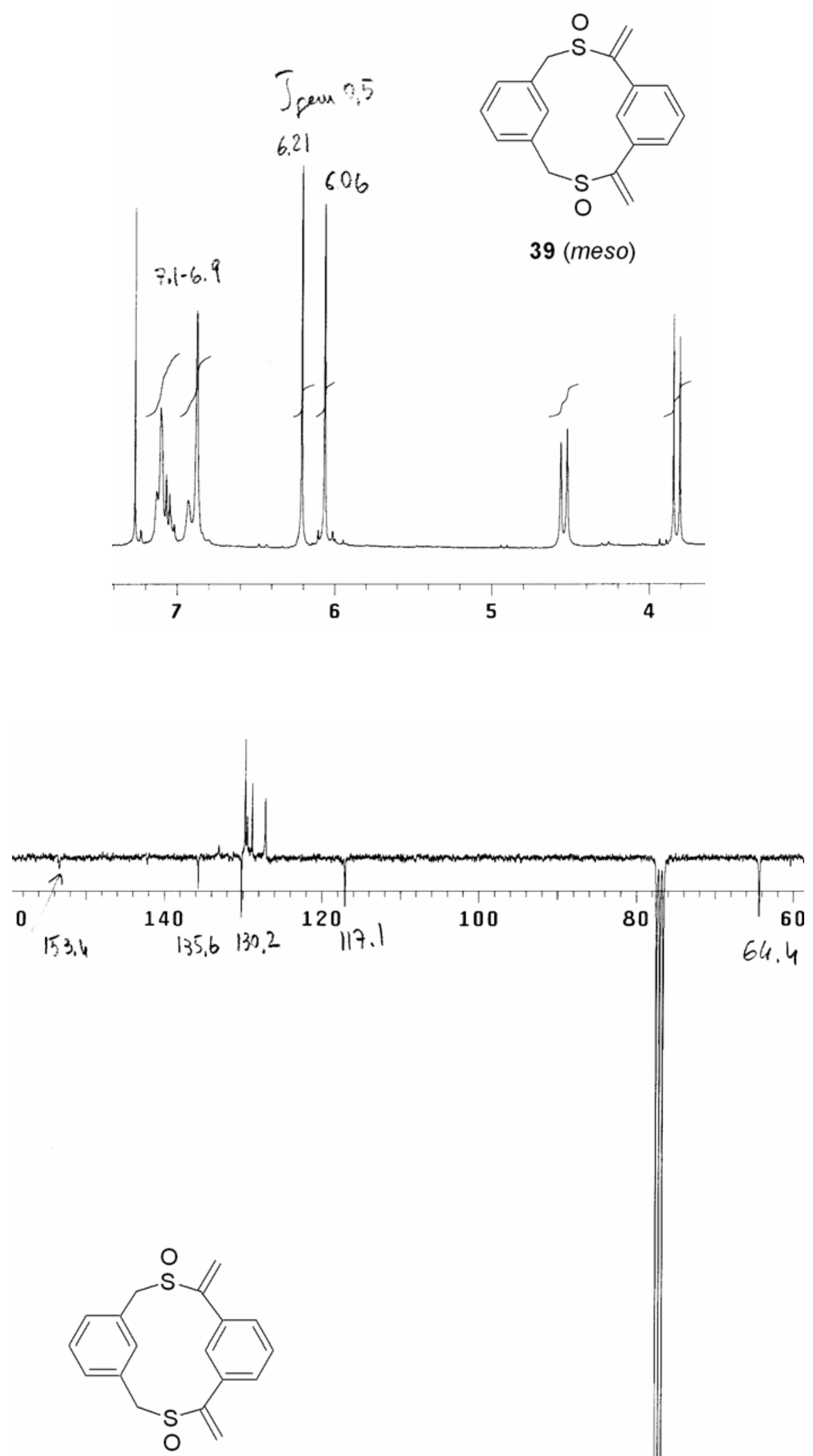

39 (meso) 

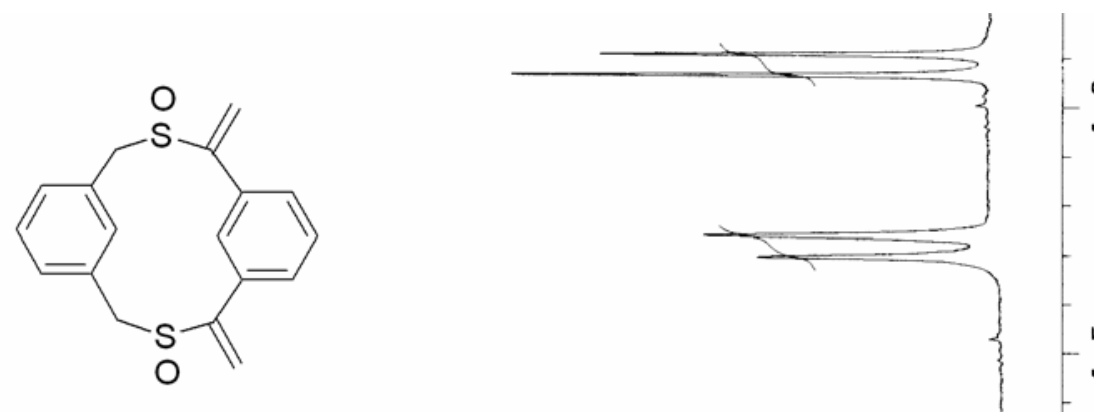

40 (racemate)

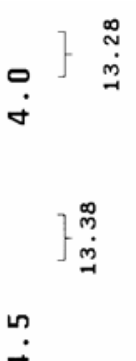

$\dot{\sigma}$

in

ก

in

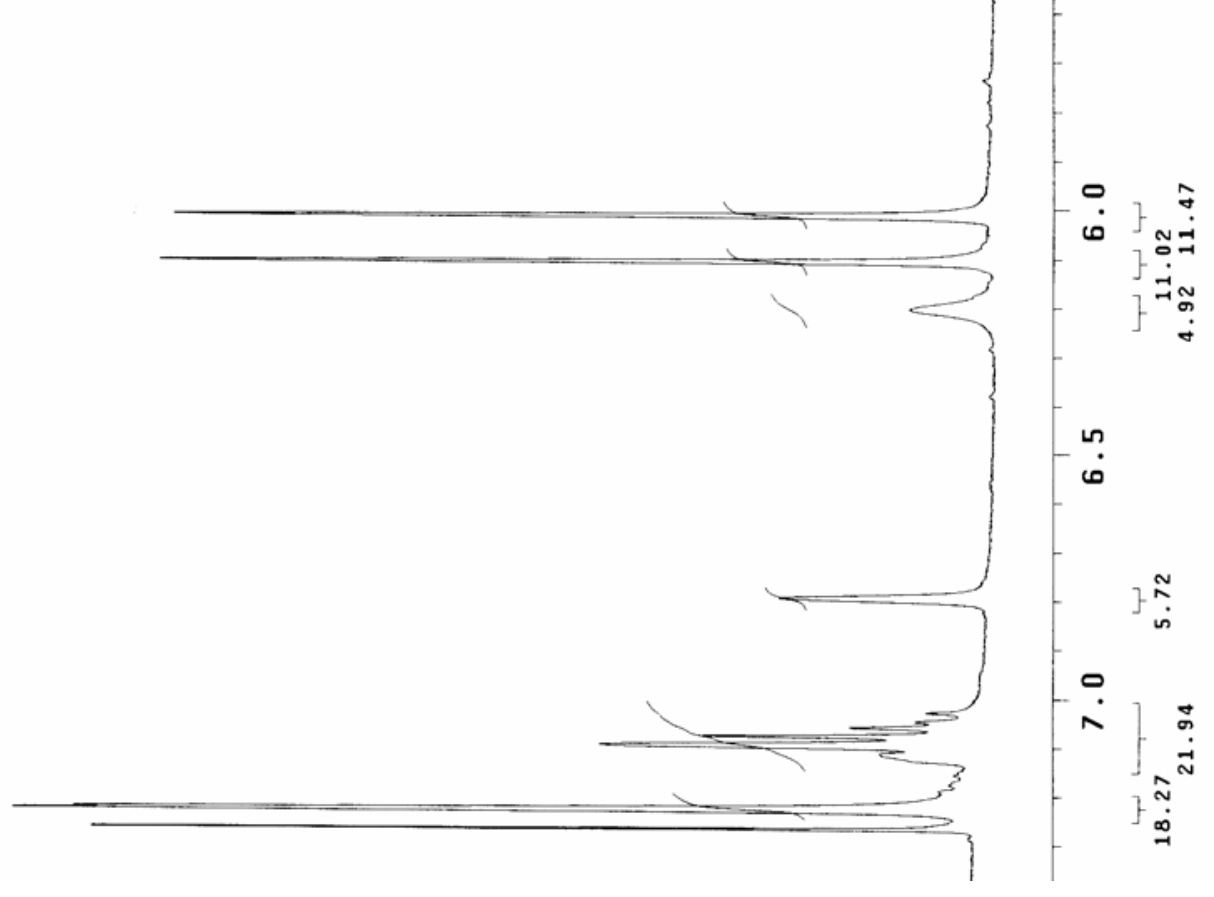




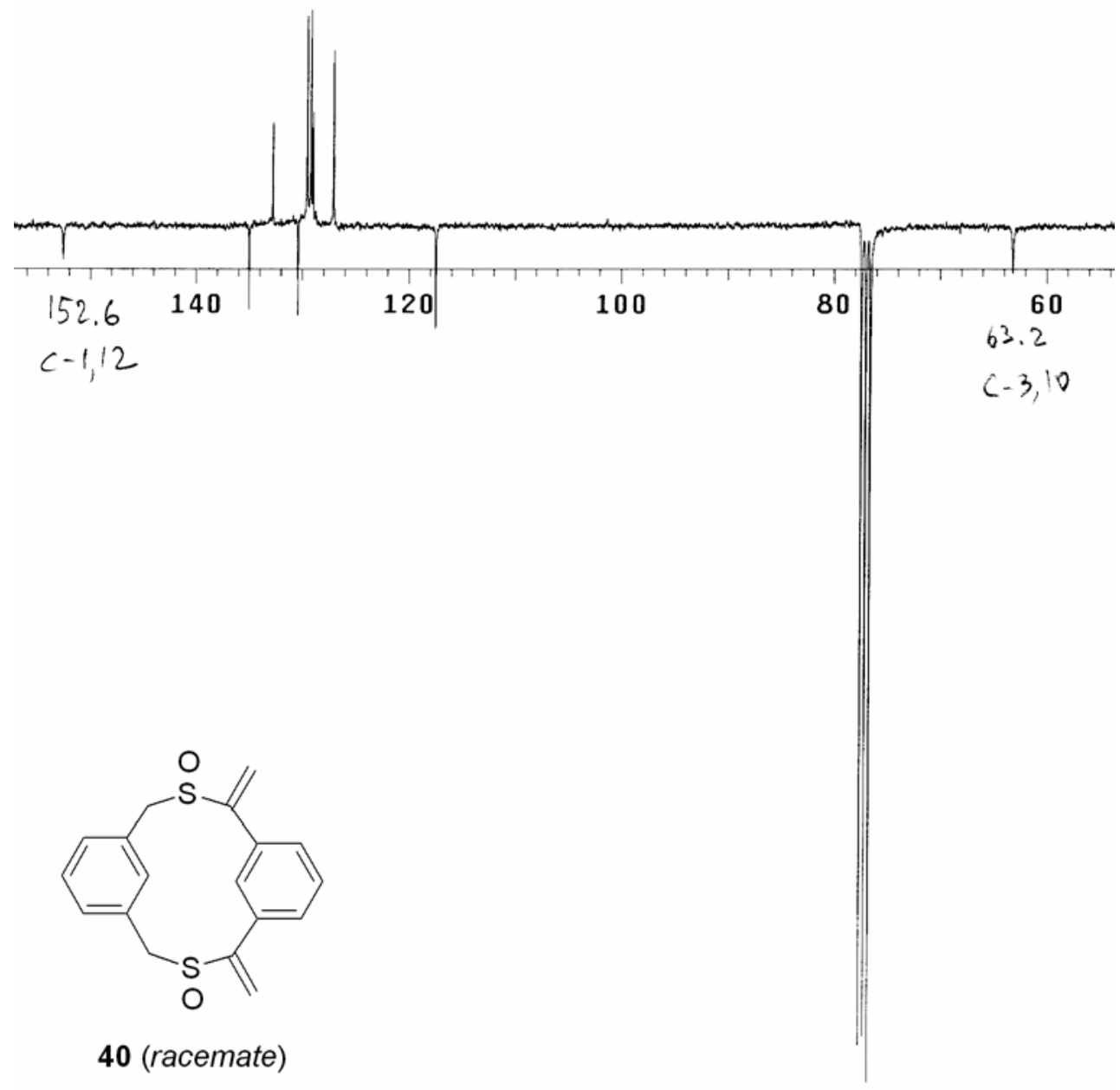




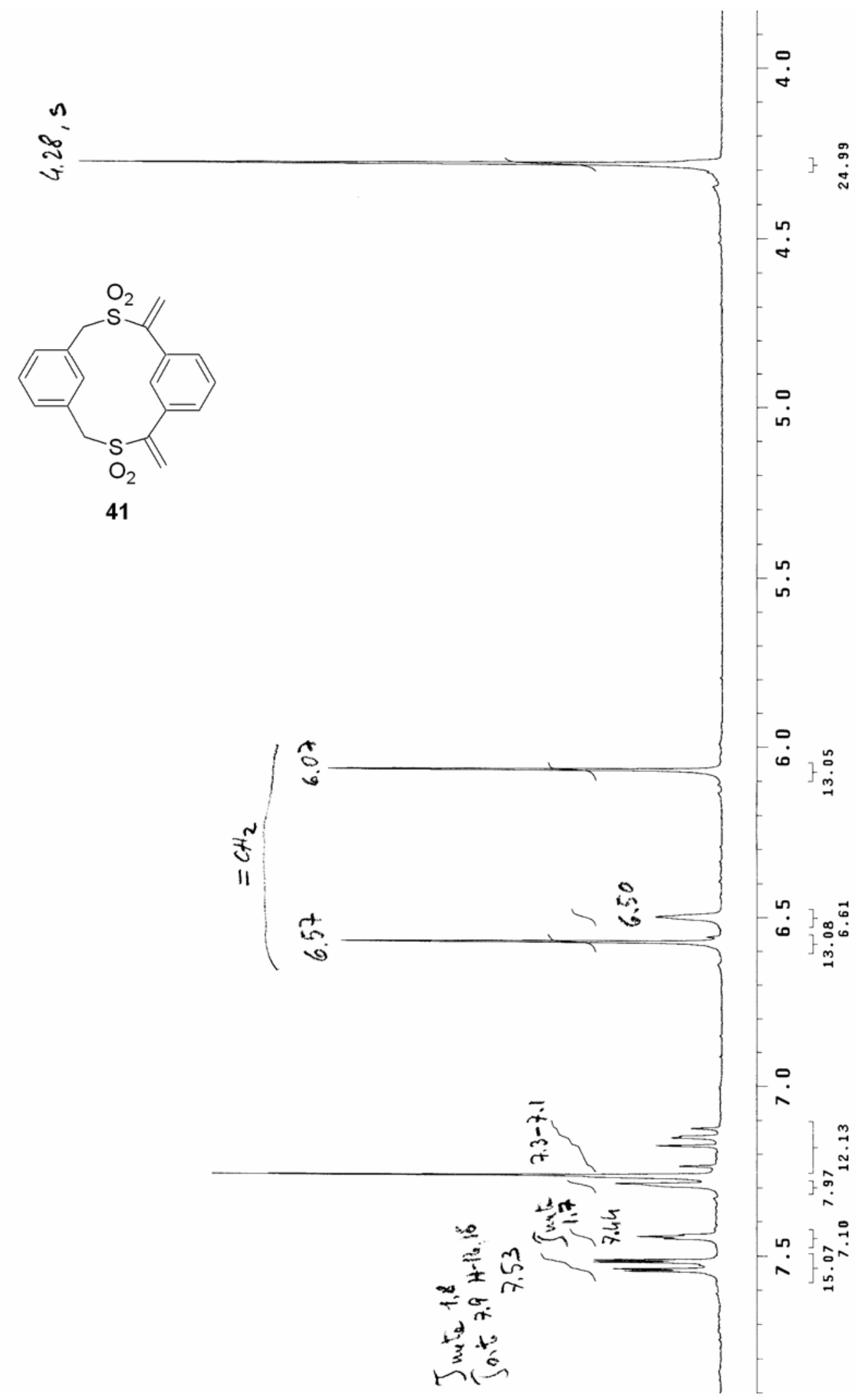




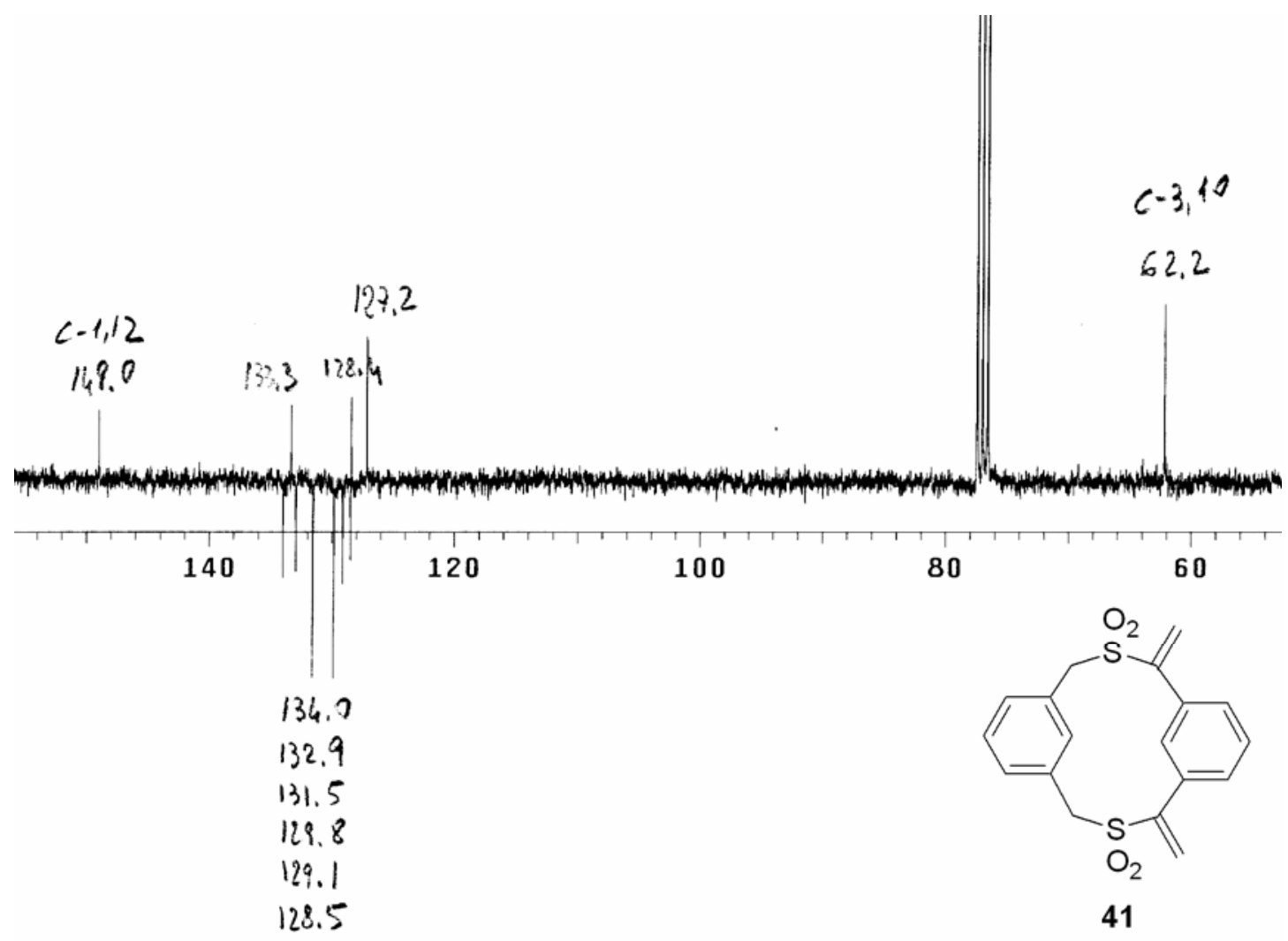




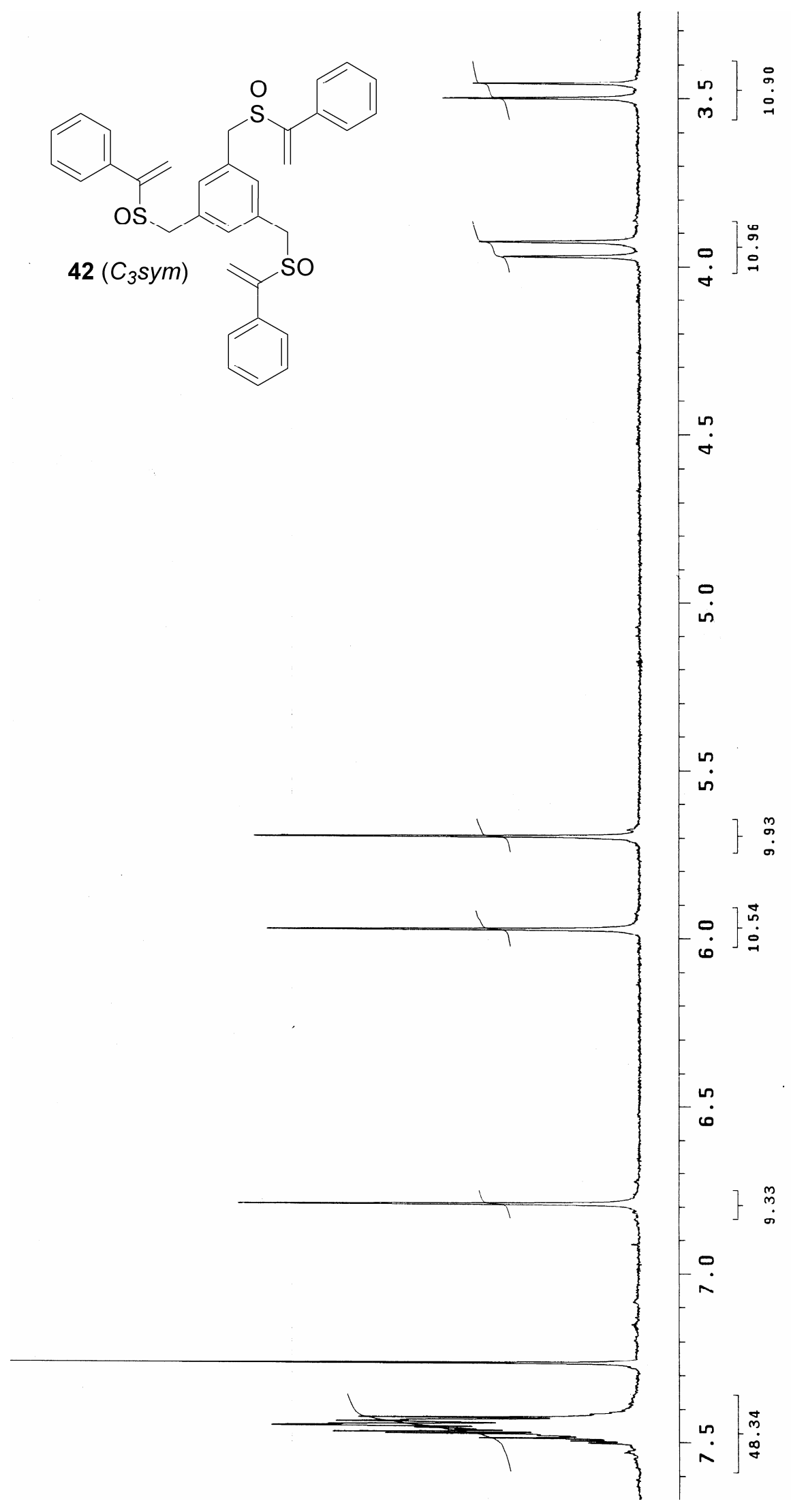




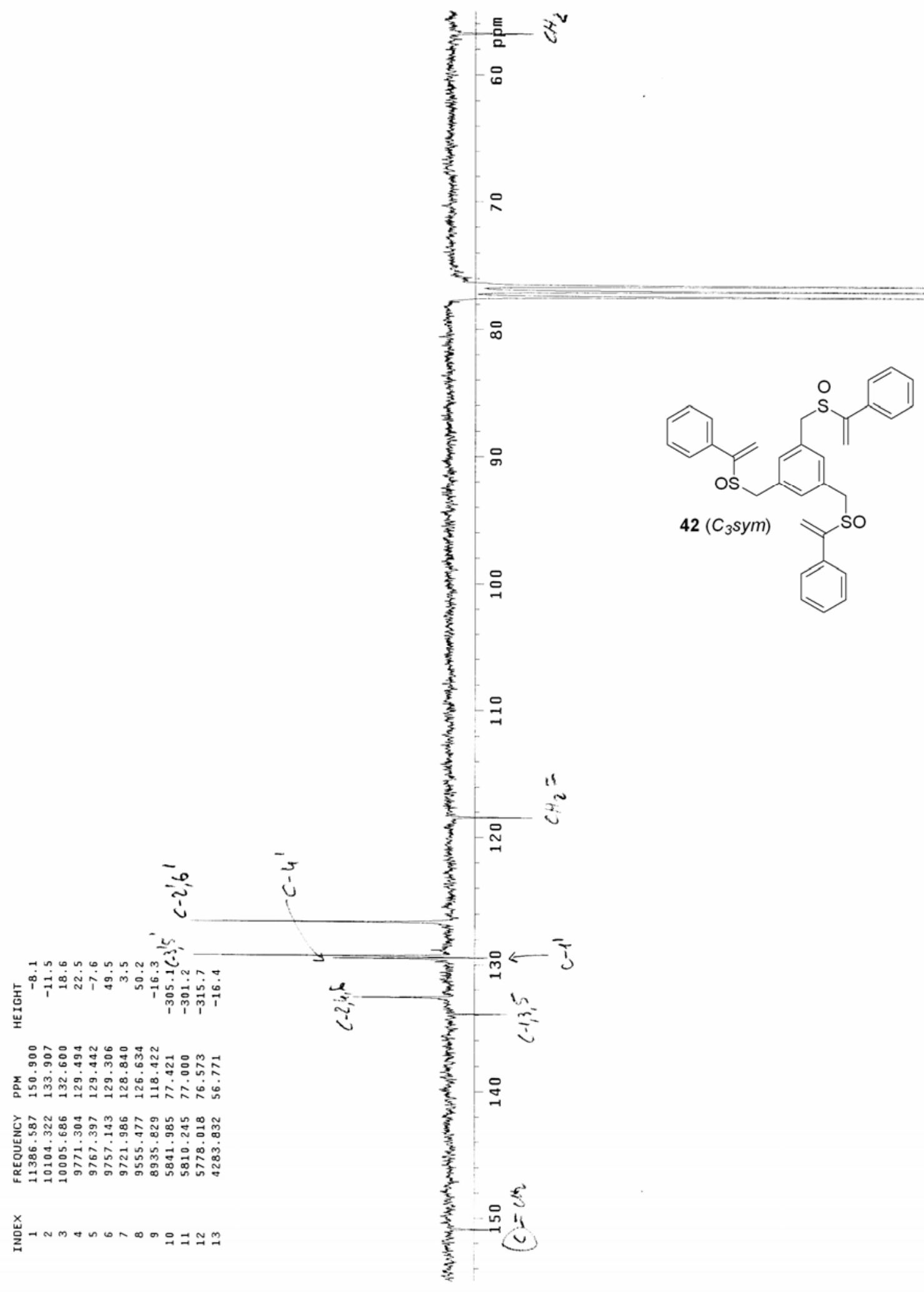

S62 


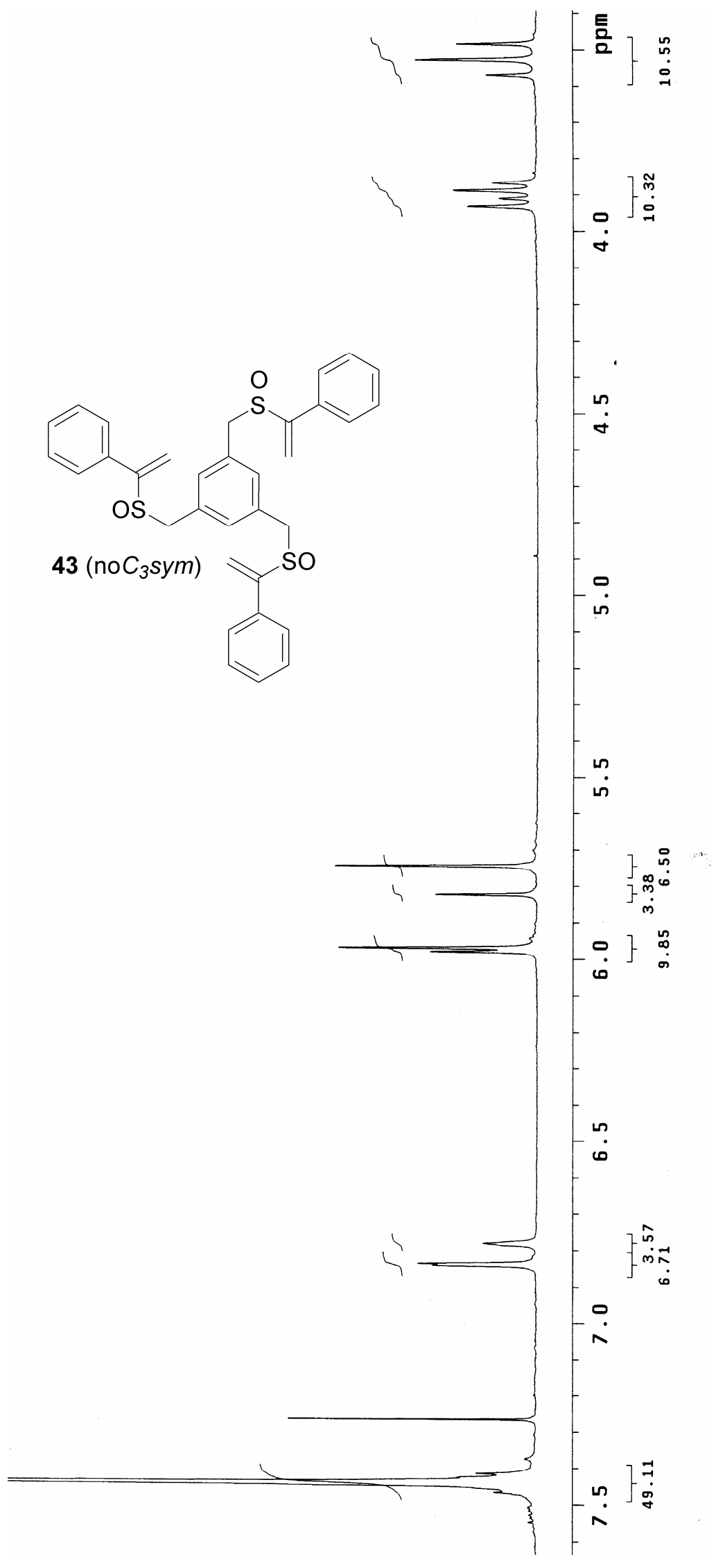



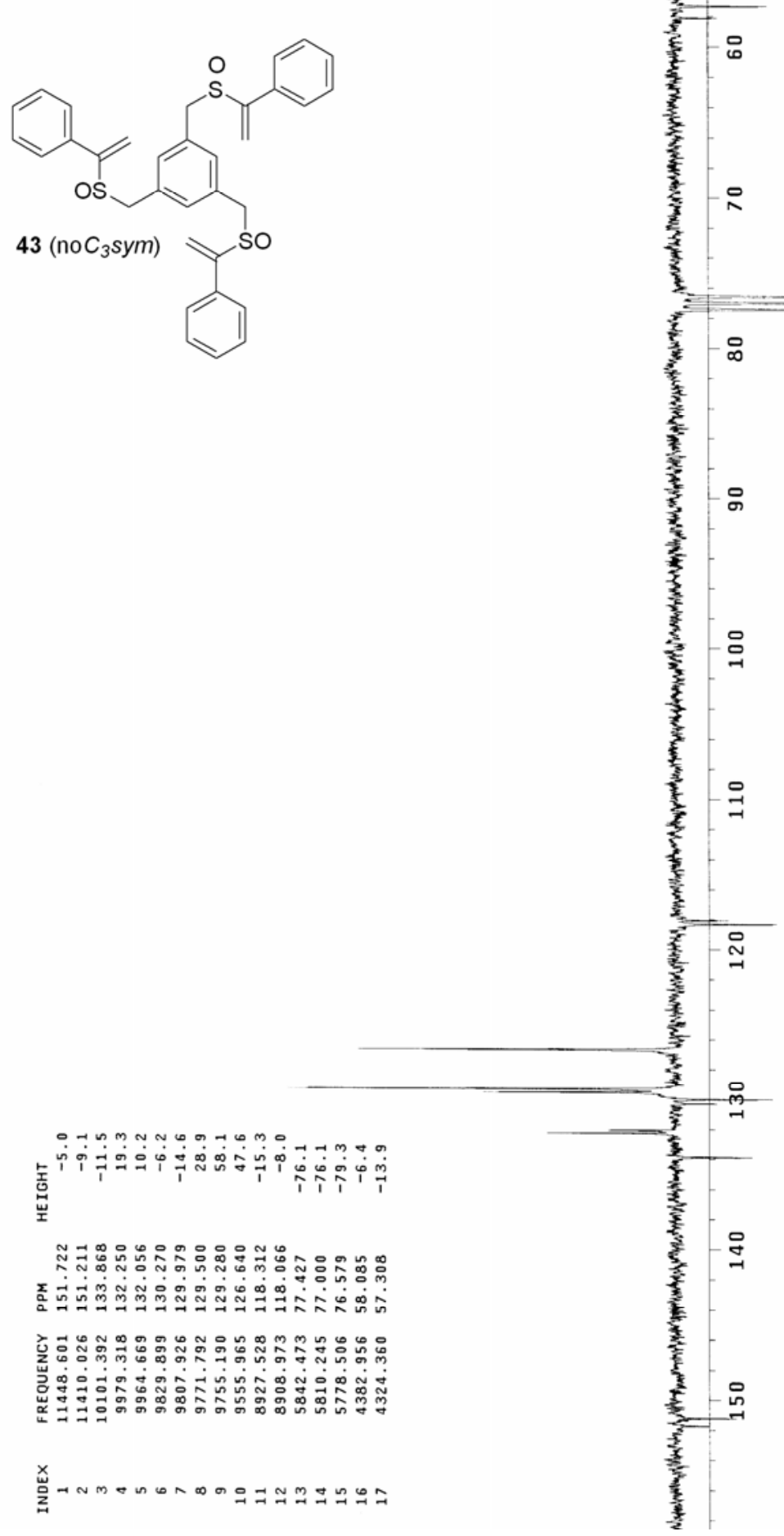

S64 


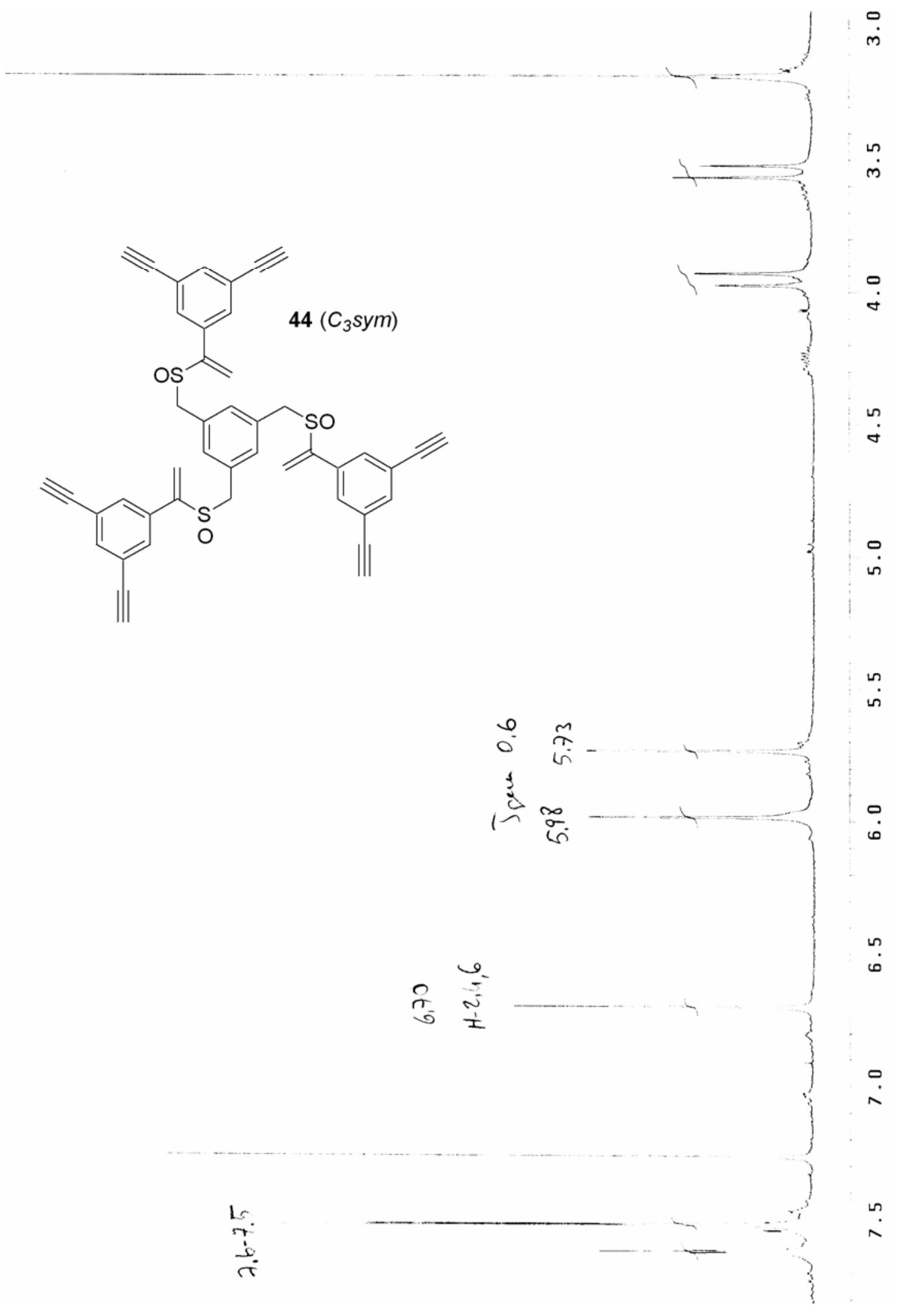




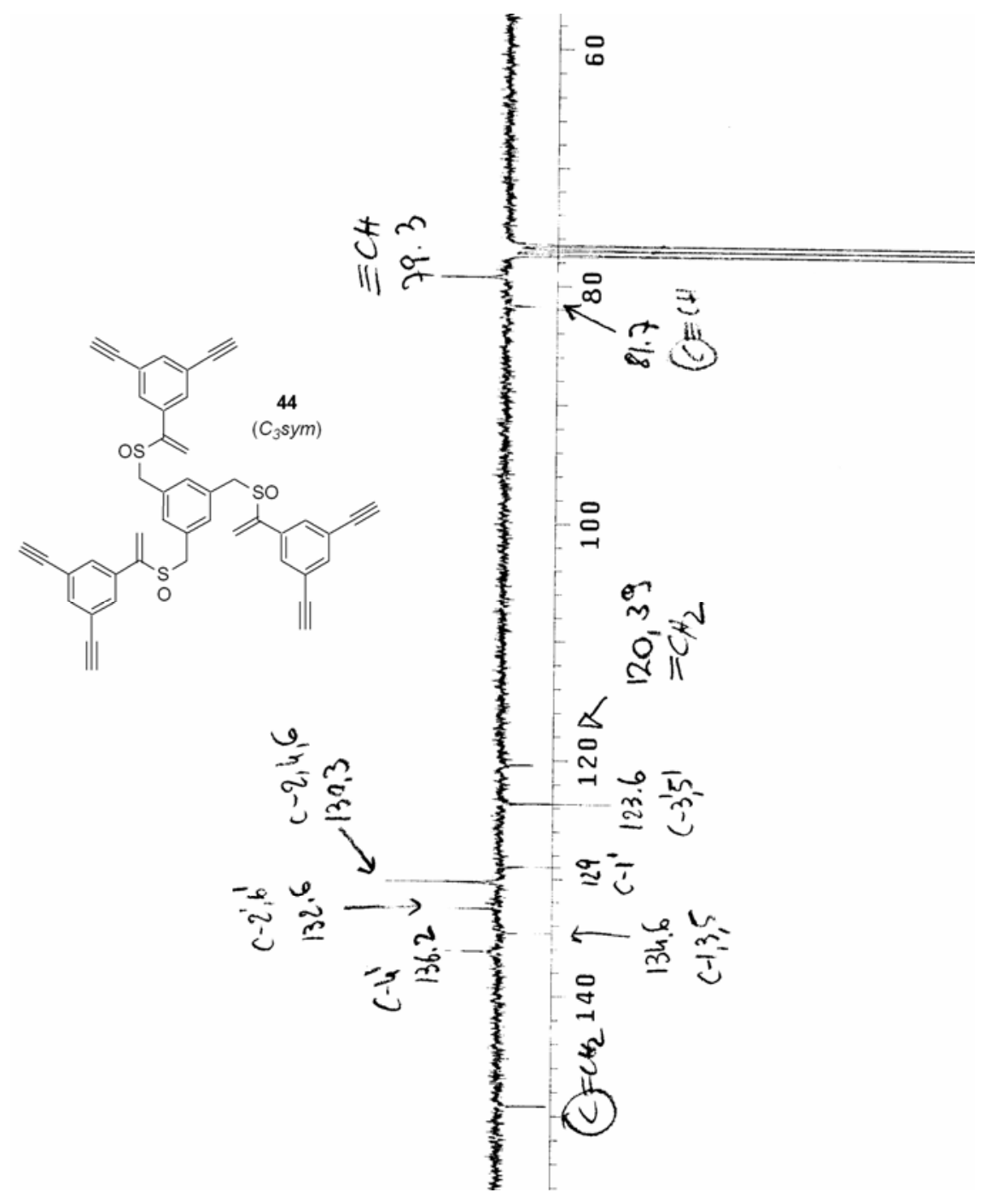




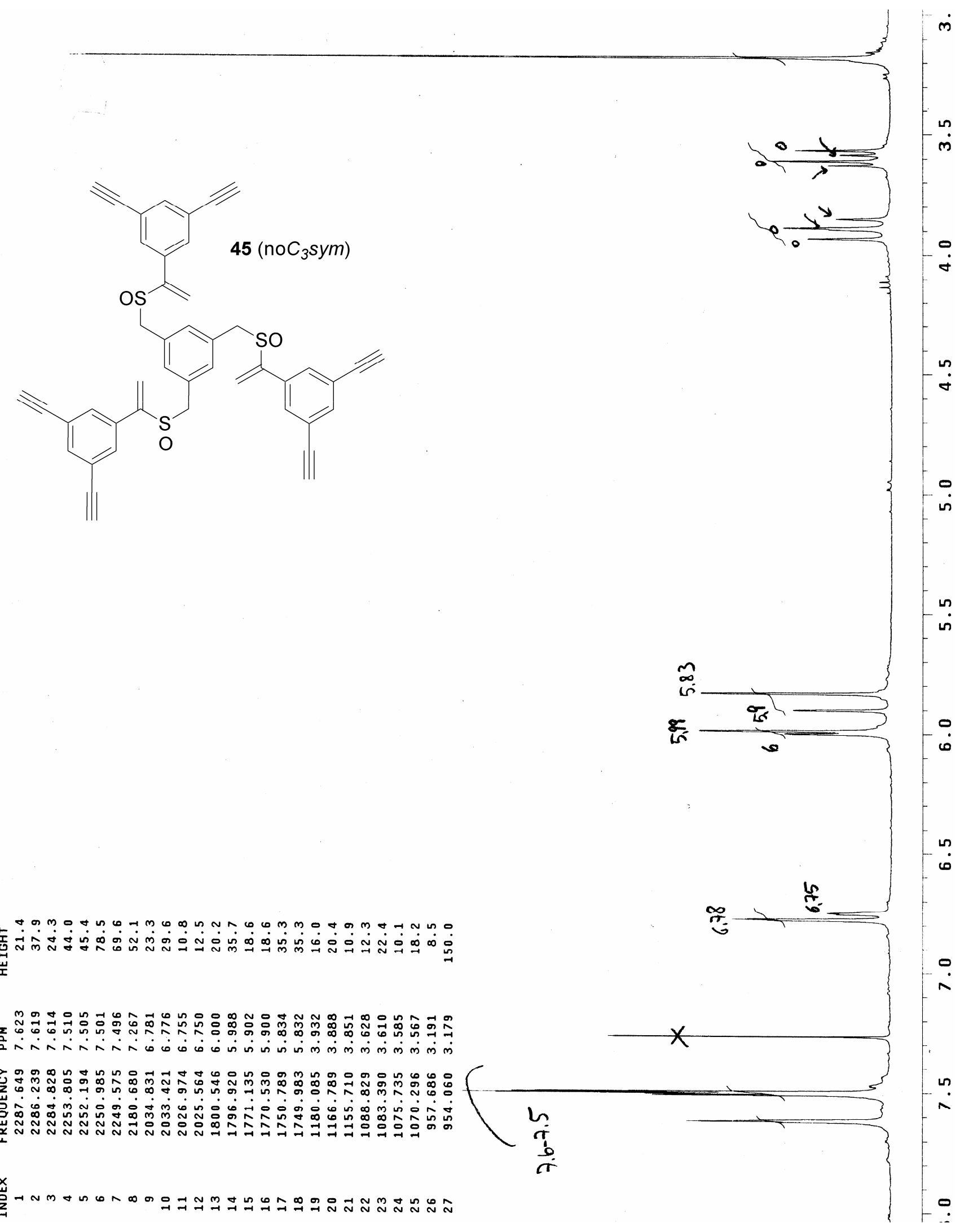




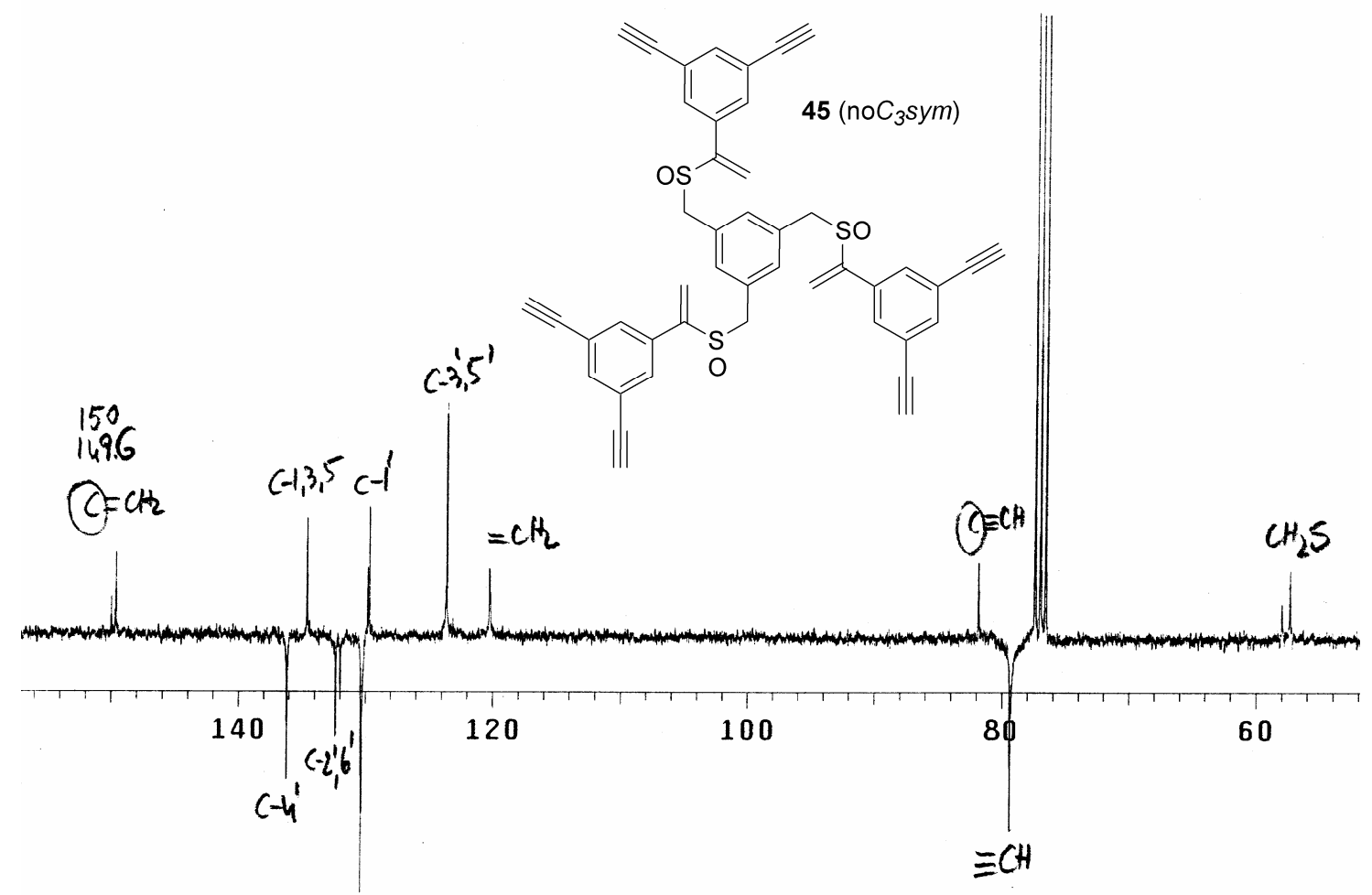

$(-2,4,6$ 


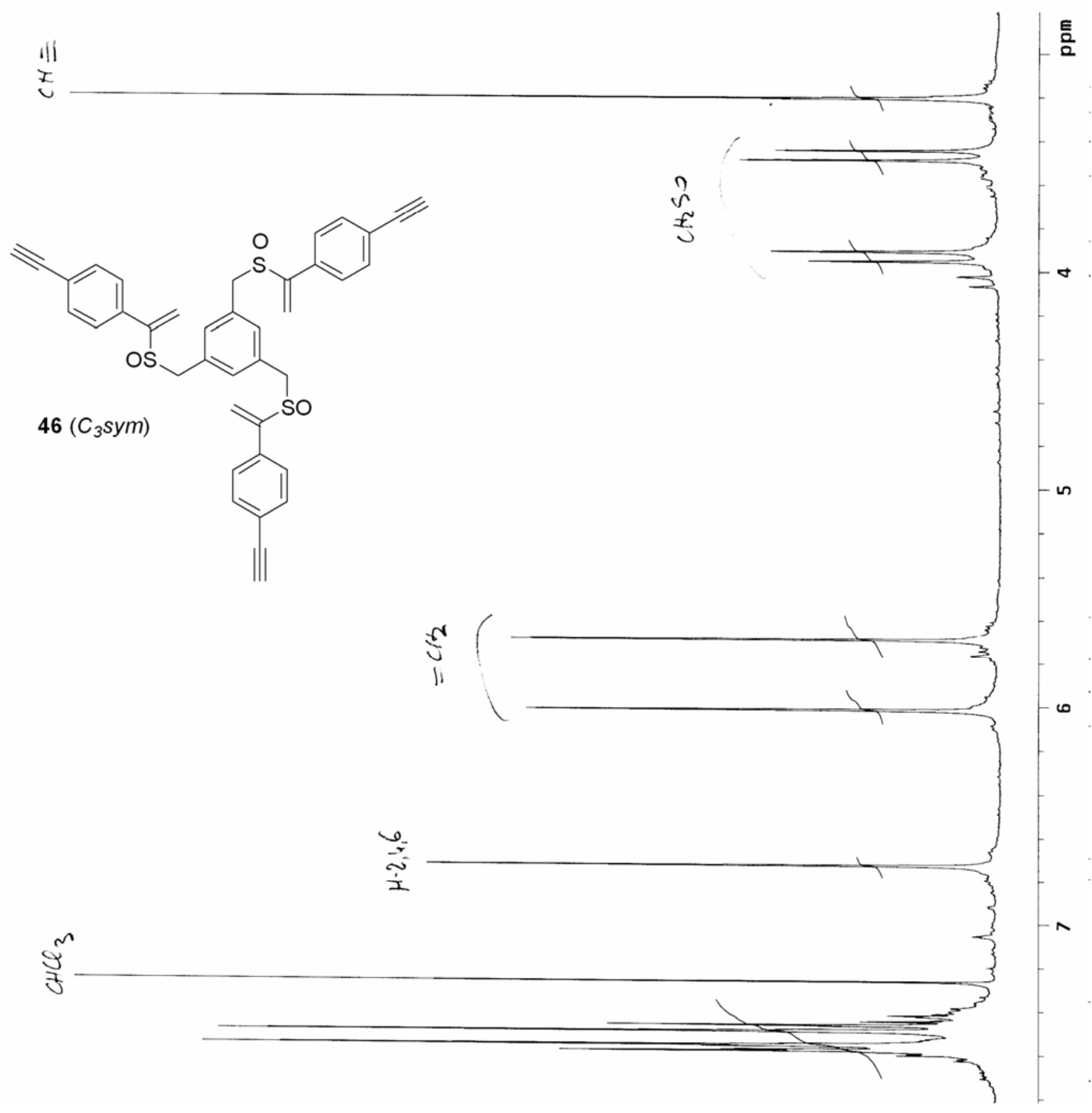




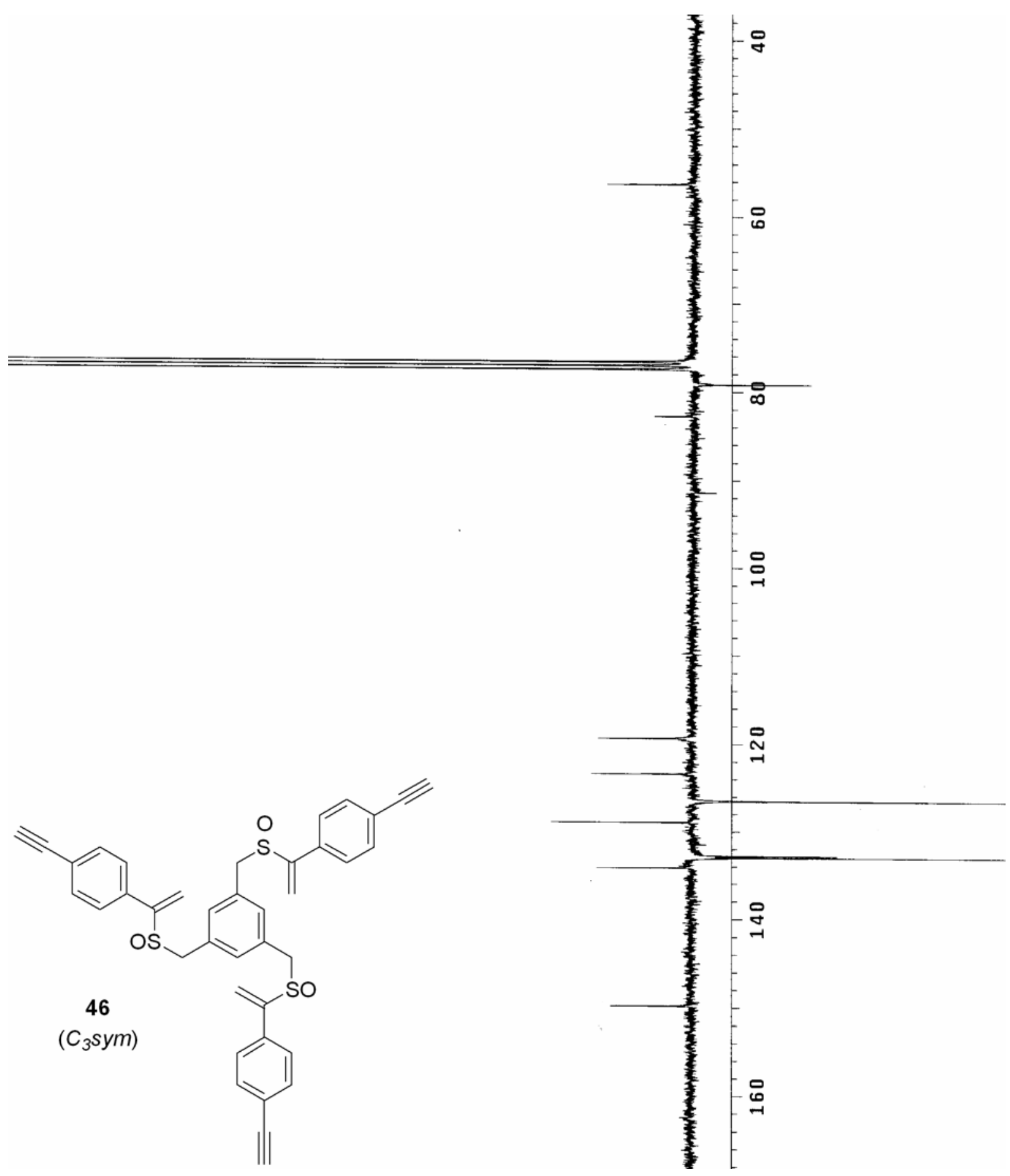




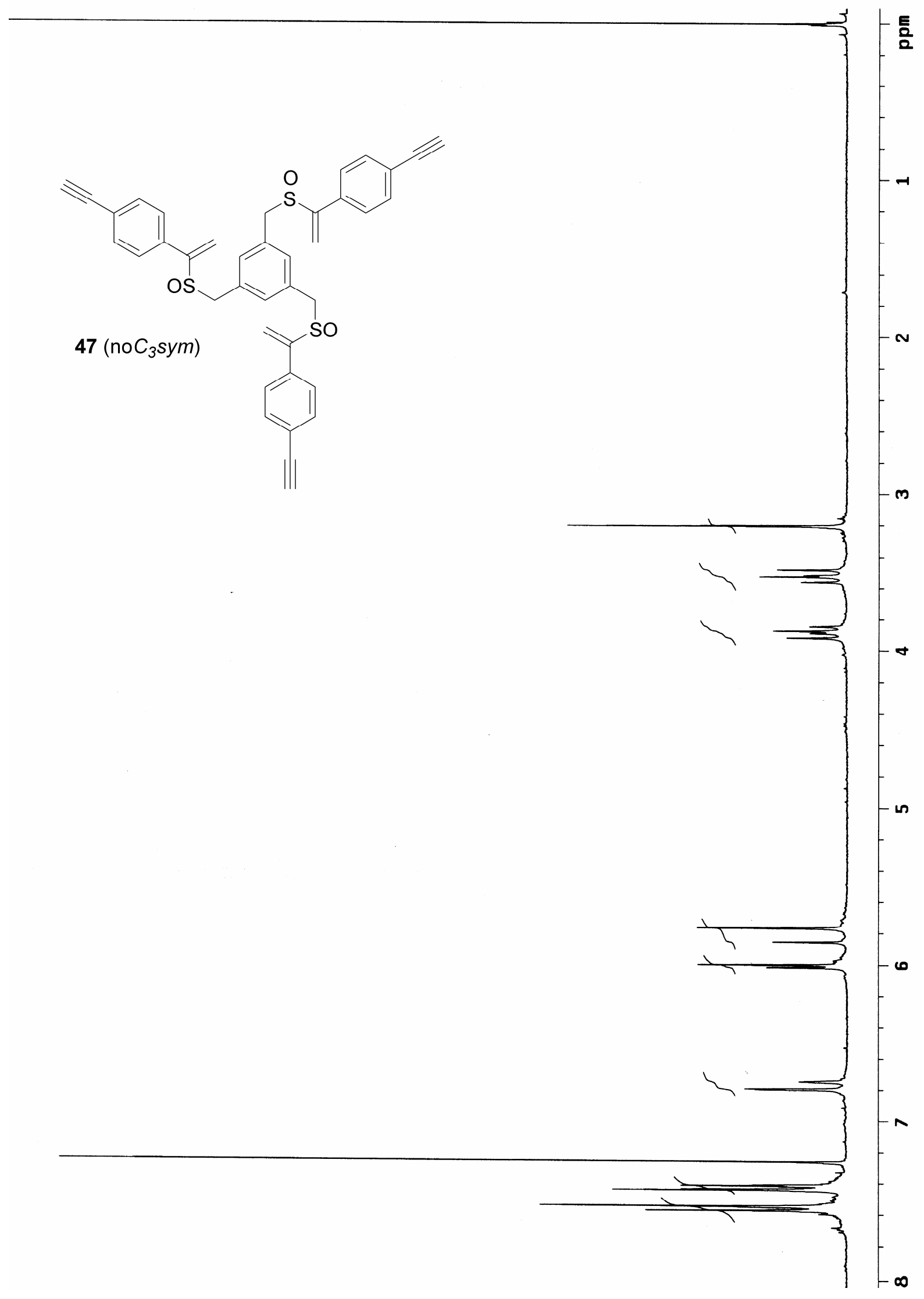




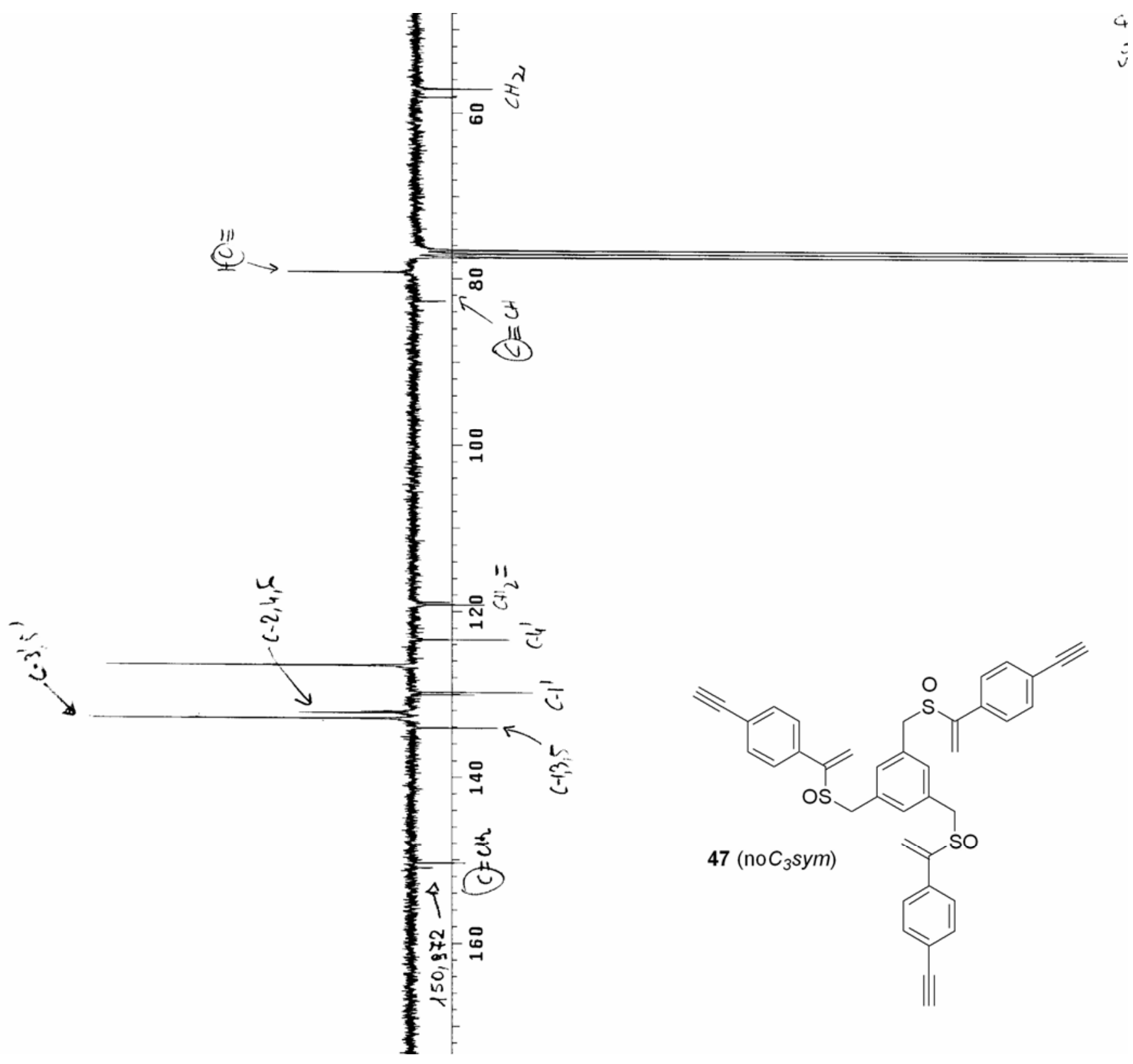




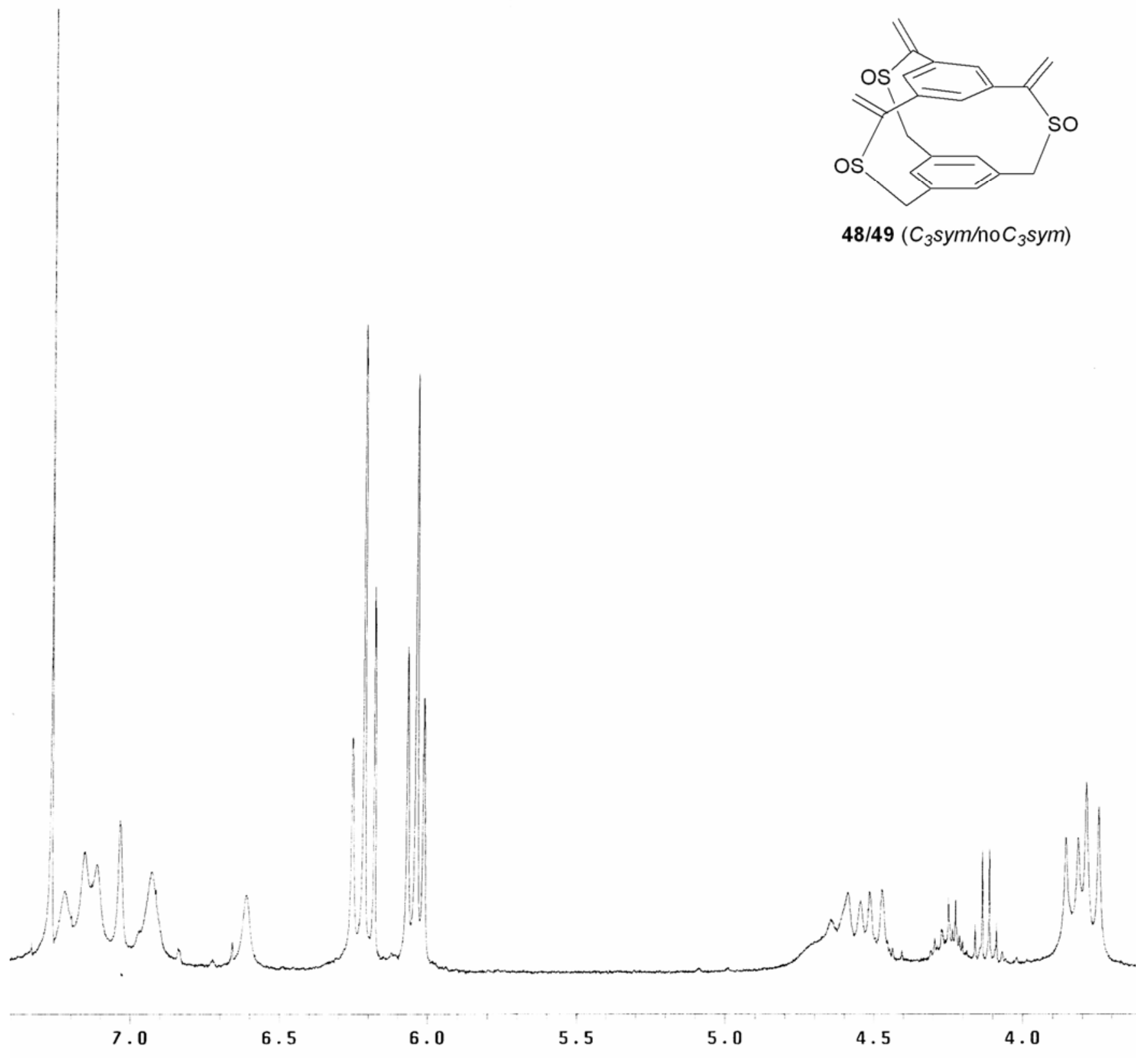




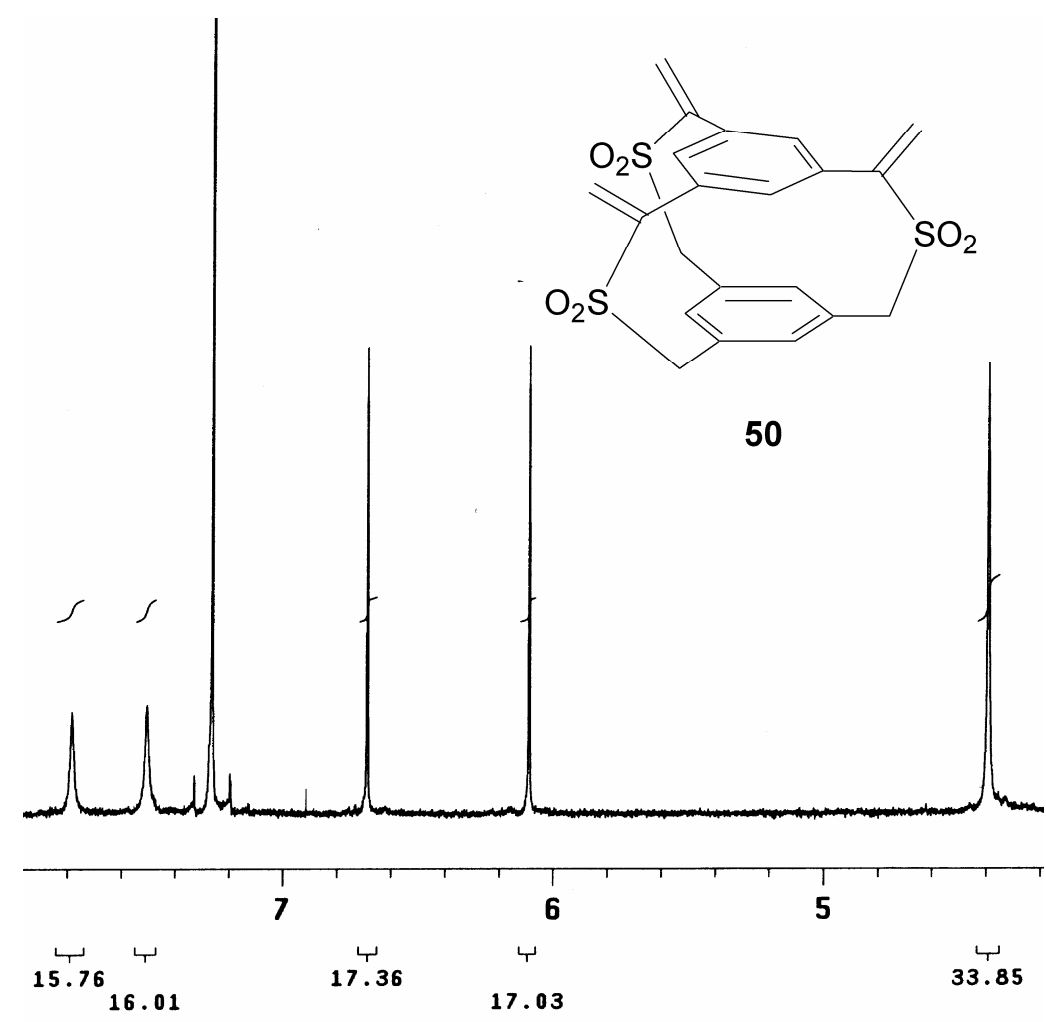




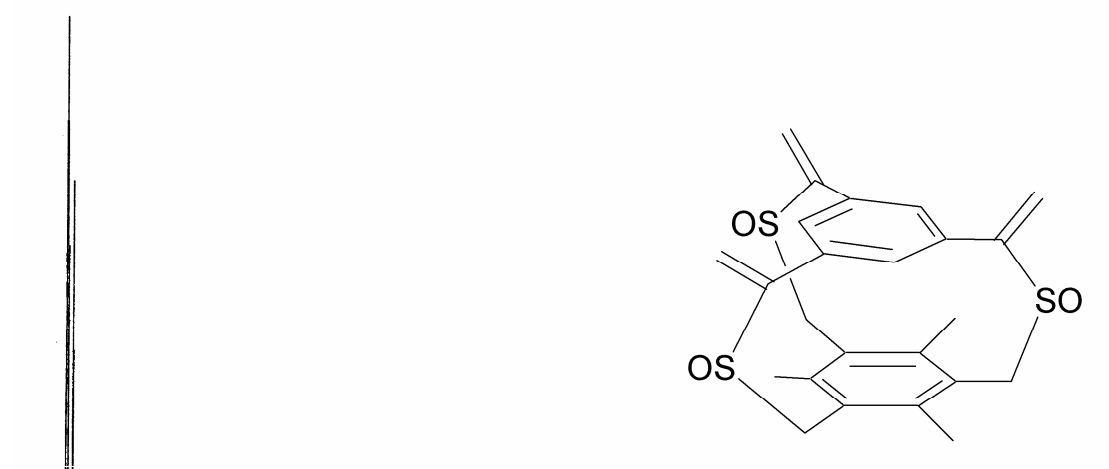

$51\left(C_{3}\right.$ sym $)$

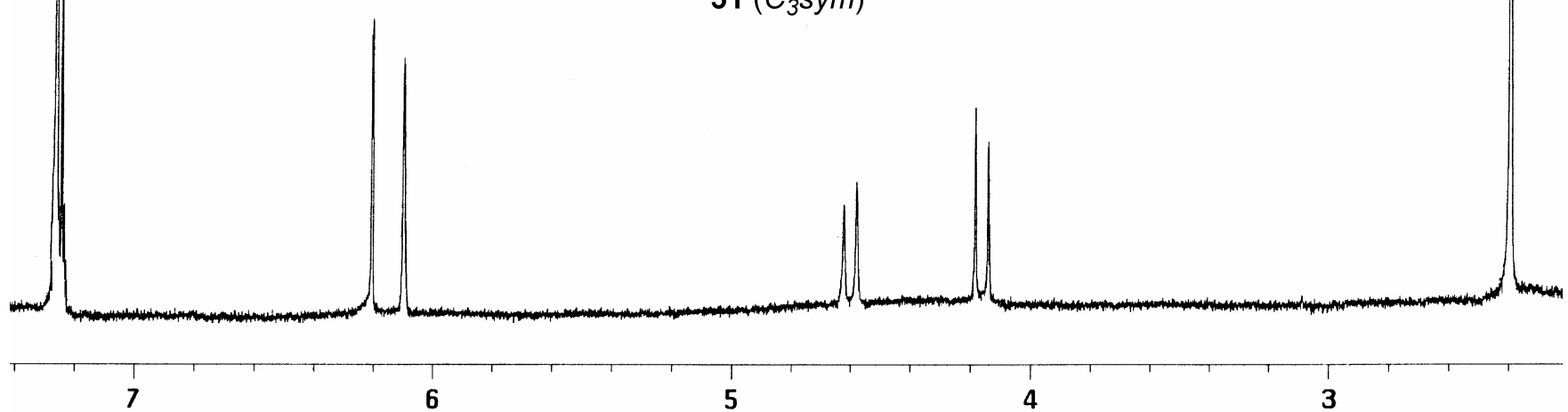




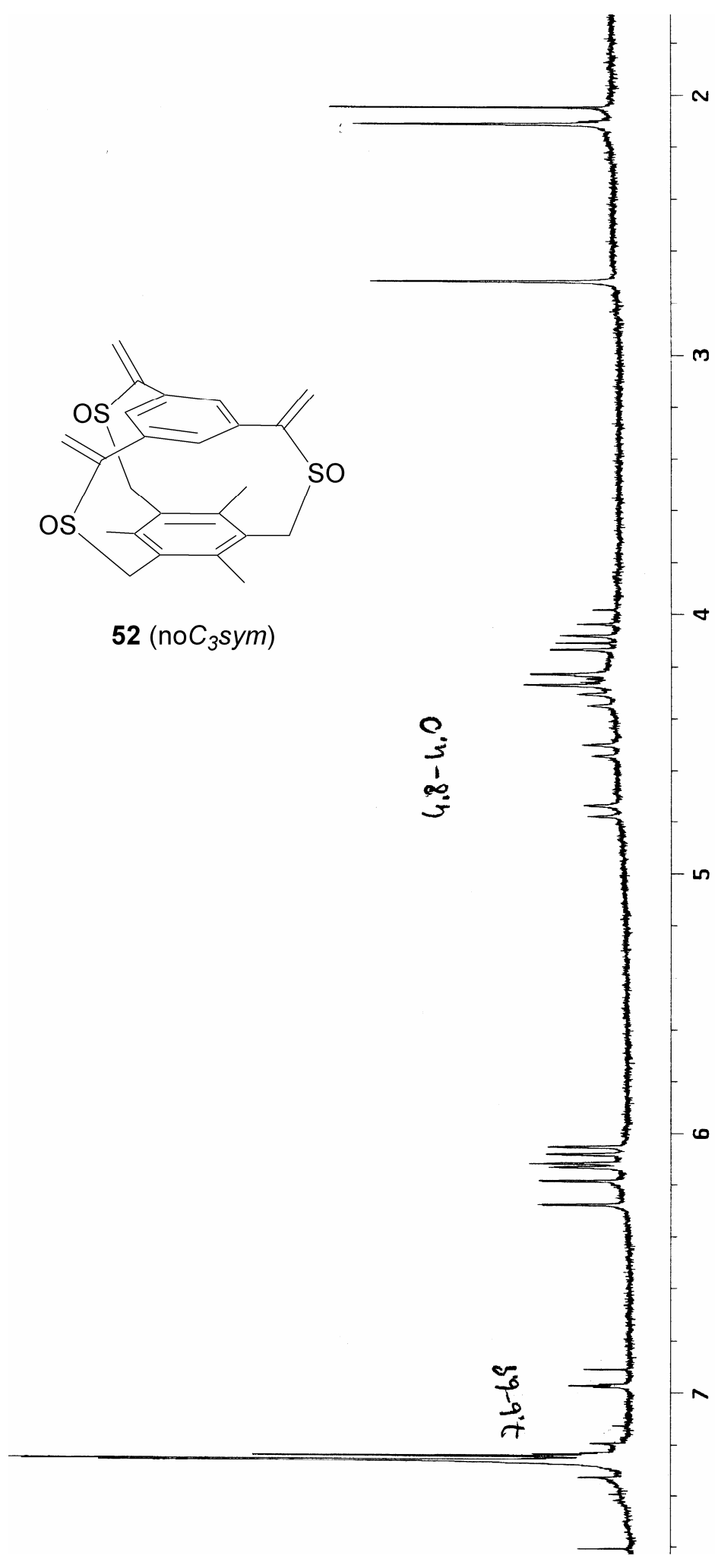




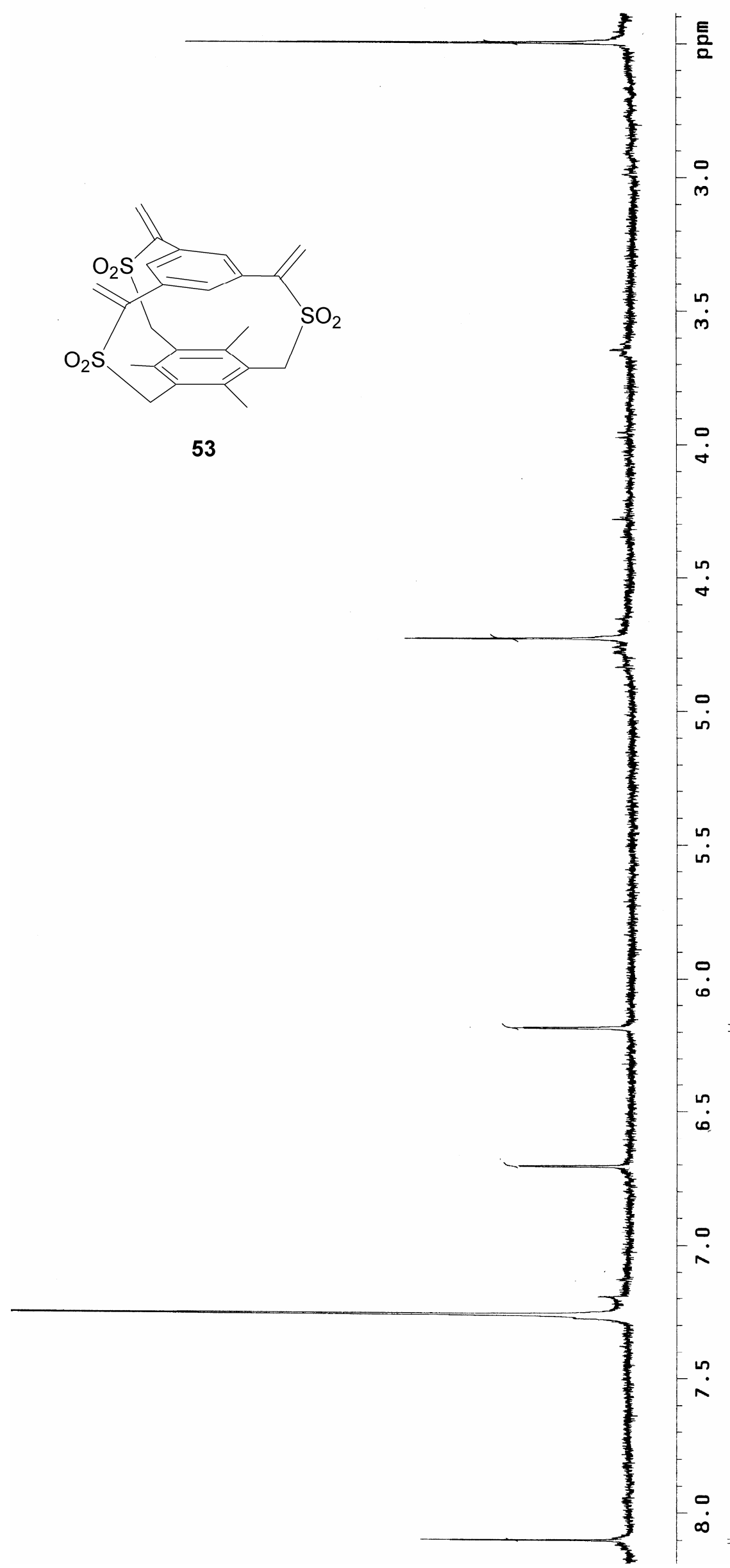

S77 